\author{
UNIVERSIDADE DE SÃO PAULO \\ ESCOLA DE ARTES, CIÊNCIAS E HUMANIDADES \\ PROGRAMA DE PÓS-GRADUAÇÃO EM SISTEMAS DE INFORMAÇÃO
}

ROBINSON CRUSOÉ DA CRUZ

Análise empírica sobre a influência das métricas CK na testabilidade de software orientado a objetos

São Paulo 


\section{Análise empírica sobre a influência das métricas CK na testabilidade de software orientado a objetos}

Dissertação apresentada à Escola de Artes, Ciências e Humanidades da Universidade de São Paulo para obtenção do título de Mestre em Ciências pelo Programa de Pós-graduação em Sistemas de Informação.

Área de concentração: Metodologia e Técnicas da Computação

Versão corrigida contendo as alterações solicitadas pela comissão julgadora em 11 de dezembro de 2017. A versão original encontra-se em acervo reservado na Biblioteca da EACH-USP e na Biblioteca Digital de Teses e Dissertações da USP (BDTD), de acordo com a Resolução CoPGr 6018, de 13 de outubro de 2011.

Orientador: Prof. Dr. Marcelo Medeiros Eler

São Paulo 
Autorizo a reprodução e divulgação total ou parcial deste trabalho, por qualquer meio convencional ou eletrônico, para fins de estudo e pesquisa, desde que citada a fonte.

Cruz, Robinson Crusoé da

Análise empírica sobre a influência das métricas CK na testabilidade de software orientado a objetos / Robinson Crusoé da Cruz ; orientador, Marcelo Medeiros Eler. - 2018.

$120 \mathrm{f}$ : : il

Dissertação (Mestrado em Ciências) - Programa de PósGraduação em Sistemas de Informação, Escola de Artes, Ciências e Humanidades, Universidade de São Paulo em 2017.

\section{Versão corrigida}

1. Teste e avaliação de software. 2. Métricas de software. 3 . Projeto de software orientado a objetos. I. Eler, Marcelo Medeiros, orient. II. Titulo. 
Dissertação de autoria de Robinson Crusoé da Cruz, sob o título "Análise empírica sobre a influência das métricas CK na testabilidade de software orientado a objetos", apresentada à Escola de Artes, Ciências e Humanidades da Universidade de São Paulo, para obtenção do título de Mestre em Ciências pelo Programa de Pós-graduação em Sistemas de Informação, na área de concentração Metodologia e Técnicas da Computação, aprovada em 11 de dezembro de 2017 pela comissão julgadora constituída pelos doutores:

Prof. Dr. Marcelo Medeiros Eler

Universidade de São Paulo

Presidente

Prof. Dr. Daniel de Angelis Cordeiro

Universidade de São Paulo

Prof. Dr. Francisco de Assis Zampirolli

Universidade Federal do ABC

Prof. Dr. Michel dos Santos Soares

Universidade Federal de Sergipe 
Dedico esta vitória aos meus pais, Marlene e José Baltazar(in-memorian), minha esposa Patrícia e meus filhos Guilherme Eduardo e Arthur Henrique. 


\section{Agradecimentos}

Agradeço a Deus por me iluminar e permitir que eu chegasse até aqui. Agradeço meus pais, Marlene e José Baltazar por serem a minha base e exemplo de vida. A minha Mãe por não ter medido esforços e as vezes ter renegado aos próprios sonhos para conseguir a felicidade dos seus filhos. Ao meu Pai, sei se estivesse aqui estaria orgulhoso deste momento. Obrigado por suas palavras nos últimos dias de vida: "Deus irá te agradecer por tudo durante sua vida...".

A minha amada esposa Patrícia, por te sido companheira em todos os momentos desde que nos conhecemos, você foi a minha base nesta conquista. Aos meus filhos, Guilherme Eduardo e Arthur Henrique, dedico a vocês este grande passo na minha vida, pois vocês são minha inspiração. Aos meus irmãos Danilo, Aparecida e Gilberto, agradeço pela a ajuda em todos os momentos da minha vida, pois sempre que precisei, estavam presentes. A todos os meus familiares, agradeço pela ajuda nos momentos que precisei.

Agradeço todos os Professores da Graduação, em especial os Professores e amigos Winicius e Wilton, por acreditarem no meu potencial e na minha capacidade em ser Professor.

Em especial, deixo uma eterna gratidão ao Professor Marcelo, que é um exemplo de orientador, Professor e pesquisador. Você foi indispensável para esta vitória. Que Deus ilumine você e sua família.

Aos Professores do Mestrado agradeço por compartilharem o conhecimento. Aos avaliadores do projeto, Professores Daniel Cordeiro, Francisco Zampirolli, André Takeshi e Michel Soares, suas contribuições foram importantes na qualidade do projeto. Agradeço a todos da USP-EACH.

Agradeço a todos meus amigos, em especial Mauricio pela amizade e incentivo, Renato pelas dicas e por ter contribuído com este projeto. Agradeço a Fundação Cultural de Araxá, mantenedora do UNIARAXÁ e o Professor Válter Gomes, pela bolsa de Mestrado concedida e por acreditarem no meu potencial.

Por fim, quero agradecer um grande amigo, Paulo Silva, que foi importante na minha trajetória, pois em 1996 foi responsável por me inserir no mundo da Computação. 
"Você precisa fazer aquilo que pensa que não é capaz de fazer."

(Eleanor Roosevelt) 


\section{Resumo}

CRUZ, Robinson Crusoé da. Análise empírica sobre a influência das métricas CK na testabilidade de software orientado a objetos. 2018. 120 f. Dissertação

(Mestrado em Ciências) - Escola de Artes, Ciências e Humanidades, Universidade de São Paulo, São Paulo, 2017.

Teste de Software tem o objetivo de executar um programa sob teste com o objetivo de revelar suas falhas, portanto é uma das fases mais importante do ciclo de vida do desenvolvimento de um software. A testabilidade é um atributo de qualidade fundamental para o sucesso da atividade de teste, pois ela pode ser entendida como o esforço necessário para criar, executar e avaliar os casos de teste em um software. Este atributo não é uma qualidade intrínseca do software, portanto não pode ser medido diretamente como a quantidade de linhas de código, por exemplo. Entretanto, ela pode ser inferida por meio das características ou métricas internas e externas de um software. Entre as características comumente utilizadas na análise da testabilidade estão as métricas CK, que foram propostas por Chidamber e Kemerer com objetivo de analisar software orientado a objetos. A maioria dos trabalhos nesta linha, entretanto, relaciona o tamanho e a quantidade de casos testes com a testabilidade de um software. Entretanto, é fundamental analisar a qualidade dos testes para saber se eles atingem os objetivos para os quais foram propostos, independente de quantidade e tamanho. Portanto, este trabalho de mestrado apresenta um estudo empírico sobre a relação entre as métricas CK e a testabilidade de um software com base na análise da adequação de seus casos de teste unitários, critérios de teste estrutural e de mutação. Inicialmente foi realizada uma Revisão Sistemática cujo objetivo foi avaliar o estado da arte da testabilidade e as métricas CK. Os resultados mostraram que apesar de existirem várias pesquisas relacionadas ao tema, existem lacunas que motivam novas pesquisas no que concerne a análise da qualidade dos testes e identificação das características das métricas que podem ser inferidas para medir e analisar a testabilidade. Em seguida, foram realizadas duas análises empíricas. Na primeira análise, as métricas foram analisadas por meio da correlação das métricas CK com a cobertura de linha de código, cobertura de branches (arestas, ramos ou desvio de fluxo) e escore de mutação. Os resultados desta análise demonstraram a importância de cada métrica dentro do contexto da testabilidade. Na segunda análise, foi realizada uma proposta de clusterização das métricas para tentar identificar grupos de classes com características semelhantes relacionadas à testabilidade. Além das análises empíricas, foi desenvolvida e apresentada uma ferramenta de coleta e análise de métricas CK com objetivo de contribuir com novas pesquisas relacionados a proposta deste projeto. Apesar das limitações das análises, os resultados deste trabalho mostraram a importância de cada métrica CK dentro do contexto da testabilidade e fornece aos desenvolvedores e projetistas uma ferramenta de apoio e dados empíricos para melhor desenvolverem e projetarem seus sistemas com o objetivo de facilitar a atividade de teste de software.

Palavras-chaves: Métricas. CK. Testabilidade. Teste de software. Cobertura de testes. Teste de mutação. Orientado a objetos 


\begin{abstract}
CRUZ, Robinson Crusoé da. Empirical analysis on the influence of CK metrics on object-oriented software testability. 2018. 120 p. Dissertation (Master of Science) - School of Arts, Sciences and Humanities, University of São Paulo, São Paulo, 2017.

Software testing have aim to run a program under test with the aim of revealing its failures, so it is one of the most important phases of the software development lifecycle. Testability is a key quality attribute for the success of the test activity, because it can be understood as the effort required to create, execute and evaluate test cases in software. This attribute is not an intrinsic quality of the software, so it can not be measured directly as the number of lines code, for example. However, it can be inferred through the or internal and external metrics of a software. Among the features commonly used in testability analysis are CK metrics, which were proposed by Chidamber and Kemerer in order to analyze object-oriented software. Most of the works in this line, however, relate the size and quantity of test cases with software testability. However, it's critical to analyze the quality of the tests to see if they achieve the objectives for which they were proposed, independent of quantity and size. Therefore, this Master's degree work presents an empirical study on the relationship between CK metrics and software testability based on the analysis of the adequacy of its unit test cases, structural test criteria and mutation. Initially, a Systematic Review was carried out to evaluate the state of the art of testability and CK metrics. The results showed that although there are several researches related to the subject, there are gaps that motivate new research in what concerns the analysis of the quality of the tests and identification of the features of the metrics that can be inferred to measure and analyze the testability. Two empirical analyzes were performed. In the first analysis, the metrics were analyzed through the correlation of the CK metrics with the code line coverage, branch coverage or mutation score. The results of this analysis showed the importance of each metric within the context of testability. In the second analysis, a metric clustering proposal was made to try to identify groups of classes with similar features related to testability. In addition to the empirical analysis, a tool for the collection and analysis of CK metrics was developed and presented, with aim to contribute with new researches related to the proposal of this project. Despite the limitations of the analyzes, the results of this work showed the importance of each CK metric within the context of testability and provides developers and designers with a support tool and empirical data to better develop and design their systems with the aim of facilitate the activity of software testing.
\end{abstract}

Keywords: Metrics. CK. Testability. Software testing. Test coverage. Mutation testing. Object oriented 


\section{Lista de figuras}

Figura 1 - Estrutura do Projeto . . . . . . . . . . . . . . . 21

Figura 2 - Representação de um grafo de fluxo de controle (GFC) . . . . . . . . . 26

Figura 3 - Teste de Unidade, Integração e de Sistema de Software Procedimental

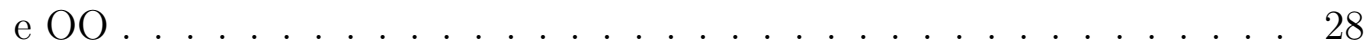

Figura 4 - Análise dos testes de softwares orientados a objetos . . . . . . . . . 30

Figura 5 - Diagrama de causa e efeito de testabilidade proposto por (BINDER,

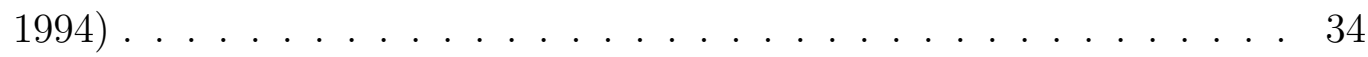

Figura 6 - Representação de CBO . . . . . . . . . . . . . . . . . 38

Figura 7 - Representação de DIT . . . . . . . . . . . . . . . . . 39

Figura 8 - Representação de NOC . . . . . . . . . . . . . . . . 41

Figura 9 - Evolução do Algoritmo kMeans . . . . . . . . . . . . . . . . . . . 47

Figura 10 - Exemplo de utilização do método kNN (FERREO, 2009) . . . . . . . . 49

Figura 11 - Exemplo de aplicação do kNN (FERREO, 2009) . . . . . . . . . . . . 50

Figura 12 - Estrutura da execução e seleção dos artigos . . . . . . . . . . . . . 53

Figura 13 - Diagrama de classe com duas análises de DIT . . . . . . . . . . . . . 72

Figura 14 - Distribuição dos valores da métrica CBO nos clusters . . . . . . . . . . 89

Figura 15 - Distribuição da cobertura de linha em cada cluster CBO . . . . . . . . 89

Figura 16 - Distribuição dos valores da métrica LCOM nos clusters . . . . . . . . . 91

Figura 17 - Distribuição da cobertura de linha em cada cluster LCOM . . . . . . . 91

Figura 18 - Distribuição dos valores da métrica RFC nos clusters . . . . . . . . . . 92

Figura 19 - Distribuição da cobertura de linha em cada cluster RFC . . . . . . . . 92

Figura 20 - Distribuição dos valores da métrica WMC nos clusters . . . . . . . . . 93

Figura 21 - Distribuição da cobertura de linha em cada cluster WMC . . . . . . . 93

Figura 22 - Média de cobertura de linha x cluster . . . . . . . . . . . . . . . 94

Figura 23 - Média de escore de mutação x cluster . . . . . . . . . . . . . . . . . . 94

Figura 24 - JHawk - Ferramenta de coleta de métricas CK . . . . . . . . . . . . . 99

Figura 25 - Eclipse Metrics - Plugin de coleta de métricas CK . . . . . . . . . . 100

Figura 26 - SUVSOFT - Uma metáfora do universo para compreensão de programas100

Figura 27 - Ferramentas de coletas de métricas de software OO . . . . . . . . . 101

Figura 28 - MineMetrics - Tela de coleta de métricas . . . . . . . . . . . . . . 103 
Figura 29 - MineMetrics - Tela de análise estatística . . . . . . . . . . . . . . . 104

Figura 30 - MineMetrics - Análise de correlação . . . . . . . . . . . . . . . . 105

Figura 31 - MineMetrics - Clusterização das métricas . . . . . . . . . . . . . . . 106 


\section{Lista de algoritmos}

Algoritmo 1 - Cobertura de linha e ramos (branches) . . . . . . . . . . . 30

Algoritmo 2 - Mutante gerado a partir do Algoritmo $1 \ldots \ldots$. . . . . . . . . . . 32

Algoritmo 3 - Exemplo de CBO . . . . . . . . . . . . . . . . . 38

Algoritmo 4 - Exemplo de análise de complexidade WMC . . . . . . . . . . . . . . . . . 42

Algoritmo 5 - Exemplo de análise do teste unitário (quantidade de TAssert e TLOC) . 57

Algoritmo 6 - Análise correta da métrica RFC pela ferramenta JHawk . . . . . . . . . . . 72

Algoritmo 7 - Análise incorreta da métrica RFC pela ferramenta JHawk . . . . . . . . 73 


\section{Lista de tabelas}

Tabela 1 - Exemplos de geração de mutantes aplicados no Algoritmo 1 . . . . . . 33

Tabela 2 - Métricas de Lorenz e Kidd . . . . . . . . . . . . . . . . . . 36

Tabela 3 - Métricas de Abreu . . . . . . . . . . . . . . . . 37

Tabela 4 - Relacionamento das métricas CK com as propostas por Abreu et al. (1995) e Lorenzen e Kidd (1994) . . . . . . . . . . . . . . . . . . . . 43

Tabela 5 - Relacionamento entre métricas CK e medidas OO . . . . . . . . 43

Tabela 6 - Relacionamento entre métricas CK e fatores de qualidade . . . . . . . 44

Tabela 7 - Critérios de inclusão e exclusão do protocolo da RS . . . . . . . . . . . 53

Tabela 8 - Artigos selecionados na Revisão Sistemática . . . . . . . . . . . . 55

Tabela 9 - Concentração de pesquisa por autores . . . . . . . . . . . 56

Tabela 10 - Concentração de trabalhos por tipo de cálculo aplicado . . . . . . . . . 59

Tabela 11 - Principais softwares utilizados nas pesquisas . . . . . . . . . . . . 60

Tabela 12 - Artigos que analisaram as métricas CK por meio de cálculos . . . . . . 61

Tabela 13 - Resultado da métrica CBO - software x classe de teste . . . . . . . . 63

Tabela 14 - Resultado da métrica DIT em relação software x classe de teste . . . . 64

Tabela 15 - Resultado da métrica LCOM em relação software x classe de teste . . . 65

Tabela 16 - Resultado da métrica NOC em relação software x classe de teste . . . . 66

Tabela 17 - Resultado da métrica RFC em relação software x classe de teste . . . . 67

Tabela 18 - Resultado da Métrica WMC em relação software x classe de teste . . . 68

Tabela 19 - Análise dos trabalhos correlatos entre as Revisões Sistemáticas (RS) . . 70

Tabela 20 - Configurações de cobertura para análise de correlação . . . . . . . . . . 78

Tabela 21 - Classes analisadas nos testes com base na configuração (Tab. 20) . . 78

Tabela 22 - Cobertura e escore de mutação dos softwares . . . . . . . . . . . . 79

Tabela 23 - Análise da correlação de CBO . . . . . . . . . . . . . . . . . 80

Tabela 24 - Análise da correlação de DIT . . . . . . . . . . . . . . . . 80

Tabela 25 - Análise da correlação de LCOM . . . . . . . . . . . . . . . . . . . . . . 81

Tabela 26 - Análise da correlação de NOC . . . . . . . . . . . . . . . . . . . 81

Tabela 27 - Análise da correlação de RFC . . . . . . . . . . . . . . . . . . 82

Tabela 28 - Análise da correlação de WMC . . . . . . . . . . . . . . . . . 82

Tabela 29 - Análise da correlação entre cobertura de linha e escore de mutação . 83 
Tabela 30 - Correlação entre as métricas CK - comparativo entre os trabalhos relacionados e esta pesquisa . . . . . . . . . . . . . . . 83

Tabela 31 - Análise da importância das métricas nos resultados de correlação . . 84

Tabela 32 - Número de clusters para cada configuração . . . . . . . . . . . . . . 86

Tabela 33 - Análise de clusterização de métricas (CBO, LCOM, RFC e WMC) . 88

Tabela 34 - Clusterização individual das métricas CBO, LCOM, RFC e WMC . . . 90 


\section{Lista de abreviaturas e siglas}

API Interface de Programação de Aplicativos

CBO Acoplamento entre objetos

CK Chidamber e Kemerer

CRM Customer Relationship Management

CSV Comma-separated values (Valores separados por Vírgula)

DIT Profundidade da árvore de herança

ERP Entrerprise Resource Planning

EM Algoritmo de Maximização de Expectativa

IDE Integrated Development environment

GFC Grafo de Fluxo de Controle

LCOM Falta de Coesão entre os métodos da classes

LK Lorenz e Kidd

LOC Quantidade de Linhas de Código

NOC Falta de Coesão entre os métodos da classe

MLR Multiple Linear Regression

OO Orientado a Objetos

PLSR Partial Least Square Regression

POO Programação Orientada a Objetos

RFC Resposta para uma classe

TAsserts Quantidade de casos de testes gerados na classe de teste

TLOC Quantidade de linhas de código da classe de teste

WMC Complexidade dos métodos por classe 


\section{Sumário}

Introdução . . . . . . . . . . . . . . . . . 18

1.1 Motivação e justificativa . . . . . . . . . . . . . . . 19

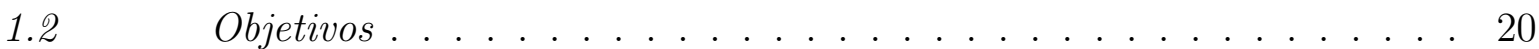

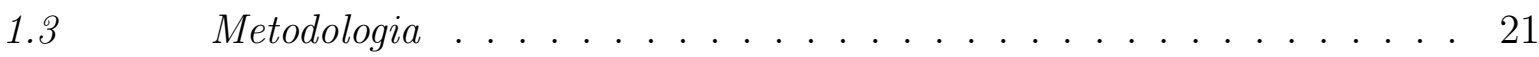

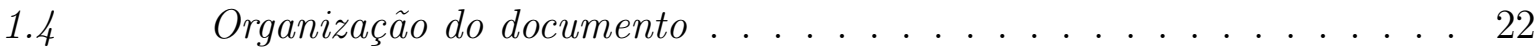

$2 \quad$ Fundamentação teórica . . . . . . . . . . . 23

2.1 Visão geral de teste de software . . . . . . . . . . . . . . . 23

2.1.1 Teste Funcional (Teste Caixa Preta) . . . . . . . . . . . . 24

2.1.2 Teste Estrutural (Caixa Branca) . . . . . . . . . . . . . 25

2.1.3 Fases de Teste . . . . . . . . . . . . . . . 27

2.1.4 Cobertura de Teste . . . . . . . . . . . . . . . 30

2.1.5 Teste de Mutação . . . . . . . . . . . . . . . . . . . . . 31

2.2 Visão geral sobre testabilidade . . . . . . . . . . . 33

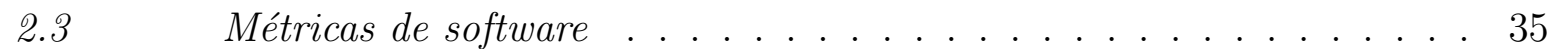

2.3.1 Métricas de software orientado a objetos . . . . . . . . 36

2.3.2 Métricas CK . . . . . . . . . . . . . . 37

2.3.3 Métricas CK e medidas de software $\mathrm{OO} \ldots \ldots . \ldots . . . . . .43$

2.4 Correlação e medidas de associação . . . . . . . . . . . . . . 44

2.5 Algoritmos de agrupamento (clusterização) . . . . . . . . 45

2.5.1 $\quad k$-Means . . . . . . . . . . . . . . . . . 46

2.5.2 Algoritmo Maximização de Expectativa (EM) . . . . . . . . . . . . 48

2.6 Algoritmo $k N N \ldots \ldots \ldots \ldots \ldots$

2.7 Considerações finais . . . . . . . . . . . . . . . 51

3 Revisão Sistemática . . . . . . . . . . . . . 52

3.1 Questões de pesquisa . . . . . . . . . . . . . . 52

3.2 Condução da Revisão Sistemática . . . . . . . . . . . . 53

3.3 Análise dos trabalhos selecionados e discussão . . . . . . . . . . . 54

3.3.1 Análise dos tipos de cálculos aplicados nas pesquisas . . . . . . . 58

3.3.2 Resultados das linguagens de programação e softwares utilizados . . 59 
3.4 Análise dos artigos que utilizaram métricas CK baseados em cálculos (A) 60

3.4.1 Resultados das pesquisas relacionadas a métrica CBO . . . . . . . 62

3.4.2 Resultados das pesquisas relacionadas a métrica DIT . . . . . . . . 64

3.4.3 Resultados das pesquisas relacionadas a métrica LCOM . . . . . . . 65

3.4.4 Resultados das pesquisas relacionadas a métrica NOC . . . . . . 66

3.4.5 Resultados das pesquisas relacionadas a métrica RFC . . . . . . . 67

3.4.6 Resultados das pesquisas relacionadas a métrica WMC . . . . . . 68

3.5 Análise dos artigos conceituais (B) . . . . . . . . . . . 68

3.6 Artigos de Revisão Sistemática $(C) \ldots \ldots \ldots$. . . . . . . 70

3.7 Lacunas dos trabalhos relacionados e ferramentas . . . . . . . . . 71

3.8 Análise crítica e considerações finais . . . . . . . . . . . . . 74

Análises Empíricas . . . . . . . . . . . . 76

4.1 Ferramentas utilizadas e softwares analisados . . . . . . . . 76

4.2 Análise Empírica da correlação entre as métricas CK e a Cobertura

de Teste e Escore de Mutação . . . . . . . . . . . . . . . . . . 77

4.2.1 Coleta dos dados e análise estatística . . . . . . . . . . . . . 78

$4.2 .2 \quad$ Análise dos resultados . . . . . . . . . . . . . . . . . . 79

4.2.3 Discussão dos resultados . . . . . . . . . . . . . . . . . . 84

4.3 Análise de agrupamento de classes de acordo com a inferência das

métricas ......................... 85

4.3.1 Definição dos clusters das classes . . . . . . . . . . . . . 86

4.3.2 Resultados . . . . . . . . . . . . . . 86

4.3.3 Discussão dos resultados . . . . . . . . . . . . . . . 94

$4.4 \quad$ Recomendações práticas . . . . . . . . . . . . . 95

4.5 Considerações finais . . . . . . . . . . . . . . 96

$5 \quad$ MineMetrics - Ferramenta de coleta de métricas, análise estatística e clusterização . . . . . . . . . . . . 98

$5.1 \quad$ Ferramentas correlatas . . . . . . . . . . . . . . . 98

$5.1 .1 \quad$ JHawk . . . . . . . . . . . . . . . . . . . . . 98

5.1.2 Eclipse Metrics Plugin . . . . . . . . . . . . . . . 99

$5.1 .3 \quad$ SUVSoft . . . . . . . . . . . . . . . . . 100 
5.1.4 Artigos de Revisão Sistemática sobre ferramentas . . . . . . . . . . 101

5.1.5 Considerações sobre as ferramentas correlatas . . . . . . . . . . . . 101

5.2 Ambiente de desenvolvimento . . . . . . . . . . . 102

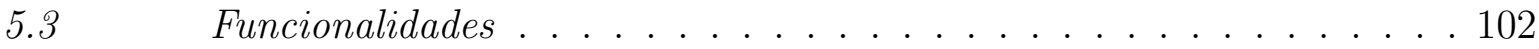

5.3.1 Coleta e importação de métricas . . . . . . . . . . . . . 102

5.3.2 Análise estatística . . . . . . . . . . . . . . 104

5.3.3 Clusterização . . . . . . . . . . . . . . . . 105

5.4 Validação da ferramenta MineMetrics . . . . . . . . . . . . . 106

5.5 Considerações finais e futuras características na ferramenta MineMetrics107

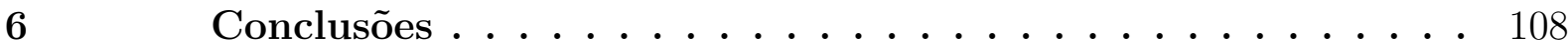

6.1 Limitações . . . . . . . . . . . . . . . . . . . . . . . 108

6.2 Trabalhos futuros . . . . . . . . . . . . . . 109

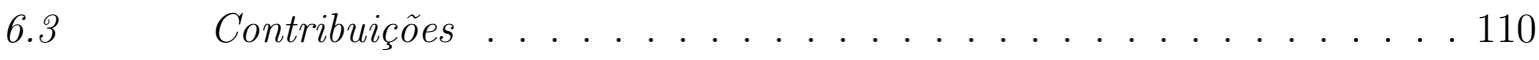

6.4 Produção bibliográfica . . . . . . . . . . . . 111

Referências $^{1} \ldots \ldots \ldots \ldots \ldots$

Apêndice A-Protocolo da Revisão Sistemática . . . . . . 118

$\overline{1}$ De acordo com a Associação Brasileira de Normas Técnicas. NBR 6023. 


\section{Introdução}

A construção de software não é uma tarefa simples e pode tornar-se muito complexa dependendo das suas características e dimensões. Esta atividade está sujeita a vários tipos de problemas que podem levar à criação de um produto com baixa qualidade ou diferente do que se esperava. Desenvolver software com qualidade e que atenda aos requisitos dos usuários não é uma vantagem competitiva e sim uma necessidade básica. Portanto, as organizações têm investido em atividades de garantia de qualidade de software para diminuir o risco de seus produtos possuírem baixa qualidade e não atenderem às expectativas dos clientes (TAHIR; MACDONELL; BUCHAN, 2014).

O Teste de Software é uma das atividades mais importantes no desenvolvimento de um software, e o principal objetivo principal é executar o software em diversos contextos com objetivo de revelar defeitos. O esforço que esta atividade demanda durante o desenvolvimento de software motivou várias pesquisas cujo objetivo é reduzir o custo desta tarefa e entender as características de um software que podem influenciar o esforço necessário para a atividade de teste (ABDULLAH; KHAN, 2013; MYERS; SANDLER, 2004). Por exemplo, no teste de software orientado a objetos as dificuldades aumentam em razão de características como herança, polimorfismo com ligação dinâmica, encapsulamento e ocultação da informação (KOSCIANSKI; SOARES, 2007; MYERS; SANDLER, 2004). Em particular, entender características internas que podem aumentar ou diminuir a complexidade ou a quantidade de casos de teste necessário para testar todas as estruturas internas de um software pode contribuir significativamente para a redução do esforço na criação e manutenção dos casos de testes criados nesta atividade.

O conjunto de fatores que influenciam o esforço requerido para testar um software é definido como o fator de testabilidade de um software, que é o grau no qual um sistema ou componente facilita o estabelecimento de critérios de teste, a criação dos casos de teste e a adequação destes aos critérios estabelecidos (IEEE, 1990). Contudo, a testabilidade não é uma característica intrínseca do software, portanto, ela não pode ser medida diretamente. Dessa forma, a testabilidade de um software pode ser apenas medida indiretamente com base em métricas internas e externas, que dizem respeito a artefatos produzidos ao longo do processo de desenvolvimento, como diagramas e código-fonte, por exemplo (LI, 1999). 
Neste sentido, muitas pesquisas já foram realizadas com o intuito de medir a testabilidade de um software com base nas métricas propostas por Chidamber e Kemerer (CHIDAMBER; KEMERER, 1994), que ficaram popularmente conhecidas como métricas CK. Essas métricas são comumente utilizadas em desenvolvimento de software porque fornecem medidas sobre diversas características de programas orientados a objetos, como coesão, acoplamento e complexidade.

\subsection{Motivação e justificativa}

Diversos estudos foram desenvolvidos durante os últimos anos para identificar se as métricas CK podem ser inferidas para medir a testabilidade de um software. Por exemplo, nas pesquisas (KHAN; MUSTAFA, 2009) e (BADRI; TOURE, 2011) foram realizados estudos com objetivo de criar equações com a utilização das métricas CK para auxiliar na análise do esforço dos testes. Outros estudos que serão apresentados na Revisão Sistemática tiveram como foco estimar o esforço dos testes por meio da análise dos casos de teste que foram necessários para testar um software. De uma forma geral, quanto maior a quantidade de testes necessários para testar o software, menor a testabilidade. Entretanto, esses estudos possuem diversas limitações: i) as métricas CK são analisadas individualmente, portanto não há análise sobre a correlação entre as métricas e sobre como isto pode influenciar a testabilidade do software; ii) o grau de testabilidade é medido com base na quantidade e tamanho dos casos de teste, e não com base na qualidade dos casos de teste; iii) não há indicação de limites de valores para cada métrica analisada que podem levar a uma alta ou baixa testabilidade; e iv) não existem recomendações práticas sobre como utilizar os dados da pesquisa durante o desenvolvimento de software com o objetivo de produzir um software mais testável.

Analisar o esforço necessário para criar os casos de teste para testar um software exige que sejam analisados mais do que o tamanho e a quantidade de casos de teste. É necessário analisar a qualidade dos casos de teste produzidos, pois as técnicas de teste existem para guiar os testadores na produção de casos de teste que satisfaçam critérios específicos, de tal forma que haja uma maior probabilidade de revelar defeitos e de que não haja testes redundantes. Os testes redundantes exercitam os mesmos aspectos do software já exercitados por outros casos de teste. Dessa forma, quando se estima a testabilidade 
de um software com base apenas na quantidade de testes produzidos, não se sabe se aqueles testes satisfizeram os critérios para os quais deveriam ser criados ou se existem vários casos de teste redundantes. Portanto, acredita-se que uma análise adequada neste contexto precisa necessariamente incluir a avaliação de quanto os casos de teste em questão satisfazem os critérios.

Um dos objetivos de se entender o quanto as métricas CK afetam a testabilidade de um software é diminuir o esforço de teste. Para reduzir o esforço de teste é preciso que os desenvolvedores produzam software mais testáveis, e para isso os resultados dos estudos nessa área precisam ser possíveis de serem aplicados na prática. Os desenvolvedores precisam ser capazes de calcular as métricas CK de suas classes e entender se os valores obtidos indicam um alto ou baixo grau de testabilidade, para então poder tomar atitudes, como refatorar o código, por exemplo, para deixar o software o mais testável possível.

\subsection{Objetivos}

O objetivo principal deste projeto de pesquisa é realizar um estudo empírico sobre a relação entre métricas CK e a testabilidade de um software. Também é objetivo deste trabalho desenvolver uma ferramenta para apoiar desenvolvedores na avaliação do código produzido e determinar o quão testável as classes desenvolvidas são, e assim poder refatorar o código de tal forma que o código produzido seja mais testável.

Para atingir os objetivos propostos, foram definidos o seguintes objetivos específicos:

- realizar um levantamento bibliográfico sobre os estudos que relacionam as métricas CK com testabilidade;

- fazer uma seleção de projetos de código aberto e comerciais para fazer análises;

- avaliar a qualidade dos testes disponíveis nos projetos selecionados;

- desenvolver uma ferramenta de coleta e análise de métricas CK;

- realizar uma análise empírica da correlação das métricas com as medidas de teste;

- aplicar um estudo de clusterização das métricas CK com objetivo de analisar as características de testabilidade de cada grupo;

- e sugerir melhores práticas de design de código para diminuir o esforço de teste. 


\subsection{Metodologia}

Figura 1 - Estrutura do Projeto

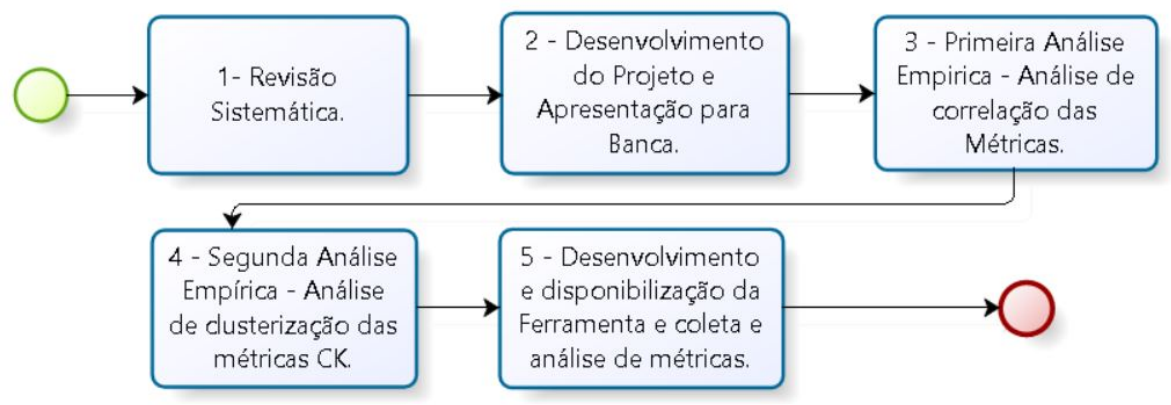

Fonte: Robinson Crusoé da Cruz, 2017

A Figura 1 representa a estrutura deste trabalho e as principais atividades são descritas a seguir:

- 1 - Revisão Sistemática: Esta fase foi importante para analisar o estado da arte relacionado a utilização das métricas CK na análise do esforço dos testes de um software. Foram realizadas análises qualitativas e quantitativas dos artigos, conforme apresentado no Capítulo 3. Outra revisão desenvolvida neste fase foi a análise das lacunas encontradas nas ferramentas e nos trabalhos correlatos.

- 2 - Desenvolvimento do Projeto e Apresentação para Banca: Nesta fase os resultados da fase de Revisão Sistemática foram organizados junto com a proposta de trabalho por meio do desenvolvimento de um projeto. Este projeto foi apresentado para banca avaliadora com objetivo principal de obter sugestões e correções sugeridas pelos avaliadores.

- 3 - Primeira Análise Empírica: Nesta fase foi desenvolvida uma análise empírica por meio da análise da correlação entre as métricas CK e as medidas de testabilidade. O objetivo foi obter um caminho diferente dos artigos analisados na revisão sistemática, porém, com comparações entre os resultados dos trabalhos da revisão sistemática e os resultados produzidos nesta fase.

- 4 - Segunda Análise Empírica: Nesta fase foi desenvolvida uma análise empírica por meio da proposta de uma metodologia de clusterização da métricas CK e a análise relacionada a testabilidade. O objetivo principal desta fase foi obter uma estrutura de agrupamento de classes de acordo com as métricas ck. 
- 5 - Desenvolvimento da Ferramenta: Nesta fase foi desenvolvida uma ferramenta de coleta e análise de métricas, com objetivo de contribuir com novas pesquisas.

\subsection{Organização do documento}

Este documento está organizado da seguinte forma. No Capítulo 2 são apresentados os conceitos fundamentais que apoiam este projeto de pesquisa. Este Capítulo está dividido em teste de software, testabilidade, métricas de software, métricas CK e um breve resumo sobre análise de correlação, associação e classificação de dados.

No Capítulo 3 é apresentada uma Revisão Sistemática (RS) sobre estudos que correlacionam as métricas CK com a testabilidade de um software. Além disso, é realizada uma análise sobre as lacunas encontradas nas ferramentas utilizadas neste projeto e sobre a definição incorreta de algumas métricas CK em trabalhos correlatos. Este capítulo foi proposto para auxiliar na compreensão do estado da arte relacionado à proposta de pesquisa deste trabalho.

No Capítulo 4 são apresentadas as Análises Empíricas do projeto: inicialmente são apresentados os resultados da análise de correlação entre as métricas CK e a cobertura de teste e escore de mutação; e em seguida é apresentada a proposta de clusterização das métricas CK com análise dos resultados relacionados a testabilidade. No Capítulo 5 é apresentado a ferramenta de coleta e análise de métricas.

Por fim, no Capítulo 6 são apresentadas as considerações finais, limitações do trabalho, contribuições e trabalhos futuros. 


\section{Fundamentação teórica}

Neste capítulo são apresentados conceitos importantes para auxiliar no desenvolvimento da pesquisa. Inicialmente, na Seção 2.1 são definidos os conceitos relacionados a teste de software, cobertura de teste, teste de mutação. Na Seção 2.2 são apresentados os conceitos relacionados a testabilidade. Nas Seções 2.3 e 2.3.2 são definidos os conceitos relacionados as métricas de software e métricas CK. Por fim, nas próximas seções são apresentados os métodos estatísticos de correlação, algoritmos de clusterização e classificação de dados.

\subsection{Visão geral de teste de software}

O teste de software é utilizado com objetivo principal de executar o software e verificar se existem falhas. Uma falha é detectada sempre que o comportamento do software executado não está de acordo com o esperado (DELAMARO; MALDONADO; JINO, 2016; MYERS; SANDLER, 2004). Um teste bem sucedido pode identificar defeitos que ainda não foram descobertos e uma atividade de teste bem planejada pode ser utilizada como um dos parâmetros para estimar a confiabilidade e a qualidade do software (KOSCIANSKI; SOARES, 2007).

O desenvolvimento de software é uma tarefa complexa e defeitos podem ser introduzidos em diversas fases do projeto, mesmo quando métodos e ferramentas de engenharia de software bem definidos são empregados (DELAMARO; MALDONADO; JINO, 2016). Por isso, a aplicação do teste pode ser considerada parte essencial no contexto de desenvolvimento de um produto de software com qualidade.

A primeira meta do teste é a validação, em que se espera que o software funcione corretamente baseado em um conjunto de casos de teste. Os testes são executados e não precisam refletir como o sistema é usado normalmente, pois o objetivo é avaliar se o software funciona sob condições não previstas. A segunda meta leva ao teste de defeitos, no qual os casos de testes são executados utilizando dados reais do funcionamento de um software (SOMMERVILLE et al., 2008).

Os testes de software não permitem provar que um software está correto, porém eles podem aumentar a confiança de que o software desempenha as funções planejadas. Contudo, como não é viável testar um software em todos os contextos e com todos os dados 
das possíveis entradas. Então, diversas técnicas e critérios de teste podem ser aplicadas para auxiliar na derivação de casos de teste que possuem maior probabilidade de revelar os principais tipos de defeitos encontrados em um software. A seguir são apresentas as técnicas e critérios de teste mais utilizados na academia e na indústria.

\subsubsection{Teste Funcional (Teste Caixa Preta)}

Teste funcional é uma técnica utilizada para projetar casos de testes no qual o software é considerado uma caixa preta. Para testá-lo, são fornecidas entradas e avaliadas as saídas geradas para verificar se estão em conformidade com os objetivos. O teste funcional é particularmente utilizado para revelar problemas, tais como: funções incorretas ou omitidas, erros de interface, erros de comportamento ou desempenho, erros de iniciação e término. Nesta fase, ao analisar o comportamento de um software, ignora-se totalmente sua construção interna, ou seja, o testador tem acesso apenas aos dados de entrada e saída por meio dos requisitos do software, sem se preocupar com detalhes da estrutura interna do software (KOSCIANSKI; SOARES, 2007).

No teste funcional, todos os defeitos podem ser encontrados ao submeter o software a todas as possíveis entradas, o que é denominado teste exaustivo. Entretanto, a quantidade de entradas pode ser infinita, ou muito grande, tornando esta alternativa impraticável. Por isto, a aplicação de técnicas de teste funcional são importantes para reduzir o esforço dos testes (DELAMARO; MALDONADO; JINO, 2016). Entre os critérios de teste que possem ser utilizado no teste funcional é possível destacar:

Partição de equivalência: consiste em dividir os testes em subconjuntos de classes de equivalência de acordo com domínio. Uma vez identificadas as classes de equivalência, deve-se determinar casos de teste, escolhendo elementos de cada classe e gerando um caso de teste para cada uma das classes de equivalência, com isto, é possível garantir com alguma segurança a qualidade dos testes, pois um elemento pode representar vários valores dentro da classe. Um exemplo seria para um teste com entrada $N$ que deveria ser entre 0 e 999, seriam geradas as seguintes classes: $(N<0),(N \geq 0),(N \leq 999)$ e $(N>999)$ (DELAMARO; MALDONADO; JINO, 2016).

Análise de valor limite: é um critério utilizado para seleção de casos de teste que exercitam os limites em que pode ocorrer uma mudança de comportamento do software. 
O emprego desta técnica deve ser utilizado para complementar a técnica de teste de equivalência (FILHO, 2009).

Teste de Comparação: baseado na comparação dos valores de saídas em versões diferentes. Ou seja, são aplicados testes com a mesma coleção de dados e softwares que possuem versões diferentes, caso o resultado de saída seja o mesmo, pode-se garantir, com alguma segurança, que os resultados estão corretos (FILHO, 2009).

\subsubsection{Teste Estrutural (Caixa Branca)}

Ao contrário do Teste Funcional (caixa-preta), nesta técnica os casos de teste são criados com base na análise da estrutura interna do software. O objetivo principal é garantir a execução das estruturas de dados de programação do software sob teste (DELAMARO; MALDONADO; JINO, 2016). Portanto, para este tipo de teste, o testador precisa ter total acesso à estrutura interna da entidade analisada (KOSCIANSKI; SOARES, 2007; MYERS; SANDLER, 2004).

É comum que no teste estrutural os critérios de teste sejam gerados com base em um modelo subjacente: o Grafo de Fluxo de Controle (GFC). Um GFC é um grafo dirigido, com um único nó de entrada e um único nó de saída, no qual cada aresta representa um possível desvio de um bloco para outro. Uma vez que o primeiro comando do bloco é executado, todos os demais comandos daquele bloco são executados sequencialmente (DELAMARO; MALDONADO; JINO, 2016). A Figura 2 representa um exemplo de um GFC. 
Figura 2 - Representação de um grafo de fluxo de controle (GFC)

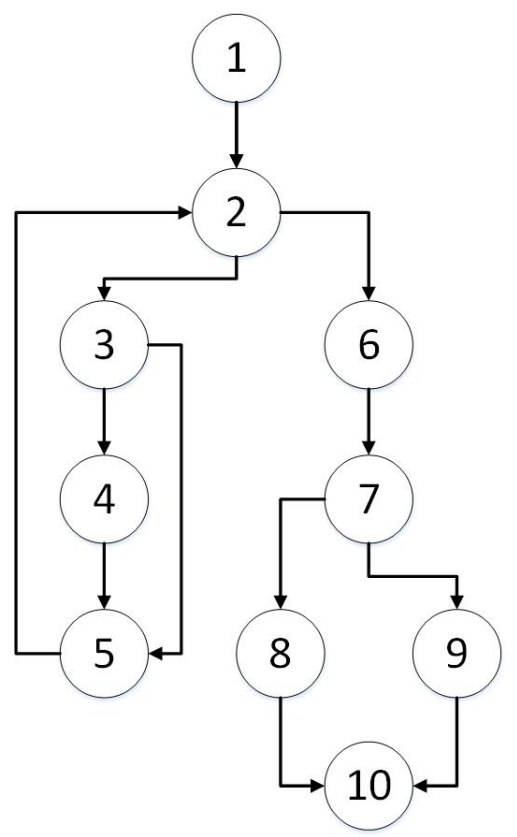

Fonte: Adaptado de (DELAMARO; MALDONADO; JINO, 2016)

A definição de um GFC é dada por: seja um GFC, $G=(N, E, s)$ em que $N$ representa o conjunto de nós, $E$ o conjunto finito de arestas, e $s$ o nó de entrada. Um caminho é considerado uma sequência finita de nós $\left(n_{1}, n_{2}, \ldots, n_{k}\right)$, com $k \geq 2$, tal que existe um arco de $n_{i}$ para $n_{i}+1$, para todo $i=1,2, \ldots, k-1$. Um caminho é considerado simples se todos os nós são distintos. Diz-se que este caminho é livre de laço. Um caminho completo é aquele que o primeiro nó é o nó de entrada e o último é um nó de saída do grafo (DELAMARO; MALDONADO; JINO, 2016). Conforme o grafo representado pela Figura 2, o caminho $(1,2,6,7,8,10)$ é um caminho simples, livre de laços. O caminho $(1,2,3,4,5,2,6,7,9,10)$ é um caminho completo, com laço.

Os critérios de teste estrutural são classificados da seguinte forma (DELAMARO; MALDONADO; JINO, 2016): baseados em complexidade, fluxo de controle e fluxo de dados. Os critérios baseados na complexidade utilizam informações sobre a complexidade do software para derivar os casos de testes. A complexidade ciclomática proposta em (MCCABE, 1976) foi um dos primeiros critérios definidos para teste estrutural. Este critério proporciona uma medida quantitativa da complexidade lógica do software. Basicamente é analisada a quantidade de caminhos independentes do conjunto básico do programa com objetivo de oferecer um limite máximo para o número de testes que devem ser realizados para garantir que todas as instruções sejam executadas (PRESSMAN, 2006; DELAMARO; MALDONADO; JINO, 2016). 
Os critérios baseados em fluxo de controle utilizam características de controle de execução do software, como comandos ou desvios, com objetivo de derivar os requisitos de testes necessários. Os critérios mais utilizados são (DELAMARO; MALDONADO; JINO, 2016):

- Todos-Nós: A execução do programa deve passar pelo menos uma vez em cada vértice do GFC, ou seja, cada comando do programa deve ser executado pelo menos uma vez;

- Todas-Arestas: Cada aresta do grafo, ou seja, cada desvio de fluxo de controle do programa deve ser executado pelo menos uma vez.

- Todos-Caminhos: Todos os caminhos possíveis do programa devem ser executados. No modo geral, este critério tem se mostrado pouco eficaz, mesmo para pequenos programas, pois executar todos caminhos de um programa pode ser uma tarefa impraticável.

Além dos critérios de fluxo de controle, existem os critérios baseados no fluxo de dados, que utilizam informações do fluxo de dados do programa para determinar os requisitos de testes. Basicamente este critério baseia-se na associação do fluxo de dados entre as variáveis e seus possíveis usos subsequentes, ou seja, gera casos de teste com análise do comportamento das variáveis do programa e combina caminhos do Grafo de Fluxo de Controle que correspondem a diferentes combinações de estados e uso das variáveis. Exemplos desta classe de critério são: Critérios de Rapps e Weyuker (RAPPS; WEYUKER, 1985) e critério de potenciais-usos (MALDONADO, 1991).

\subsubsection{Fases de Teste}

Os testes são divididos em fases (Figura 3), sendo que em cada uma das fases são realizados planejamentos baseados em uma determinada fase do desenvolvimento do software. As três principais fases de teste de software, seja para sistemas convencionais ou orientado a objetos, são descritas a seguir. 
Figura 3 - Teste de Unidade, Integração e de Sistema de Software Procedimental e OO

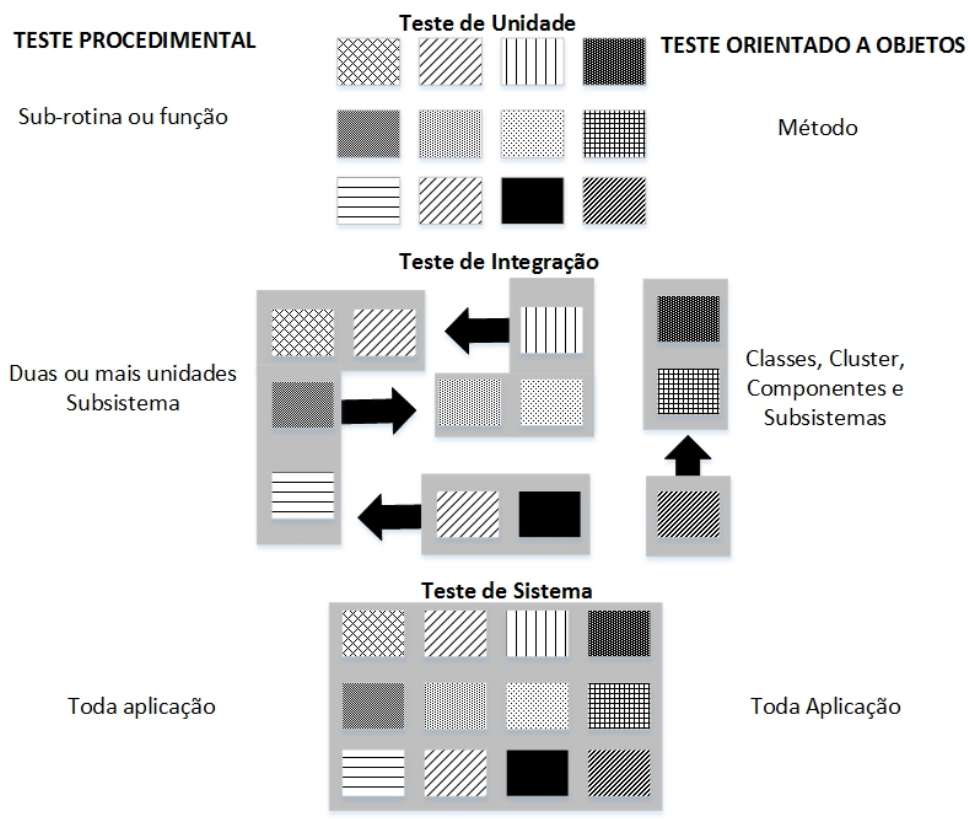

Fonte: Adaptado de (BINDER, 1994 apud DELAMARO; MALDONADO; JINO, 2016)

Teste de Unidade: O objetivo é analisar se a unidade testada realiza as funcionalidades especificadas e se o código implementado está de acordo com as especificações do projeto. Esta fase é a primeira e mais básica de todas, sendo a unidade um componente de código sob a responsabilidade do programador. Por exemplo, uma unidade pode ser considerada uma função em programação procedimental e um método ou classe na programação OO. Esta fase pode ser dividida na depuração do código por meio dos compiladores, com análise visual dos dados e na verificação da lógica da unidade (BOAS, 2003).

Teste de Integração: Nesta fase, os componentes que realizam alguma funcionalidade em comum são agrupados para que sejam realizados testes da sua funcionalidade em conjunto (SOMMERVILLE et al., 2008).

Teste de Sistema: Nesta fase são realizados testes nas funcionalidades do software antes da entrega ao cliente com objetivo de garantir que o software atenda os requisitos do projeto. Ao utilizar um processo de desenvolvimento iterativo o teste pode ser realizado com partes do software que serão entregues ao cliente (SOMMERVILLE et al., 2008).

Existem várias propostas idênticas sobre a divisão das fases de teste para Software OO, por exemplo, a proposta que descreve que os testes devem ser divididos em 4 fases: (1) teste de unidade, que realiza os testes dos métodos individualmente; (2) teste de classe, que realiza o teste de integração entre os métodos e uma classe; (3) teste de integração, que realiza os testes entre as classes do sistema e (4) teste de sistema, que testa a funcionalidade 
do sistema como um todo (DELAMARO; MALDONADO; JINO, 2016). A diferença está na fase do teste de unidade, pois para alguns autores, a menor unidade do software OO é a classe e para outros é o método.

Além das fases descritas anteriormente, na literatura existem outras propostas de fases de teste, como por exemplo: teste de releases, que é o processo de teste das versões que são distribuídas aos clientes com objetivo de aumentar a confiança de que o software atende os requisitos, antes da entrega final do produto; teste de desempenho, que realiza os testes para analisar se o software desenvolvido suporta a carga máxima necessária; teste de integração, é aplicado no paradigma OO na análise de componentes; teste de caminho, que tem como objetivo exercitar caminhos independentemente da execução de um componente ou de um software (SOMMERVILLE et al., 2008).

Ao comparar as fases de teste de software entre sistemas procedimentais e Orientado a Objetos, é possível destacar algumas diferenças. O teste de software OO consiste em realizar sequências de envios de mensagens de forma organizada para atingir o maior número possível de estados que um objeto possa assumir (KOSCIANSKI; SOARES, 2007). Ao testar um software OO, o conceito de unidade modifica a forma de testar, pois o teste de classe para software OO pode ser equivalente ao teste de unidade para software estruturado. Contudo, diferente do teste unitário de software estruturado, que testa os dados analisando o algoritmo de um módulo, o teste unitário de classe tende a testar um método específico dentro de uma classe (PRESSMAN, 2006).

Segundo Pfleeger (2004), as propriedades da OO ajudam a minimizar as atividades de teste, mas isto nem sempre é verdade. Por exemplo, o encapsulamento isola os componentes desenvolvidos separadamente e ao adicionar uma nova subclasse ou modificar uma subclasse existente é preciso testar novamente os métodos herdados a partir de cada uma de suas superclasses.

Graham (1996) sugere uma divisão entre os aspectos da orientação a objetos que tornam os testes mais fáceis e quais os tornam mais difíceis (Figura 4). Por exemplo, os objetos tendem a ser pequenos e a complexidade que pode geralmente residir no componente é frequentemente transferida para a interface entre os componentes. Essa diferença quer dizer que o teste de unidade de software OO é menos complexo, ao passo que o teste de integração deve ser muito mais extensivo. 
Figura 4 - Análise dos testes de softwares orientados a objetos

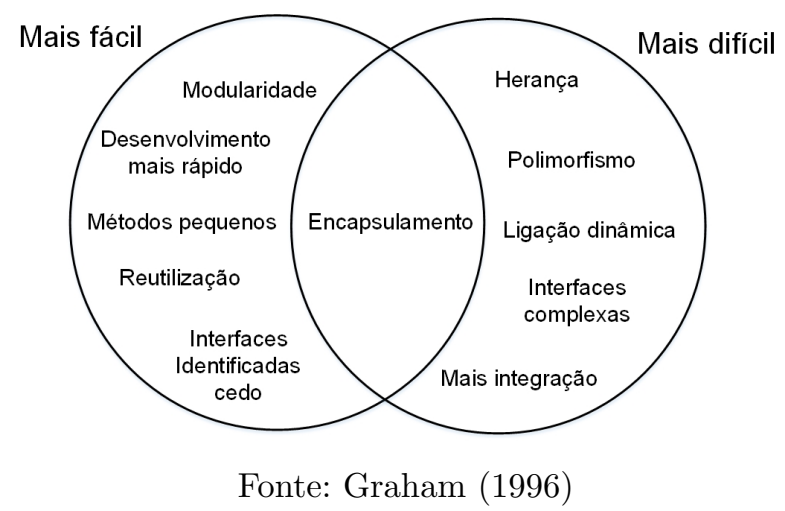

Teste de software OO é estrategicamente similar ao teste desenvolvido no paradigma procedimental, porém, são taticamente diferentes. Teste de software convencional é organizado com uma visão de software de entrada-processo-saída ou detalhes algorítmicos de módulos individuais e teste de software OO tem o foco no projeto e nas sequências apropriadas de operações para executar e analisar o estado da classe (PRESSMAN, 2006).

\subsubsection{Cobertura de Teste}

Cobertura de teste é o grau no qual um determinado teste ou conjunto de teste atende todos os requisitos de teste especificados para um determinado sistema ou componente (IEEE, 1990). A análise de cobertura é utilizada para fornecer informações sobre a qualidade dos testes, analisando partes de seu código ou especificações que são executadas ou não durante os testes. No teste estrutural a cobertura está relacionada a porcentagem de linhas de código, condições, ramificações e caminhos cobertos pelos casos de teste. A seguir, são definidas as principais medidas de cobertura que podem ser utilizadas no teste estrutural:

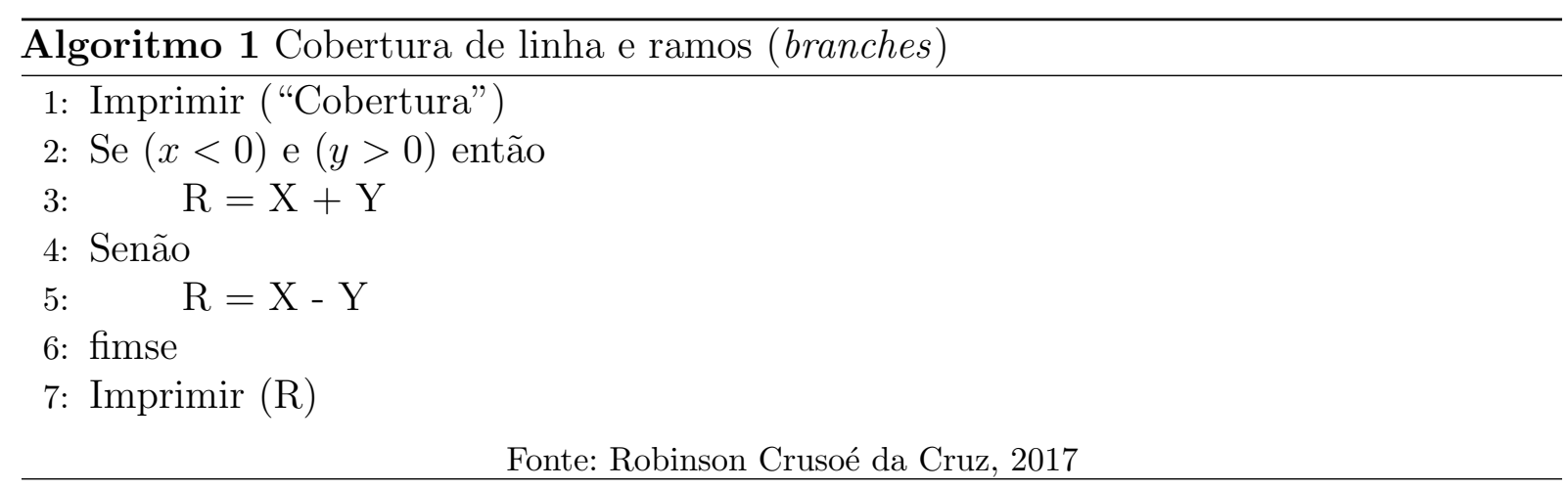


- Cobertura de Linha de Código (Line Coverage): o objetivo da análise de cobertura de linha é tentar garantir que cada linha do código a ser testada seja executada pelo menos uma vez. Então, a porcentagem das linhas executadas é a medida da adequação dos testes, onde espera-se 100\% de cobertura (ZHU; HALL; MAY, 1997; PATTON, 2001). Por exemplo, para testar todas as linhas (100\%) do código do Algoritmo 1, seriam necessários dois testes: o primeiro teste seria T1 ( $\mathrm{x}=-1$, $\mathrm{y}=5)$ onde seria executadas as linhas $1,2,3,7$ e no segundo teste T2 $(x=5, y=6)$ onde seria executadas as linhas 1,2,4,5,6,7. Esta medida de cobertura está relacionada ao critério Todos-Nós definida na Seção 2.1.2, pois exige a cobertura de todos os comandos.

- Cobertura de Ramos (Branch Coverage): O critério de cobertura de ramos que também é conhecido como cobertura de decisões, exige que todas as transferências de controle no programa sob teste sejam exercitadas durante o teste. A porcentagem de transferência de controle executadas durante o teste é uma medida de adequação do teste (ZHU; HALL; MAY, 1997). Ao executar os casos de teste T1 e T2 todas as transferências de controle seriam testadas com $100 \%$ de cobertura de branches. Esta medida de cobertura está relacionada com o critério de Todas-Arestas que foi definido na Seção 2.1.2. Ou seja, para cobrir todos os Ramos é preciso que cada teste de decisão assuma os valores true e false pelo menos uma vez.

- Cobertura de Condições (Condition Coverage): Cobertura de condições analisa as possíveis condições que levam a transferência de comandos. Por exemplo, no Algoritmo 1 para realizar uma transferência de controle na condição definida na Linha 2 e executar o comando a Linha 3 seria necessário executar o teste T1 ( $\mathrm{x}=-1$, $\mathrm{y}=5)$. Entretanto, para executar o comando da Linha 5 existem algumas condições representadas pelos testes: $\mathrm{T} 2(\mathrm{x}=5, \mathrm{y}=6), \mathrm{T} 3(\mathrm{x}=-1, \mathrm{y}=-5), \mathrm{T} 4(\mathrm{x}=5, \mathrm{y}=-5)$. Note que os testes T2, T3 e T4 garantem a passagem pelo caminho da Linha 5, contudo, são condições diferentes que levam a esta execução.

\subsubsection{Teste de Mutação}

Teste de mutação gera diferentes versões (mutantes) do software em teste, introduzindo pequenas mudanças que são supostos defeitos no código. Após a geração dos 
mutantes, os casos de testes são executados e espera-se que os casos de teste falhem, pois, a intenção das mutações é inserir falhas no código original. Quando a execução do teste sobre um mutante falha, significa que o mutante está morto, caso o contrário, o mutante é considerado como vivo. Novos casos de teste são então gerados para eliminar os mutantes que ficaram vivos. Porém, nem sempre é possível eliminar todos os mutantes, pois podem existir mutantes que sejam equivalentes ao programa original (OFFUTT, 1994). Ou o esforço para criar casos de teste capazes de revelar o defeito inserido é muito alto e os desenvolvedores se dão por satisfeito com os resultados obtidos.

O escore de mutação é uma medida que indica a eficiência de um conjunto de teste em revelar falhas nas versões defeituosas (mutantes). O cálculo é realizado com a proporção de mutantes mortos sobre a quantidade de mutantes gerados, desconsiderando os mutantes equivalentes. A adequação do escore de mutação é calculada de acordo com a Equação 1 (ZHU; HALL; MAY, 1997):

$$
M C=\frac{D}{M-E}
$$

onde $D$ é o número de mutantes mortos, $M$ é o total de mutantes gerados e $E$ o total de mutantes equivalentes. Onde mutantes equivalentes possuem a mesma funcionalidade do código original, porém, com a execução de um caminho diferente (OFFUTT, 1994).

Os mutantes são gerados baseados em operadores, como: aritmético, condicional, encapsulamento, herança e polimorfismo. Por exemplo, o operador COR (Relational Operator Replacement) realiza as possíveis mutações de um determinado código realizando a troca dos operadores relacionais, simulando erros que um desenvolvedor pode cometer durante a codificação. O Algoritmo 2 representa uma mutação do Algoritmo 1. Na linha 2 o operador relacional $<$ foi substituído pelo operador $==$. Esta mudança introduz um erro e espera-se que o mutante seja morto ao executar um teste unitário neste mutante.

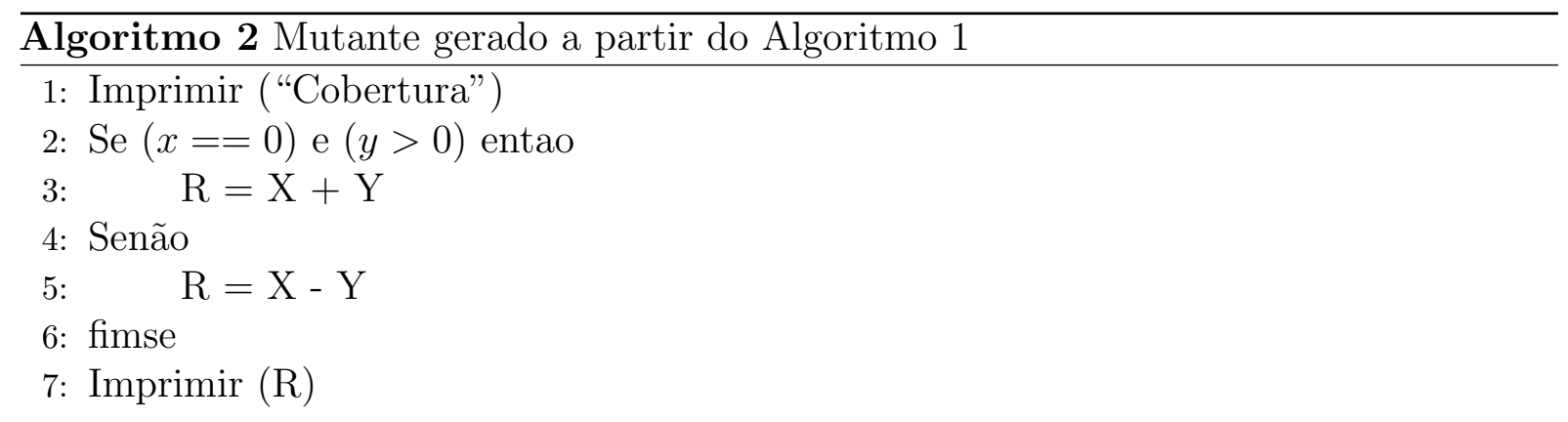


O custo computacional do teste de mutação é alto, pois para cada método pode ser gerado $N$ mutantes. E para cada mutante é preciso executar todos os casos de teste criados para o método original. A Tabela 1 representa alguns operadores de mutação que podem ser aplicados no Algoritmo 1. Nota-se que os mutantes na Tabela 1 representam apenas três possíveis mutantes.

Tabela 1 - Exemplos de geração de mutantes aplicados no Algoritmo 1

\begin{tabular}{l|c|c|c|c}
\hline \multicolumn{1}{c}{ Operador } & Operador & Código Original & Mutação & Linha Código \\
\hline Aritmético & $\begin{array}{l}\text { AOR - Substituição de } \\
\text { Operador Aritmético }\end{array}$ & $\mathrm{R}=\mathrm{X}+\mathrm{Y}$ & $\mathrm{R}=\mathrm{X}{ }^{*} \mathrm{Y}$ & 3 \\
\hline Relacional & $\begin{array}{l}\text { ROR - Substituição de } \\
\text { Operador Relacional }\end{array}$ & $(\mathrm{X}>0)$ & $(\mathrm{X}<0)$ & 2 \\
\hline Lógico & $\begin{array}{l}\text { LOR - Substituição de } \\
\text { Operador Lógico }\end{array}$ & $\mathrm{Se}(\mathrm{x}==0) \mathbf{e}(\mathrm{y}>0)$ & $\mathrm{Se}(\mathrm{x}==0)$ ou $(\mathrm{y}>0)$ & 2 \\
\hline
\end{tabular}

Fonte: Robinson Crusoé da Cruz, 2017

\subsection{Visão geral sobre testabilidade}

Testabilidade de software é um atributo de qualidade que avalia a complexidade e o esforço necessário para realizar as atividades de teste e pode ser considerada um aspecto fundamental na detecção de erros (ISO, 1991). A testabilidade é o grau no qual um sistema ou componente pode ser testado. Para testar um componente é preciso ser capaz de controlar as entradas e observar suas saídas, pois um software com alta testabilidade possibilita que sejam realizadas análises durante os testes. Por outro lado, um software com baixa testabilidade esconde as falhas durante os testes impossibilitando análises durante as fases de testes (VOAS; MILLER, 1993; BINDER, 1994; IEEE, 1990).

A testabilidade não é uma característica intrínseca do software, e por isso não pode ser medida de forma direta, como o número de linhas de código, por exemplo. Em geral, a testabilidade é inferida com base em métricas internas e externas. Na literatura, é possível encontrar vários fatores internos e externos de um software que podem ser relacionados à testabilidade. Em relação à análise interna de um software, é possível analisar as medidas de tamanho do software, complexidade do código e acoplamento. Além disso, pode-se considerar os fatores externos: critérios de testes, documentação, ferramentas de testes, capacidade de processamento, entre outros fatores (BADRI; TOURE, 2012; BRUNTINK; DEURSEN, 2004). Também existe na literatura trabalhos relacionados à testabilidade de software na perspectiva de técnicas e ferramentas de geração automática de casos de teste, 
que avalia características como complexidade ciclomática, quantidade e profundidade de laços, complexidade de expressões matemáticas e de expressões lógicas, entre outros (ELER; ENDO; DURELLI, 2014; ELER; ENDO; DURELLI, 2016).

Figura 5 - Diagrama de causa e efeito de testabilidade proposto por (BINDER, 1994)

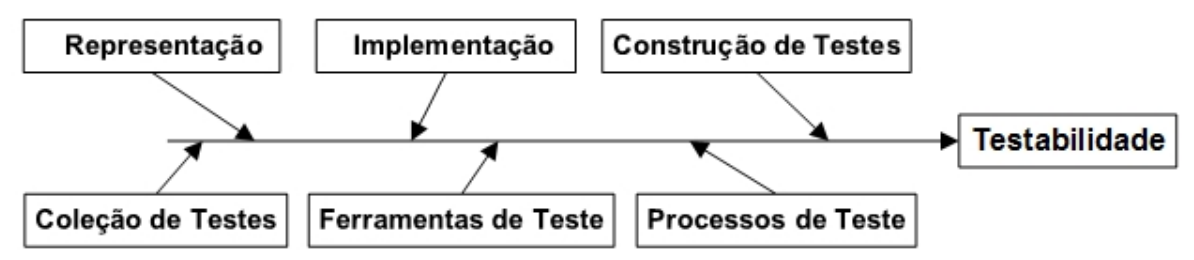

Fonte: Binder (1994)

Para Binder (1994), a testabilidade é um resultado de seis fatores primários representados pelo diagrama de causa e efeito representado pela Figura 5. Cada um desses fatores pode facilitar ou dificultar os testes em muitos caminhos:

- Representação: uma representação é necessária para o desenvolvimento dos casos de testes. Por exemplo, para definir que um caso de teste tenha passado ou falhado é preciso que o mesmo possua uma representação explicita do resultado esperado, pois sem uma representação não é possível determinar as características dos testes;

- Implementação: características de implementação determinam o controle e observação. Dependendo do tipo de paradigma de programação a análise da testabilidade pode ser um obstáculo. Por exemplo, a programação orientada a objetos através do uso da encapsulamento pode dificultar os testes. A forma de implementação pode aumentar ou diminuir a testabilidade, seja com utilização de herança ou outra característica da POO. Por outro lado, as características do projeto e do desenvolvedor podem interferir no grau de testabilidade. Por exemplo, um desenvolvedor pode aumentar a complexidade de um método devido a sua falta de experiência, conhecimento da linguagem ou matemático;

- Construção de Testes: capacidade de construção de testes pode melhorar o controle e observação e desassociar a capacidade de teste das características da aplicação. Então, na fase de desenvolvimento é preciso analisar as características que podem dificultar ou facilitar a construção dos casos de teste;

- Coleção de Testes: uma coleção de casos de teste adequada é útil e necessária. Para aumentar a testabilidade é necessário desenvolver uma coleção de testes que ofereça a maior cobertura possível do programa; 
- Ferramentas de Teste: ferramentas de testes são necessárias para eficácia dos testes. Notoriamente, o teste unitário pode ser realizado sem o auxílio de uma ferramenta, porém esta tarefa se torna inviável. Então, utilizar uma ferramenta aumenta a qualidade dos testes e auxilia na testabilidade;

- Processos de Teste: sem uma abordagem organizada e eficaz dos testes, a técnica de testabilidade é irrelevante. Ou seja, organizar e definir uma abordagem organizada pode definir o sucesso dos testes. Por exemplo, utilizar a abordagem de classe de equivalência no teste pode auxiliar no sucesso dos testes.

\subsection{Métricas de software}

Métricas de software são medidas internas e externas de um produto de software que podem auxiliar no planejamento e desenvolvimento de software. Em geral, métricas de software podem ser classificadas em duas categorias (LI, 1999): métricas de produtos de software e métricas de processos de software.

Métricas de produtos de software são obtidas por meio da análise do código fonte da aplicação e outros artefatos do projeto. Por exemplo, o tamanho do software em quantidade de linhas de código (LOC) pode ser considerado uma métrica de produto de software. Para Sommerville et al. (2008), métricas de produtos são características do próprio software e, infelizmente, as características de um software que podem ser facilmente medidas, podem não ter um relacionamento claro e consistente com atributos de qualidade devido a fatores como tecnologia de desenvolvimento e tipo de sistema.

As métricas de produtos se dividem em duas classes: (i) Métricas dinâmicas, coletadas por meio de medições realizadas em um programa em execução; e (ii) Métricas estáticas, coletadas por meio de medições realizadas em representações do sistema, através do projeto, software ou documentação (SOMMERVILLE et al., 2008).

Métricas de processo de software são medidas do processo de desenvolvimento do software, por exemplo, o esforço para desenvolver o software em tempo pode ser considerado uma métrica de processo de software.

Sobre as métricas de software, Sommerville et al. (2008) afirmam que revisões de softwares são onerosas, demoradas e inevitavelmente atrasam a conclusão de um sistema de software. Utilizar métricas de software pode auxiliar na derivação de valores numéricos 
para algum atributo de qualidade ou de um processo de software. Ao comparar estes valores aos padrões que se aplicam em uma organização é possível tirar conclusões sobre a qualidade do software.

Contudo, existem métricas difíceis de serem mensuradas, principalmente as que dependem de fatores internos do software. Então, ao utilizar as métricas é preciso analisar se os dados são confiáveis para que não sejam realizadas inferências incorretas sobre as características de um software (KOSCIANSKI; SOARES, 2007).

\subsubsection{Métricas de software orientado a objetos}

A Programação Orientado a Objetos (POO) é o paradigma de desenvolvimento de software mais utilizada na Indústria e Academia, e foi rapidamente aceita como o paradigma preferencial de desenvolvimento de software para projetos de grande escala (KHAN; MUSTAFA, 2009). A partir da definição do Paradigma OO, surgiram pesquisas que tiveram como objetivo a criação de métricas exclusivas deste paradigma. Entre essas pesquisas é possível citar as dez métricas propostas por Lorentz e Kidd (LORENZEN; KIDD, 1994) e as seis propostas por Abreu (ABREU et al., 1995). As Tabelas 2 e 3, retiradas da pesquisa de (HARRISON; COUNSELL; NITHI, 1997), descrevem um resumo sobre estas métricas.

Tabela 2 - Métricas de Lorenz e Kidd

\begin{tabular}{c|l}
\hline SIGLA & \multicolumn{1}{|c}{ DESCRIÇÃO DA MÉTRICA } \\
\hline PM & Total de métodos públicos da classe. \\
NM & Total de métodos da Classe. \\
NPV & Total de variáveis públicas da classe. \\
NV & Total de variáveis da classe. \\
NMI & Total de métodos herdados por uma subclasse. \\
NMO & Total de métodos sobrescritos por uma subclasse. \\
NMA & Total de métodos adicionados por uma subclasse. \\
AMS & Média de linhas de código dos métodos da classe. \\
NCR & Total de vezes que uma classe é utilizada(referenciada). \\
NF & Total de filhos (Subclasses) de uma classe. \\
\hline
\end{tabular}

Fonte: Harrison, Counsell e Nithi (1997) 
Tabela 3 - Métricas de Abreu

\begin{tabular}{c|l}
\hline SIGLA & \multicolumn{1}{|c}{ DESCRIÇÃO DA MÉTRICA } \\
\hline $\mathbf{P F}$ & Número de métodos sobrescritos em uma classe. \\
$\mathbf{C F}$ & Número de comunicações entre as classes. Similar a métrica NCR (Tabela 2). \\
MHF & Total de Métodos escondidos(Privados ou Protegidos) em relação ao total de métodos. \\
AHF & Total de Métodos escondidos (Privado ou Protegidos) em relação ao total de atributos da Classe. \\
MIF & Total de métodos herdados da casse em relação ao total de métodos da classe. \\
AIF & Total de Atributos herdados em relação ao total de atributos da clsse \\
\hline
\end{tabular}

Fonte: Harrison, Counsell e Nithi (1997)

\subsubsection{Métricas CK}

As seis métricas CK foram propostas em 1994 por Chidamber e Kemerer (CHIDAMBER; KEMERER, 1994) para aplicação de medidas em softwares desenvolvidos no paradigma orientado a objetos. Chidamber e Kemerer utilizaram uma abordagem para identificar possíveis medidas que poderiam ser aplicadas na identificação de fatores relacionados à manutenabilidade, qualidade e testabilidade.

As métricas são definidas em:

- CBO (Coupling between Object Classes): Acoplamento entre objetos de classe.

- DIT (Depth of Inheritance Tree): Profundidade na árvore de herança.

- LCOM (Lack of Cohesion of Methods): Falta de coesão dos métodos da classe.

- NOC (Number of Children): Número de filhos da classe.

- RFC (Response for a Class): Resposta para uma classe.

- WMC(Weighted Methods per Classe): Complexidade dos métodos da classe.

Acoplamento entre objetos - CBO

Chidamber e Kemerer (1994) definem CBO como a contagem do número de classes no qual a classe analisada está acoplada. Teoricamente, um objeto é acoplado por outro objeto se um executa ação do outro objeto. Por exemplo, quando uma classe utiliza métodos de outras classes ou quando uma classe utiliza variável de outra classe.

Ao analisar o exemplo apresentado no Algoritmo 3, nota-se que a classe B utilizou um método (linha 10) e uma variável (linha 11) da classe A, ou seja, a classe B utilizou uma ação e uma variável da classe A e como consequência o CBO da classe B é igual a 1. A classe C também possui CBO igual a 1 pois utilizou uma variável (linha 17) da classe A. 
O valor do CBO da classe A é igual a 2, mesmo que não tenha utilizado outras classes, porém, ela foi utilizada pelas classes B e C.

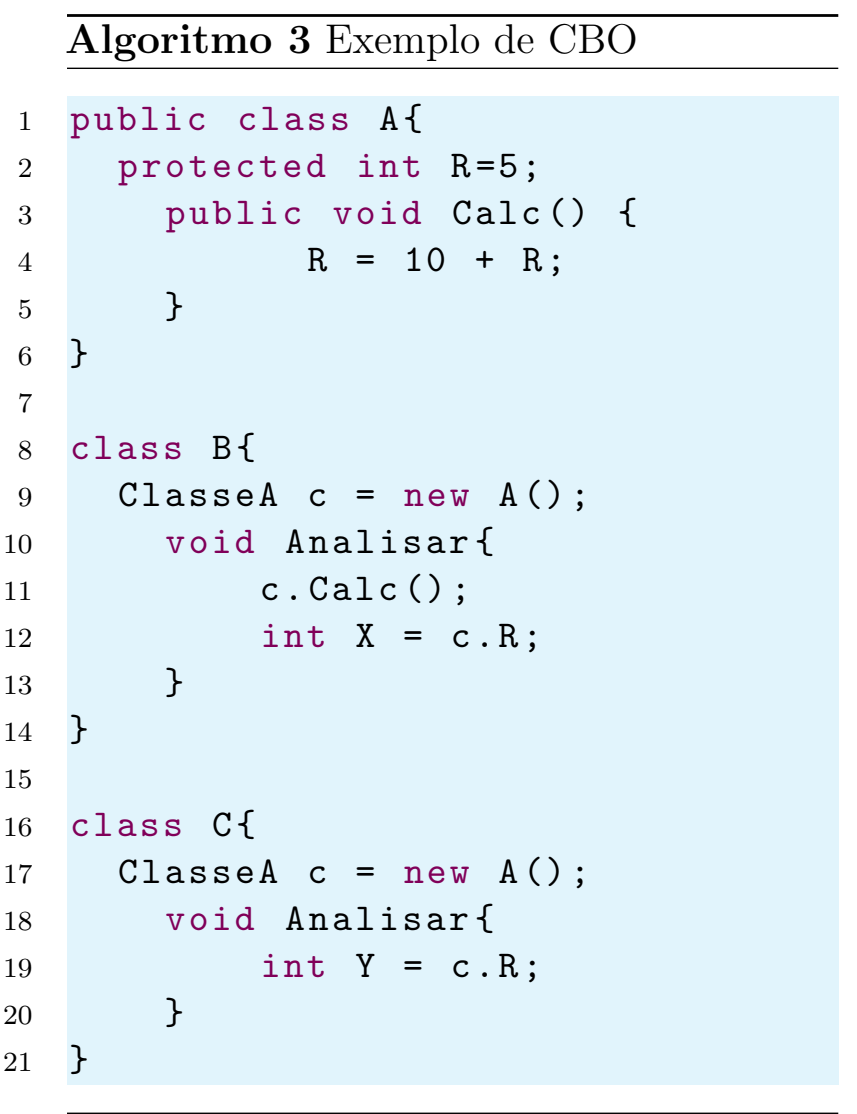

Figura 6 - Representação de CBO

Fonte: Robinson Crusoé da Cruz, 2017

Alguns pontos importantes são relatados por Chidamber e Kemerer (1994) relacionado a esta métrica:

- excessivo acoplamento entre objetos é prejudicial ao reúso;

- quanto maior o acoplamento, maior pode ser a dificuldade de manutenção;

- um alto acoplamento pode influenciar nos testes, pois quanto maior o acoplamento, mais rigoroso precisam ser os testes.

Profundidade na árvore de herança - DIT

A métrica DIT pode ser definida como a posição da classe na árvore de herança. Chidamber e Kemerer (1994) definem que é uma medida de como uma classe ancestral pode potencialmente afetar a classe analisada por DIT. Conforme o diagrama de classes (Figura 7), as classes podem ser classificadas com a seguinte estrutura relacionada a DIT: Classe A possui DIT 0, Classe B e C possuem DIT 1 e por último a Classe D com DIT 2. 
Figura 7 - Representação de DIT

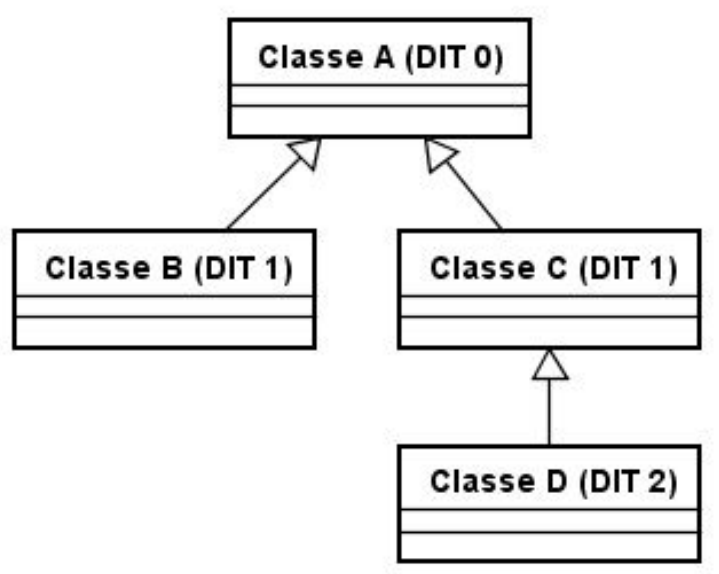

Fonte: Robinson Crusoé da Cruz, 2017

Baseado na Figura 7, o fator de herança DIT indica que métodos da classe D precisam ser testados, toda vez que suas superclasses C e A forem alteradas. Segundo Harrison, Counsell e Nithi (1997), DIT foi criada para indicar o potencial de reuso e para analisar a complexidade do projeto. De acordo com Khanna (2014), se DIT cresce, maior é a complexidade, pois mais métodos podem ser herdados, o que torna mais difícil calcular o comportamento da classe.

Falta de coesão entre os métodos da classe - LCOM

LCOM é a medida que quantifica a falta de coesão dos métodos de uma classe. Ou seja, dois métodos são coesos se os mesmos compartilham atributos de classe (CHIDAMBER; KEMERER, 1994). Para quantificar este resultado, todos os métodos das classes são analisados em pares, por meio da quantificação dos atributos de classes em comum

O cálculo de LCOM é representado pela Equação 2, onde $P$ representa o número de pares de métodos em uma classe que não possuem atributos de classe em comum e $Q$ o número de pares de métodos que possuem pelo menos um atributo em comum.

$$
L C O M=\left\{\begin{aligned}
|P|-|Q|, & \text { Se }|P|>|Q|, \\
0, & \text { Caso Contrário. }
\end{aligned}\right.
$$


Exemplo: se uma classe X possui quatro métodos que utilizaram os seguintes conjuntos de atributos de classe (instância):

- $\mathrm{M} 1=\{\mathrm{a}, \mathrm{b}, \mathrm{c}\}$

- $\mathrm{M} 2=\{\mathrm{a}, \mathrm{b}\}$

- $\mathrm{M} 3=\{\mathrm{c}, \mathrm{d}, \mathrm{e}, \mathrm{f}\}$

- $\mathrm{M} 4=\{\mathrm{g}, \mathrm{h}\}$

A primeira etapa é enumerar todas as combinações de pares de métodos e analisar se ambas compartilham atributos de instância em comum:

1. $M 1 \cap M 2=\{a, b\}$

2. $M 1 \cap M 3=\{c\}$

3. $M 1 \cap M 4=\emptyset$

4. $M 2 \cap M 3=\emptyset$

5. $M 2 \cap M 4=\emptyset$

6. $M 3 \cap M 4=\emptyset$

Portanto, sendo $\mathrm{P}=\{3,4,5,6\}$ as combinações de métodos que não possuem atributos de classe em comum, com soma final igual a 4 . $\mathrm{E} \mathrm{Q}=\{1,2\}$ as combinações de métodos que possuem atributos de classe em comum, com soma final igual a 2. Então, LCOM da classe $\mathrm{X}$ é igual a 2 (JULIANO, 2014).

Alguns pontos importantes podem ser considerados relacionado a análise da métrica LCOM: (i) alta coesão, ou seja, baixo LCOM promove a utilização do encapsulamento na classe; (ii) falta de coesão, LCOM alto, pode indicar que uma classe deveria ser dividida em duas ou mais subclasses; (iii) com a falta de coesão, aumenta o risco de erro na fase de desenvolvimento do software (CHIDAMBER; KEMERER, 1994).

Segundo a literatura, esta métrica possui um fator negativo, pois LCOM analisa somente a falta de coesão e não se os métodos são coesos, pois o cálculo não permite valor negativo.

Número de filhos da classe - NOC

Chidamber e Kemerer (1994) definem NOC como o número de subclasses da classe analisada, baseado na hierarquia de classe. Isto define como analisar quais serão as classes 
afetadas em caso de alterações na classe. Chidamber e Kemerer (1994) descrevem os pontos importantes relacionados a esta métrica:

- quanto maior o número de filhos, maior a reutilização do código;

- uma classe que possui um número grande de subclasses (filhos), pode indicar o uso impróprio da herança;

- uma classe com um grande número de filhos pode indicar sua importância dentro do contexto, indicando que a classe precisa de cuidados relacionados aos testes.

Por meio do diagrama de classe representado pela Figura 8 é possível analisar a métrica NOC como: classe A possui NOC (3), porque a mesma possui três subclasses (filhos), classe B, D e E possuem NOC (0) porque não possuem subclasses (filhos) e a Classe C com NOC (1), porque possui apenas uma subclasse (filho).

Figura 8 - Representação de NOC

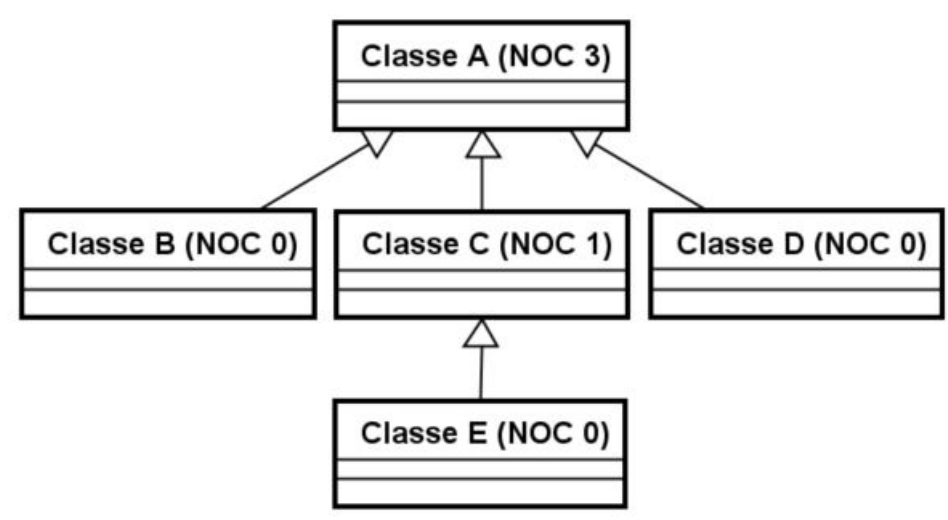

Fonte: Robinson Crusoé da Cruz, 2017

De acordo com Harrison, Counsell e Nithi (1997), NOC pode ser utilizada para indicar o nível de reusabilidade de um sistema e, consequentemente, como um possível indicador para a importância da classe relacionado aos testes.

Resposta para uma classe - RFC

Análise do RFC está relacionada à quantidade de métodos que podem ser executados em resposta a uma mensagem recebida por um objeto. A análise é feita pela quantidade de métodos da classe mais a quantidade de métodos externos utilizados pelos métodos da classe (CHIDAMBER; KEMERER, 1994). 
O cálculo da métrica RFC pode ser definido como:

$$
R F C=\left\{M_{i}\right\} \cup_{i}\left\{R_{i}\right\}
$$

onde, $\left\{R_{i}\right\}$ é igual a todos métodos externos utilizados pelos métodos da classe I e $\left\{M_{i}\right\}$ é igual a todos os métodos da classe I.

É possível afirmar que RFC possui uma relação direta com a métrica CBO, pois quando uma classe utiliza métodos de classes externas é aplicado um acoplamento entre as classes. Ao analisar o Algoritmo 3, é possível definir que a classe A possui $\mathrm{RFC}=1$, a Classe B e C possuem $\mathrm{RFC}=2$.

Alguns pontos importantes relacionados à métrica RFC são descritos por (CHIDAMBER; KEMERER, 1994): (i) se existe um grande número de métodos que podem ser invocados em resposta a uma mensagem, o teste e depuração da classe torna-se mais complicado, uma vez que requer um maior nível de compreensão; (ii) Um alto número de métodos invocados pode aumentar a complexidade da classe.

Complexidade dos métodos por classe - WMC

O WMC é uma medida para analisar a complexidade dos métodos de uma classe (CHIDAMBER; KEMERER, 1994). Esta métrica tem sido também utilizada para estimar, além do nível de testabilidade de uma classe, aspectos relacionados à reusabilidade e manutenibilidade (HARRISON; COUNSELL; NITHI, 1997). Para calcular o WMC é possível utilizar vários caminhos, por exemplo, pela complexidade ciclomática proposta por (MCCABE, 1976).

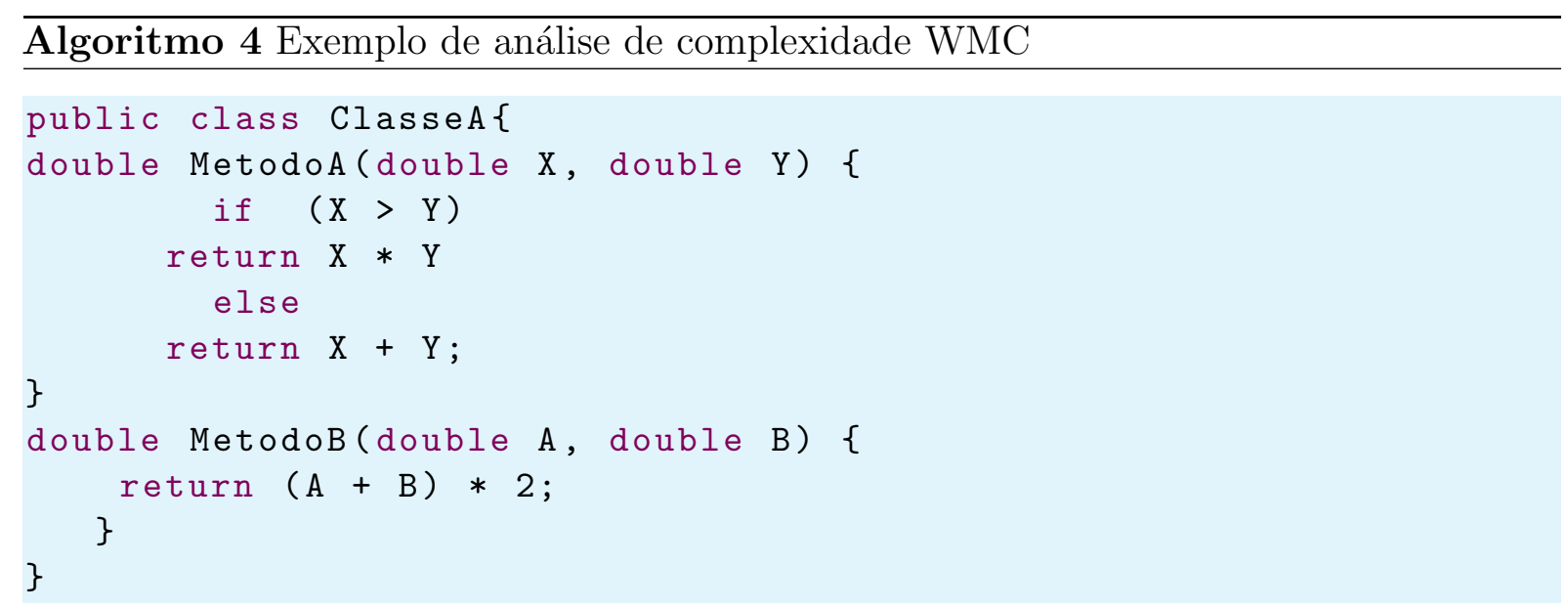


Ao analisar o Algoritmo 4 é possível definir a complexidade do Método A igual a 2, pois existem dois caminhos que podem ser executados e no Método B igual a 1, pois existe apenas um caminho. O valor de WMC da classe é igual a 3, que é calculado com a soma da complexidade dos métodos A e B.

\subsubsection{Métricas CK e medidas de software OO}

É possível relacionar as métricas CK com as propostas de (LORENZEN; KIDD, 1994) e (ABREU et al., 1995) descritas na Seção 2.3.1. Os dados da Tabela 4, demonstram que, as métricas CK possuem um relacionamento entre as métricas propostas por outros autores.

Tabela 4 - Relacionamento das métricas CK com as propostas por Abreu et al. (1995) e Lorenzen e Kidd (1994)

\begin{tabular}{c|c|c}
\hline Métrica CK & Métricas de Abreu & Métricas de Lorenz e Kidd \\
\hline CBO & CF & NMI, NMO, NF \\
DIT & PF, MIF, AIF & NV \\
LCOM & PF, MIF, AIF & NMI, NMO, NF \\
NOC & MHF & PM, NM \\
RFC & & \\
WMC & & \\
\hline
\end{tabular}

Fonte: Robinson Crusoé da Cruz, 2017

De acordo com a Tabela 4, as métricas CK que possuem maior relacionamento com as métricas propostas (LORENZEN; KIDD, 1994) e (ABREU et al., 1995) são DIT e NOC. O resultado deste relacionamento mostra que a métrica CK possui uma medida mais acumulativa, por exemplo, a métricas MHF (Total de Métodos escondidos), MIF (Total de métodos herdados) propostas por (ABREU et al., 1995), estão contidas na análise das métricas DIT e NOC.

A Tabela 5 representa o relacionamento entre medidas $\mathrm{OO}$ e métricas CK, baseado na pesquisa (KULKARNI; KALSHETTY; ARDE, 2010).

Tabela 5 - Relacionamento entre métricas CK e medidas OO

\begin{tabular}{l|l}
\hline Medidas de OO & \multicolumn{1}{|c}{ Métricas CK } \\
\hline Classe & WMC, RFC, LCOM \\
Atributo & LCOM \\
Método & WMC, RFC, LCOM \\
Herança & DIT, NOC \\
Coesão & LCOM \\
Acomplamento & CBO, RFC \\
\hline
\end{tabular}

Fonte: (KULKARNI; KALSHETTY; ARDE, 2010) 
Por fim, a Tabela 6 propõe uma análise do relacionamento entre os fatores de qualidade e as métricas CK. Nota-se que neste estudo as métricas DIT e NOC foram desconsideradas na análise da testabilidade, fato que é analisado na Revisão Sistemática (Capítulo 3).

Tabela 6 - Relacionamento entre métricas CK e fatores de qualidade

\begin{tabular}{l|l}
\hline \multicolumn{1}{c|}{ Medidas de OO } & \multicolumn{1}{c}{ Métricas CK } \\
\hline Compreensibilidade & RFC, CBO, DIT \\
Reusabilidade & WMC, CBO, DIT, NOC \\
Testabilidade & RFC, CBO, WMC \\
Manutenabilidade & WMC, CBO \\
Esforço de desenvolvimento & WMC, LCOM \\
Acomplamento & CBO, RFC \\
\hline
\end{tabular}

Fonte: (KULKARNI; KALSHETTY; ARDE, 2010)

\subsection{Correlação e medidas de associação}

A análise de correlação é um método estatístico amplamente utilizado para analisar o grau de relacionamento entre duas variáveis. Este método, quando aplicado auxilia a obter resposta para seguinte dúvida: quando uma variável $X$ é alterada, ela provoca alterações no valor de outra variável $Y$ ? Para descobrir se existe relacionamento, é possível aplicar técnicas de correlação com a utilização de cálculos que seguem uma distribuição normal, como cálculo de Pearson e outras para variáveis que não seguem uma distribuição teórica conhecida, como o cálculo de Spearman.

O coeficiente de Spearman mede a intensidade da relação entre duas variáveis ordinais (X e Y), e seu coeficiente não é sensível à presença de outliers, ou seja, não exige que os dados provenham de duas populações normais.

O coeficiente de Spearman pode ser definido por:

$$
\rho=1-\frac{6 \sum_{i=1}^{n} d_{i}^{2}}{n^{3}-n}
$$

onde $n$ representa o números de pares $\left(x_{i}, y_{i}\right)$ e $d_{i}=\left(\right.$ postos $x_{i}$ dentro os valor de $\left.\mathrm{x}\right)$ (postos de $y_{i}$ dentro os valores de $y$ ). Se os postos de $x$ são exatamente iguais aos postos de $y$, então todos os $d_{i}$ serão zero e $\rho$ será 1 .

O coeficiente de Spearman $\rho$ varia entre -1 e 1. Quanto mais próximo de 1, maior a correlação positiva. Quanto mais próximo de -1, maior relação inversa, ou seja, quando uma 
variável cresce a outra diminui. E valores próximo a 0 indicam que não existe correlação ou pode ser considerada baixa.

O coeficiente de correlação $\rho$ apresentado anteriormente é um valor de interpretação puramente matemático, ficando isento de qualquer implicação de causa e efeito, pois o fato de duas variáveis ter a tendência de aumentar ou diminuir não pressupõe que uma delas exerça efeito direto ou indireto sobre a outra (OLIVEIRA, 2012). Para realizar a análise de causa e efeito, é preciso calcular o coeficiente de significância estatística que é representado pela letra grega $\alpha$. No caso do Spearman, é possível aplicar o cálculo de t-Student ${ }^{1}$ que é definido por:

$$
t=\rho-\sqrt{\frac{n-2}{1-\rho^{2}}},
$$

onde $t$ tem $n-2$ graus de liberdade e geralmente o cálculo da significância utilizado é no máximo de até $\alpha=0.05$, ou seja, em até $5 \%$ o resultado deve-se ao acaso.

\subsection{Algoritmos de agrupamento (clusterização)}

Segundo Silva, Peres e Boscarioli (2016), denomina-se agrupamento o processo pelo qual se estuda as relações de similaridade entre os exemplares, determinando como estão organizados em grupos. Para aplicar o agrupamento é possível utilizar algoritmos que podem ser classificados como: hierárquico, por partição, baseadas em densidades, rede neural artificial, SVM (Máquina de Vetores de Suporte) e entre outros algoritmos disponíveis na literatura.

Ao analisar um conjunto de classes coletadas de um sistema, é possível definir grupos de classes de acordo com suas características utilizando um algoritmo de agrupamento. Por exemplo, LOC (quantidade de linhas de código), NOA (Número de atributos de classe) ou de acordo com as métricas CK. Neste projeto foram utilizados os seguintes algoritmos de agrupamentos (clusterização): kMeans (kMédias) e EM-Expectative Maximization (Maximização de Expectativa), que são apresentados a seguir.

\footnotetext{
1 Distribuição de probabilidade estatística publicada por William Sealy Gosset.
} 


\subsection{1 $k$-Means}

Entre os algoritmos de agrupamento (clustering), $k$-Means ( $k$-médias) pode ser considerado o mais popular. O objetivo deste algoritmo é encontrar partições no conjunto de dados de forma que $k$ grupos disjuntos de exemplares sejam descobertos. A definição começa inicialmente com definições aleatórias de $k$ vetores que representam a quantidade de centroides. Durante a iteração do algoritmos, os exemplares são analisados e classificados de acordo com sua proximidade (similaridade) com cada centroide (HARTIGAN; WONG, 1979; SILVA; PERES; BOSCARIOLI, 2016). A execução do algoritmo pode ser definida em três passos (JAIN; MURTY; FLYNN, 1999):

- 1 - são definidos $k$ centroides e sua posição é definida aleatoriamente;

- 2 -cada $k$ é analisado e atribuído um valor colocando o mais próximo do cluster adequado;

- 3 - se um critério de convergência não for cumprido, o algoritmo volta para o item 2, caso contrário o algoritmo é finalizado. Um critério de convergência pode ser a não variação do " $k$ " relacionado ao estado atual.

A Figura 9 representa a execução do algoritmo $k$ Means, onde foi definido $k=4$. Cada elemento no gráfico pode representar uma medida de uma classe, por exemplo, o valor de CBO (Acomplamento entre os objetos de classe). Nota-se que na primeira Figura 9 (A) os centroides foram definidos de forma aleatória e nas iterações seguintes os valores do centroides, são reajustados até chegar no ponto de convergência representado pela Figura 9 (D). 
Figura 9 - Evolução do Algoritmo kMeans
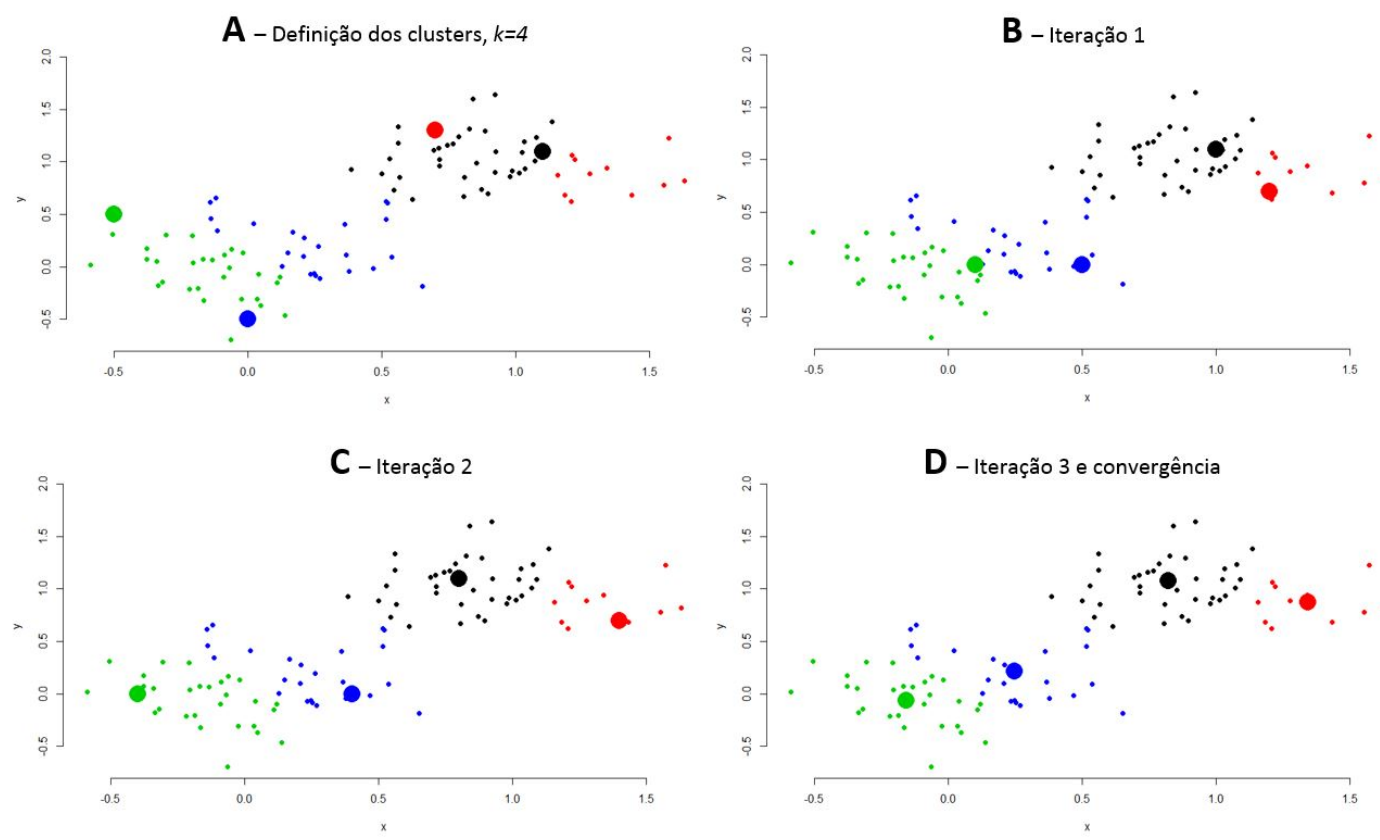

Fonte: Robinson Crusoé da Cruz, 2017

Uma das opções para calcular a nova posição de cada centroide é ajustar a sua coordenada de acordo com valor médio das coordenadas dos exemplares associados a ele, para isto é possível utilizar o cálculo representado pela Equação 6 (SILVA; PERES; BOSCARIOLI, 2016):

$$
c_{p}=\frac{1}{n} \sum_{n=1}^{n} x_{n}
$$

em que $x_{n}$ é cada exemplar associado ao centroide $c_{p}$, sendo $p=1,2, \ldots, k$ e $n$ o número de exemplares relacionados ao centroide analisado $\left(c_{p}\right)$.

Existem problemas neste algoritmo que são citados na literatura, pois, em existem casos onde o clusters finais nem sempre podem representar a solução ideal. Este resultado está relacionado com a forma aleatória da definição dos clusters iniciais. Diferente do algoritmo k-Means, o algoritmo EM apresentado a seguir trabalha com a probabilidade de um determinado exemplo pertencer a um cluster (SANCHES, 2003). 


\subsubsection{Algoritmo Maximização de Expectativa (EM)}

O algoritmo Maximização de Expectativa (ou do inglês Expectation MaximinizationEM) é um método que gera uma sequência de melhoria de soluções aproximadas para cada classe, que também é chamado de método iterativo para encontrar a máxima verossimilhança. O algoritmo foi proposto (DEMPSTER; LAIRD; RUBIN, 1977) como um método que permite a estimação de parâmetros em modelos probabilísticos com dados incompletos (dados latentes ou não observados) (MATHUR et al., 2016; CARVALHO, 2014).

O EM pode ser utilizado na clusterização de dados, onde cada cluster representa uma distância de probabilidade, ou seja, cada elemento é classificado em um determinado cluster com base em um peso. Inicialmente, $k$ objetos são selecionados aleatoriamente para apresentar os centroides dos clusters. Após esta definição os clusters são refinados em duas Etapas.

Etapa E (Expectativa): Esta etapa trabalha com as variáveis desconhecidas, usando a estimativa atual dos parâmetros. Neste passo cada objeto $x_{i}$ é associado ao agrupamento $C_{k}$, utilizando a seguinte equação:

$$
P\left(x_{i} \in C_{k}\right)=p\left(\frac{C_{k}}{x_{i}}\right)=\frac{p\left(C_{k}\right) p\left(\frac{x_{i}}{C_{k}}\right)}{p\left(x_{i}\right)}
$$

onde

$$
p\left(\frac{x_{i}}{C_{k}}\right)=N\left(m_{k}, E_{k}\right)
$$

em que $m_{k}$ é a média e $E_{k}$ o valor esperado, aplicando-se uma distribuição normal.

Etapa M (Maximização): Com novas frequências obtidas na Etapa E, é produzida uma nova estimativa de parâmetros até alcançar sua convergência (onde não exista alteração dos valores), em que é utilizado a equação de verossimilhança das distribuições de probabilidades:

$$
m_{k}=\frac{1}{n} \sum_{i=1}^{n} \frac{x_{i} p\left(x_{i} \in C_{k}\right)}{\sum_{j} p\left(x_{i} \in C_{j}\right)}
$$

As duas Etapas são iterativas, onde novas probabilidades encontradas na Etapa M são utilizadas na inferência da Etapa E. A representação da interação é idêntica a definida no algoritmo k-Means (Figura 9), com a diferença do cálculo de ajuste dos centroides. 


\subsection{Algoritmo $k N N$}

Classificar um novo elemento desconhecido consiste em compará-lo com outros elementos conhecidos analisando sua similaridade em relação as características em comum. Por exemplo, um biólogo descobre uma nova espécie de planta e para classificá-la é necessário comparar suas características com as classes de plantas conhecidas.

O algoritmo $k \mathrm{NN}$ ( $k$-Nearest Neighbor) é um algoritmo do tipo lazy ${ }^{2}$ da família dos algoritmos supervisionados, introduzido por (AHA; KIBLER; ALBERT, 1991).

A ideia geral é encontrar os $k$ vizinhos mais próximos da amostra a ser classificada. Os algoritmos da família $k \mathrm{NN}$ requerem pouco esforço durante a etapa de treinamento. Por outro lado, o custo computacional para rotular um elemento desconhecido é relativamente alto, pois no pior dos casos, este elemento deverá ser comparado com todas as amostras do conjunto já classificado (FERREO, 2009).

A Figura 10 ilustra a ideia para um problema de classificação, o valor do atributo 2 representa a quantidade de linhas de código de uma classe (LOC) e o valor do atributo 1 representa a quantidade de métodos (NOM), no qual, exemplos com rótulo positivo (+) referem-se a classes com alta testabilidade e exemplos com rótulo (-) com baixa testabilidade. Considerando o algoritmo $k \mathrm{NN}$ para classificação, com $k=1$ vizinhos, o novo elemento $E i$ seria classificado de acordo com o único vizinho mais próximo, que pertence a classe com alta testabilidade $(+)$.

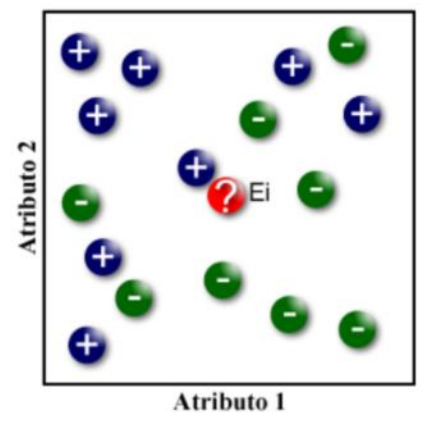

Figura 10 - Exemplo de utilização do método kNN (FERREO, 2009)

2 algoritmos lazy necessitam manter os exemplos na memória para classificar novos exemplos (REZENDE, 2003). 
O algoritmo de classificação $k \mathrm{NN}$ possui o seguintes passos durante a sua execução:

\section{Definir a base de dados de treinamento}

Esta base é formada pelos elementos já classificados de acordo com suas características e semelhanças que serão utilizadas para classificar um elemento ainda não classificado.

\section{Medida de distância}

Corresponde a uma função matemática utilizada para calcular a distância entre os elementos da base de treinamento e o novo elemento que será classificado. Um dos métodos mais aplicados é a distância euclidiana, descrita pela Equação 10.

$$
\operatorname{distancia}(X, Y)=\sqrt{\sum_{i=1}^{n}\left(x_{i}-y_{i}\right)^{2}},
$$

em que $X$ é o elemento a ser classificado e $Y$ o elemento da base conhecida (classificado) e $X=\left(x_{1}, x_{2}, x_{3}, \ldots, x_{n}\right)$ e $Y=\left(y_{1}, y_{2}, y_{3}, \ldots, y_{n}\right)$ representam os conjuntos de características em comum, por exemplo, $\left(x_{1}, y_{1}\right)$ pode representar a quantidade de linhas de código (LOC) da classe desconhecida $X$ e da classe conhecida $Y$.

\section{Definir o valor de $k$}

O valor de $k$ representa a quantidade de objetos (vizinhos) utilizados na comparação, ou seja, quantos vizinhos serão analisados para classificar o elemento desconhecido. Exemplo: ao definir $k=1$ o elemento desconhecido $E i$ seria classificado conforme a Figura 11-(a), por outro lado, ao definir $k=4$ o elemento desconhecido $E i$ seria classificado conforme Figura 11-(b) (FERREO, 2009).

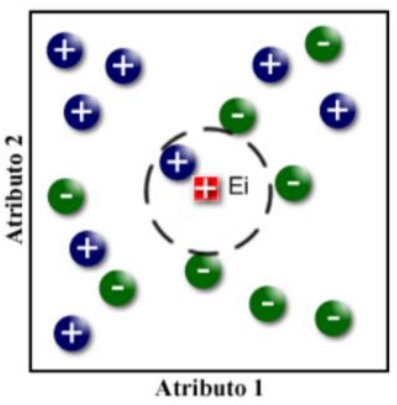

(a) Exemplo de $1 N N$

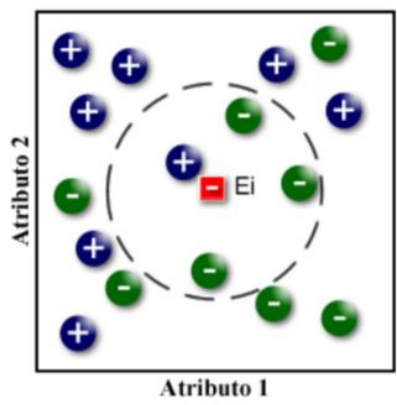

(b) Exemplo de $4 N N$

Figura 11 - Exemplo de aplicação do kNN (FERREO, 2009) 


\subsection{Considerações finais}

Este capítulo abordou os principais conceitos que formam a base teórica para compreensão da proposta desta pesquisa. Relacionado a teste e testabilidade foi possível compreender que são vários os fatores que podem influenciar na qualidade de um produto de software e que testabilidade é uma característica difícil de ser analisada. Entretanto, analisar a testabilidade é crucial para o sucesso do processo de teste de um produto de software. A compreensão das métricas de software, em especial as propostas por Chidamber e Kemerer (CK), foi importante para analisar as características de um software que podem ser mensuradas para auxiliar na análise da testabilidade. Compreender os métodos estatísticos, algoritmo de classificação e clusterização foi importante para auxiliar na análise dos resultados dos artigos que serão apresentados no Capítulo 3 e no desenvolvimento da pesquisa e da ferramenta de coleta e análise de métricas. 


\section{Revisão Sistemática}

Este capítulo apresenta uma Revisão Sistemática (RS) sobre a relação entre as métricas de software Orientado a Objetos e a testabilidade. Em especial, foram analisadas as métricas CK propostas por (CHIDAMBER; KEMERER, 1994) por estarem na proposta desta pesquisa. Em princípio, foram considerados os trabalhos que tiveram como proposta principal a análise estatística de correlação. Entretanto, outros trabalhos foram considerados baseados nas questões de pesquisa. Neste capítulo é realizada uma análise das lacunas encontradas nas ferramentas utilizadas neste projeto e um estudo sobre as medidas das métricas CBO e DIT.

\subsection{Questões de pesquisa}

Para auxiliar na seleção dos trabalhos, na análise inicial da Revisão Sistemática foram abordadas algumas questões de pesquisa:

Q1: Qual a influência das métricas CK na testabilidade?

Q2: Existe uma correlação entre as métricas CK e testabilidade?

Q3: Existem lacunas a serem exploradas sobre as métricas CK e a testabilidade?

Para auxiliar na seleção de trabalhos, foram considerados os seguintes veículos de busca:

- Biblioteca Digital ACM (http://portal.acm.org/);.

- Biblioteca Digital IEEE (http://ieeexplore.ieee.org/Xplore);

- Portal de Busca Capes (http://www.periodicos.capes.gov.br);

- Google Scholar (http://scholar.google.com.br/).

O Google Scholar foi utilizado na fase de busca exploratória e principalmente para analisar o tema relacionado às publicações e pesquisas realizadas na Indústria. O portal de busca da CAPES foi utilizado como centralizador de pesquisas para outros veículos de busca. 


\subsection{Condução da Revisão Sistemática}

A análise foi conduzida entre os meses de Novembro/2015 e Março/2016 e sua estrutura foi dividida em três fases (Figura 12):

Figura 12 - Estrutura da execução e seleção dos artigos

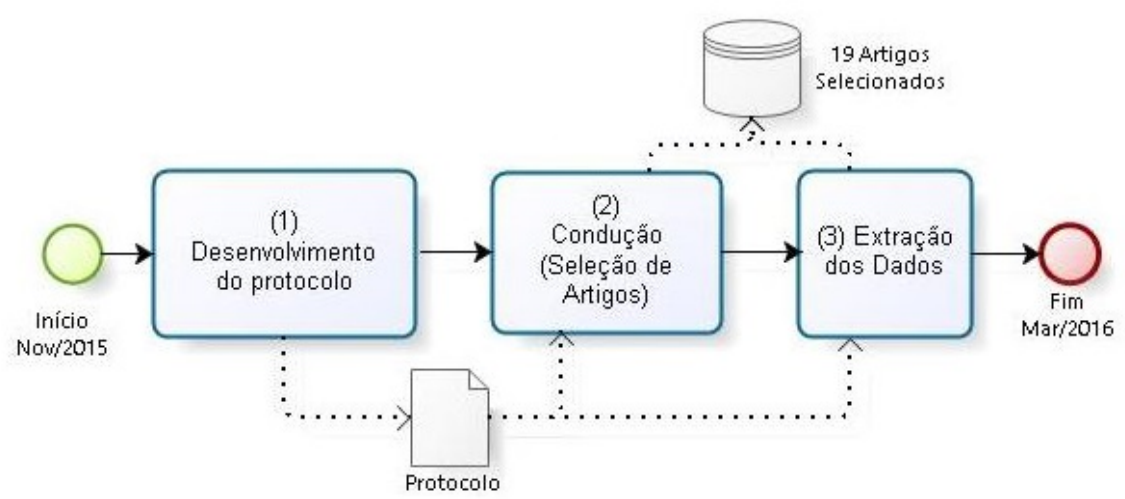

Fonte: Robinson Crusoé da Cruz, 2017

\section{(1) Desenvolvimento do protocolo:}

Nesta fase, foram definidas as premissas para auxiliar na pesquisa e condução da revisão. Foram realizadas buscas exploratórias utilizado o Google Scholar para auxiliar na definição das palavras chaves e strings de busca.

\section{(2) Condução (seleção de artigos)}

Nesta fase, foram realizadas buscas nas bases de dados utilizando as questões de pesquisas. Foram utilizadas as seguintes strings de busca: Testability and CK metric, Test and $C K$ Metrics e $C K$ metrics. Foram selecionados e analisados os títulos e resumos de cada trabalho e os critérios de inclusão e exclusão foram aplicados, conforme mostra a Tabela 7.

Tabela 7 - Critérios de inclusão e exclusão do protocolo da RS

\begin{tabular}{c|l}
\hline \multicolumn{1}{c|}{ Tipo } & \multicolumn{1}{c}{ Descrição } \\
\hline Inclusão & Abordou estudo de testabilidade no paradigma orientado a objetos. \\
Inclusão & Aplicou estudo de testabilidade relacionada a análise das métricas CK. \\
Inclusão & Aplicou estudo de revisão sistemática sobre testabilidade. \\
Exclusão & $\begin{array}{l}\text { Não analisa a testabilidade relacionada com métricas baseadas em medidas de } \\
\text { software orientado a objetos. }\end{array}$ \\
Exclusão & Não descreve sobre o relacionamento de métricas CK e testabilidade. \\
\hline
\end{tabular}


Para seleção dos artigos o texto completo deveria estar disponível na web. O período de pesquisa de publicação dos artigos foi entre os anos de 1994 e 2015. Este período está diretamente relacionado ao ano de publicação da proposta das métricas CK (CHIDAMBER; KEMERER, 1994).

\section{(3) Extração dos Dados}

Nesta fase foi executada a extração dos dados dos artigos selecionados de acordo com os critérios de extração definidos no protocolo (Apêndice A). Uma nova seleção foi aplicada e os artigos em duplicidade ou que não estavam de acordo com os critérios de exclusão foram removidos, conforme representado na Tabela 7. Outros artigos foram adicionados baseado na análise das citações presentes nos artigos analisados ou por apresentar estudos que possam contribuir com a proposta de pesquisa deste trabalho. No total foram analisados 81 artigos por meio da análise do resumo e título, dos quais 19 artigos foram selecionados.

\subsection{Análise dos trabalhos selecionados e discussão}

Para responder e auxiliar nas questões de pesquisa, os artigos incluídos foram lidos na íntegra e todos os artigos analisados foram publicados em eventos da área de Engenharia de Software. No que diz respeito à concentração de pesquisa, os resultados demonstram que existe uma diversidade e uma vasta pesquisa relacionada ao tema. Porém, algumas lacunas foram encontradas, principalmente relacionadas às limitações de pesquisa e base de testes. A Tabela 8 representa os artigos que foram selecionados de acordo com ano de publicação e tipo da classificação de pesquisa. O tipo de pesquisa $\mathbf{A}$ refere-se a artigos que avaliaram a relação da métrica com testabilidade usando algum tipo de cálculo, enquanto os tipos $\mathbf{B}$ e $\mathbf{C}$, correspondem a análises teóricas e revisões sistemáticas sobre o tema. Mais detalhes sobre esses três tipos serão apresentados adiante no texto. 


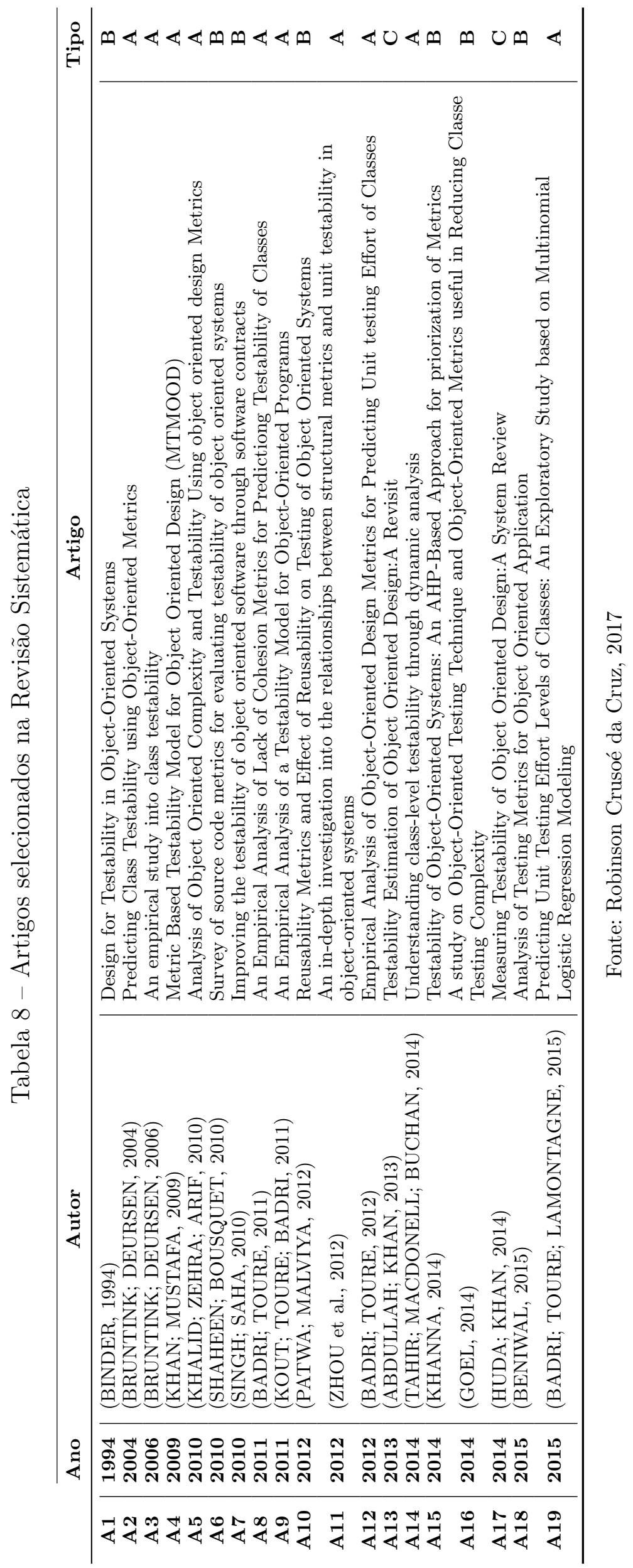


Entre os artigos selecionados, (BINDER, 1994) pode ser considerado importante para analisar o impacto da testabilidade, principalmente por abordar um estudo sistemático analisando várias métricas, inclusive as propostas por (CHIDAMBER; KEMERER, 1994). O mesmo propôs uma análise empírica sobre a causa e efeito em testabilidade, conforme representado pela Figura 5.

No que se refere à concentração de pesquisa, é possível destacar que pesquisadores que possuem mais de uma publicação, conforme a Tabela 9. Os trabalhos de (BRUNTINK; DEURSEN, 2004) e (BRUNTINK; DEURSEN, 2006) podem ser considerados como resultados parciais entre os mesmos, pois ao analisar a publicação de 2006 os resultados são idênticos ao estudo de 2004, porém, com modificações e melhorias significativas entre os dois trabalhos, principalmente na quantidade de softwares analisados.

Tabela 9 - Concentração de pesquisa por autores

\begin{tabular}{l|c|c|c}
\hline \multicolumn{1}{c}{ Autor(es) } & Universidade & Qtde & Pesquisas \\
\hline $\begin{array}{l}\text { Magiel Bruntink e } \\
\text { Arie van Deursen }\end{array}$ & $\begin{array}{c}\text { Universidade de Amsterdam } \\
\text { Holanda }\end{array}$ & 2 & $\begin{array}{c}\text { (BRUNTINK; DEURSEN, 2004), } \\
\text { (BRUNTINK; DEURSEN, 2006) }\end{array}$ \\
\hline M. H. Khan & $\begin{array}{c}\text { Universidade de Lucknow } \\
\text { Índia }\end{array}$ & 2 & $\begin{array}{c}\text { (HUDA; KHAN, 2014), } \\
\text { (ABDULLAH; KHAN, 2013) }\end{array}$ \\
\hline Fadel Touré & $\begin{array}{c}\text { Universidade de Quebec } \\
\text { Canadá }\end{array}$ & 4 & $\begin{array}{c}\text { (BADRI; TOURE, 2011), } \\
\text { (BADRI; TOURE, 2012), } \\
\text { (KOUT; TOURE; BADRI, 2011), } \\
\text { (BADRI; TOURE; LAMONTAGNE, 2015) }\end{array}$ \\
\hline
\end{tabular}

Fonte: Robinson Crusoé da Cruz, 2017

Baseado nos dados de extração definidos no protocolo da Revisão Sistemática e conforme representado na Tabela 8 , os trabalhos selecionados foram divididos em três tipos para auxiliar na análise e discussão dos resultados:

\section{(A) Análise dos artigos que utilizaram métricas CK baseado em cálculos.}

Os trabalhos com este perfil utilizaram a coleta das métricas $C K$ por meio da análise do código fonte, ou diagrama de classes. A maioria dos testes foi baseado na análise dos pares de classe $\left(C, C_{t}\right)$, sendo $C$ a classe do software a ser testada e $C_{t}$ a classe equivalente gerada pela ferramenta de testes. As métricas de quantidade de linhas de código geradas na classe de teste (TLOC) e quantidade de casos de testes (TAsserts) gerados, foram correlacionadas com as métricas CK da classe a ser testada $(C)$. 


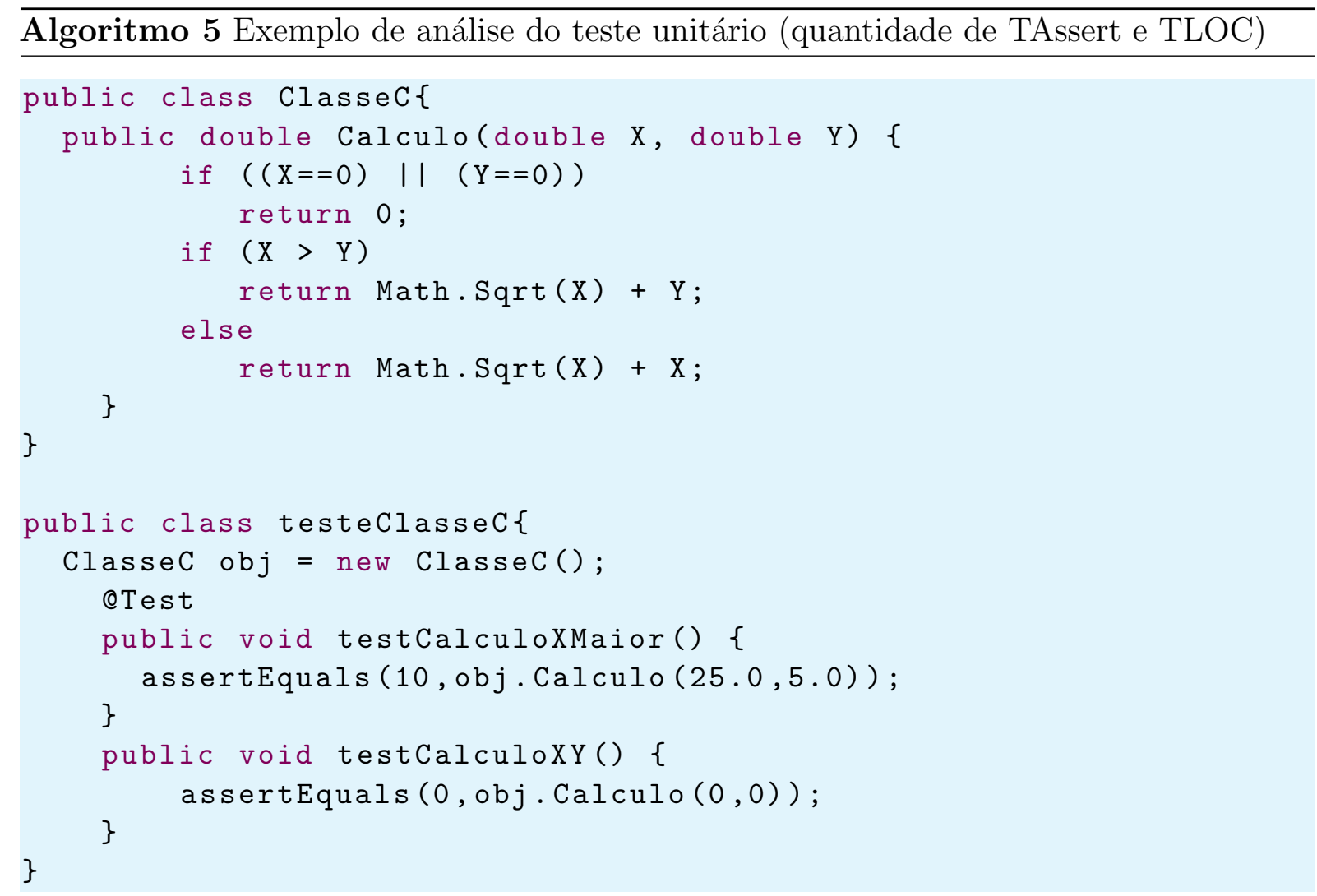

Fonte: Robinson Crusoé da Cruz, 2017

O Algoritmo 5 representa duas classes: ClasseC $(C)$ representa a classe a ser testada e a classe testeClasseC $\left(C_{t}\right)$ representa a classe de teste gerada pela ferramenta de teste. Ao analisar as métricas da classe testeclasseC $\left(C_{t}\right)$ é possível quantificar em 7 linhas de código (TLOC) e 2 casos de teste gerados (TAsserts) nas linhas 16 e 19.

A análise da correlação é baseada nos pares de classe e na aplicação de cálculos estatísticos de correlação. Por exemplo, ao analisar um determinado software que possui 10 classes, os passos e o cálculo da correlação entre a quantidade de casos de teste (TAssert) e a métrica RFC, seria:

- para cada uma das classes do software é gerado uma classe de teste com os devidos casos de teste, ou seja, seriam geradas 10 classes de teste;

- para cada classe de teste gerada, são contabilizadas a quantidade de TAssert;

- em cada uma das classes a serem testadas é contabilizado a quantidade do RFC;

- os pares de classes $\left(C, C_{t}\right)$ são analisados com a utilização da correlação.

Ao aplicar o cálculo de correlação, conforme apresentado na Seção 2.4, são definidas as variáveis $X$ e $Y$ do gráfico de dispersão, sendo $X$ a medida da métrica RFC, considerada a variável que pode influenciar a variável $Y$ que é representada pela quantidade de TAssert. 
Ao aplicar o cálculo de correlação o resultado será um valor entre -1 e 1 , onde quanto mais próximo de 0 , menor a correlação, quanto mais próximo de 1 maior a correlação positiva, ou seja, se $X(R F C)$ cresce, $Y$ (TAssert) cresce proporcionalmente. Quanto mais próximo de -1 , maior a correlação inversa, ou seja, se $X(R F C)$ cresce, $Y$ (TAssert) diminui proporcionalmente. Uma análise da significância estatística $(\alpha)$ é aplicada para analisar se o resultado possui significância, ou seja, se não foi um acaso.

Alguns trabalhos agrupados nesta classe utilizaram outros tipos de cálculos sem aplicação da análise da correlação estatística. Em muitos casos, o cálculo foi baseado na criação de um coeficiente. Os trabalhos deste item são apresentados na Seção 3.4.

\section{(B) Análises conceituais.}

A maioria das pesquisas com este perfil, propõem conceitos ou novas métricas para analisar a testabilidade. Os resultados são discutidos e apresentados na Seção 3.5.

\section{(C) Artigos de Revisão Sistemática - Trabalhos correlatos}

Nesta classe, foram selecionados artigos para auxiliar na comparação entre os resultados e objetivos da revisão sistemática desenvolvida neste projeto com trabalhos correlatos. Os resultados são discutidos e apresentados na Seção 3.6.

Antes de iniciar a análise dos artigos classificados anteriormente, nas próximas seções são propostas análises dos resultados relacionado ao tipo de cálculo utilizado nos artigos analisados (Seção 3.3.1) e sobre as linguagem e ferramentas de testes utilizadas (Seção 3.3.2).

\subsubsection{Análise dos tipos de cálculos aplicados nas pesquisas}

Nesta seção é apresentada uma análise dos cálculos utilizados nos artigos analisados na Revisão Sistemática. Em relação à análise de correlação entre métricas de software OO e testabilidade, vários artigos utilizaram a análise da correlação aplicando análises das métricas coletadas no nível de código fonte ou com dados obtidos por meio do diagrama de classe. Entre os cálculos de correlação utilizados, foi utilizado o ShapiroWilk em (TAHIR; MACDONELL; BUCHAN, 2014), e Spearman como o mais utilizado conforme representado pela Tabela 10 . 
Tabela 10 - Concentração de trabalhos por tipo de cálculo aplicado

\begin{tabular}{l|c|c}
\hline \multicolumn{1}{c}{ Tipo de Cálculo } & Qtde & Pesquisas \\
\hline $\begin{array}{l}\text { Cálculo de correlação de } \\
\text { Spearman's rank }\end{array}$ & 6 & $\begin{array}{c}\text { (BRUNTINK; DEURSEN, 2004), } \\
\text { (BRUNTINK; DEURSEN, 2006), } \\
\text { (KHAN; MUSTAFA, 2009), } \\
\text { (BADRI; TOURE, 2011), } \\
\text { (KOUT; TOURE; BADRI, 2011), } \\
\text { (BADRI; TOURE, 2012) }\end{array}$ \\
\hline \begin{tabular}{l|c} 
Regressão Linear Múltipla e Simples \\
Regressão Linear dos Mínimos
\end{tabular} & 3 & $\begin{array}{c}\text { (ZHOU et al., 2012), } \\
\text { Quadrados }\end{array}$ \\
\hline Correlação de Shapiro-W & 1 & $\begin{array}{c}\text { (BOURE; LAMONTAGNE, 2015), } \\
\text { (BADRI; TOURE, 2012) }\end{array}$ \\
\hline
\end{tabular}

Fonte: Robinson Crusoé da Cruz, 2017

O artigo (ZHOU et al., 2012) utilizou dois tipos de cálculos: (MLR) Regressão Linear Múltipla e (PLSR) Regressão dos Quadrados Mínimos. Um dos objetivos da utilização de dois cálculos foi analisar qual o melhor cálculo para o modelo. Os resultados indicam que (PLSR) contém melhores resultados referente ao MLR.

3.3.2 Resultados das linguagens de programação e softwares utilizados

Nesta Seção são apresentadas análises relacionadas às linguagens de programação e softwares utilizados nas pesquisas. Sobre a linguagem de programação, na maioria dos artigos que analisaram as métricas por meio do código fonte, os softwares foram desenvolvidos na linguagem Java e que na maioria dos casos, possuíam testes unitários disponíveis. 
Tabela 11 - Principais softwares utilizados nas pesquisas

\begin{tabular}{|c|c|c|}
\hline Sofware & Descrição & Pesquisas \\
\hline ANT & $\begin{array}{l}\text { Utilizada para construção de } \\
\text { Aplicações Java }\end{array}$ & $\begin{array}{c}\text { (BRUNTINK; DEURSEN, 2004), } \\
\text { (BRUNTINK; DEURSEN, 2006), } \\
\text { (KOUT; TOURE; BADRI, 2011), } \\
\text { (BADRI; TOURE, 2011), } \\
\text { (BADRI; TOURE, 2012), } \\
\text { (ZHOU et al., 2012), } \\
\text { (BADRI; TOURE; LAMONTAGNE, 2015) }\end{array}$ \\
\hline $\begin{array}{l}\text { JFREECHART } \\
\text { (JFC) }\end{array}$ & $\begin{array}{l}\text { Ferramenta para geração de gráficos em } \\
\text { aplicações Java. }\end{array}$ & $\begin{array}{c}\text { (KOUT; TOURE; BADRI, 2011) } \\
\text { (BADRI; TOURE, 2011) } \\
\text { (ZHOU et al., 2012), } \\
\text { (BADRI; TOURE, 2012), } \\
\text { (BADRI; TOURE; LAMONTAGNE, 2015) }\end{array}$ \\
\hline DocGen & $\begin{array}{l}\text { É um gerador de documentação que gera a } \\
\text { documentação por meio do código fonte. }\end{array}$ & $\begin{array}{l}\text { (BRUNTINK; DEURSEN, 2004), } \\
\text { (BRUNTINK; DEURSEN, 2006) }\end{array}$ \\
\hline $\begin{array}{l}\text { Dependency } \\
\text { Finder }\end{array}$ & $\begin{array}{l}\text { Utilizada para extrair dependências e } \\
\text { métricas de classe OO da linguagem Java. }\end{array}$ & (TAHIR; MACDONELL; BUCHAN, 2014) \\
\hline JabRef & $\begin{array}{l}\text { É uma ferramenta suporte para } \\
\text { gerenciamento de referências com base em } \\
\text { arquivos BibTex para ferramenta Latex. }\end{array}$ & (TAHIR; MACDONELL; BUCHAN, 2014) \\
\hline MOEA & $\begin{array}{l}\text { Ferramenta para desenvolvimento, } \\
\text { experimentação e otimização de algoritmos. }\end{array}$ & (TAHIR; MACDONELL; BUCHAN, 2014) \\
\hline POI & $\begin{array}{l}\text { Ferramenta para criação e manutenção de } \\
\text { APIs Java para manipulação de arquivos no } \\
\text { formato do Open Office. }\end{array}$ & (BADRI; TOURE, 2012) \\
\hline $\mathrm{ZPC}$ & $\begin{array}{l}\text { Ferramenta que extrai strings adequadas } \\
\text { para localização de arquivo cobol. }\end{array}$ & (BRUNTINK; DEURSEN, 2006) \\
\hline
\end{tabular}

Fonte: Robinson Crusoé da Cruz, 2017

A Tabela 11 representa os softwares mais utilizados nos estudos selecionados na Revisão Sistemática. Em relação a ferramenta de testes, JUnit foi a mais utilizada, pois conforme descrito anteriormente, grande parte dos softwares utilizados foram desenvolvidos na linguagem Java, e JUnit é a ferramenta de testes mais utilizada em softwares desenvolvidos nesta linguagem.

Nas próximas seções as pesquisas são apresentadas de acordo com: (A) Análise dos artigos que utilizaram métricas CK baseados em cálculos, (B) Análise dos artigos conceituais e (C) Artigos de revisão sistemática (trabalhos correlatos).

\subsection{Análise dos artigos que utilizaram métricas $C K$ baseados em cálculos (A)}

A Tabela 12 representa dez artigos que serão apresentados nesta seção e que realizaram análise por meio de cálculos. Para sintetizar a importância da métrica em cada pesquisa, foram definidos os seguintes marcadores para definir a importância de cada métrica na pesquisa: 
Não foi importante nos resultados da pesquisa.

Parcialmente importante nos resultados da pesquisa.

Relevante nos resultados da pesquisa.

Tabela 12 - Artigos que analisaram as métricas CK por meio de cálculos

\begin{tabular}{|c|c|c|c|c|c|c|c|}
\hline ARTIGO(Pesquisa) & & $\mathrm{CBO}$ & DIT & LCOM & NOC & RFC & WMC \\
\hline A4-(KHAN; MUSTAFA, 2009) & DC & $\diamond$ & & & & & \\
\hline A5-(KHALID; ZEHRA; ARIF, 2010) & DC & $\diamond$ & $\diamond$ & & $\diamond$ & & \\
\hline A2-(BRUNTINK; DEURSEN, 2004) & $\mathbf{C F}$ & $\nabla$ & $\diamond$ & $\diamond$ & $\diamond$ & $>$ & $>$ \\
\hline A3-(BRUNTINK; DEURSEN, 2006) & $\mathbf{C F}$ & 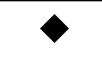 & $\diamond$ & 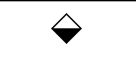 & $\diamond$ & $\nabla$ & 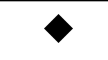 \\
\hline A9-(KOUT; TOURE; BADRI, 2011) & $\mathbf{C F}$ & 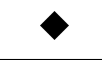 & $>$ & & & & \\
\hline A8-(BADRI; TOURE, 2011) & $\mathbf{C F}$ & & & $\nabla$ & & & \\
\hline A11-(ZHOU et al., 2012) & $\mathbf{C F}$ & 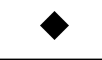 & $\diamond$ & $\nabla$ & $\diamond$ & $\diamond$ & 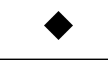 \\
\hline A12-(BADRI; TOURE, 2012) & CF & $>$ & $\diamond$ & $\diamond$ & $\diamond$ & $>$ & $>$ \\
\hline A14-(TAHIR; MACDONELL; BUCHAN, 2014) & $\mathbf{C F}$ & $\nabla$ & & & & & \\
\hline A19-(BADRI; TOURE; LAMONTAGNE, 2015) & CF & 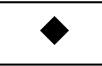 & & & & & $\nabla$ \\
\hline SOMA & & 9 & 6 & 5 & 5 & 4 & 5 \\
\hline
\end{tabular}

Fonte: Robinson Crusoé da Cruz, 2017

Em grande parte dos artigos foram realizadas análises de correlação entre as métricas das classes com base nos pares de classes $\left(C, C_{t}\right)$, sendo $C$ a classe a ser testada e $C_{t}$ a classe de teste gerada. Apenas os trabalhos (ZHOU et al., 2012), (BRUNTINK; DEURSEN, 2004), (BRUNTINK; DEURSEN, 2006) e (BADRI; TOURE, 2012) analisaram todas as métricas propostas por CK. No artigo (BADRI; TOURE, 2011) foi realizada uma pesquisa apenas com base na análise da métrica LCOM (falta de coesão da classe) e suas variações. Entre as métricas, CBO (Acoplamento entre classes) foi a mais utilizada.

Os trabalhos foram classificados em DC e CF, sendo DC a representação dos trabalhos que realizaram estudos baseados no diagrama de classe e CF por meio do código fonte. Nota-se que apenas duas pesquisas utilizaram o Diagrama de Classe para extração das métricas CK, além deste fato, é notório que não é possível coletar as métricas LCOM, RFC e WMC com base no Diagrama de Classes. Em (KOUT; TOURE; BADRI, 2011), as métricas foram utilizadas somente nas classes de teste geradas para correlacionar com coeficiente proposto na pesquisa. Nas próximas seções são discutidos os trabalhos que analisam cada uma das seis métricas propostas por CK e seu impacto na testabilidade do software. 


\subsubsection{Resultados das pesquisas relacionadas a métrica CBO}

Nesta seção são analisados os resultados dos artigos que analisaram a métrica CBO (Acoplamentos entre classe). A Tabela 12 apresenta os trabalhos que analisaram esta métrica e o resultado da importância da métrica na pesquisa.

Em A4-(KHAN; MUSTAFA, 2009), foi realizada uma análise das métricas retiradas por meio do Diagrama de Classes (DC), a proposta foi baseada em MTMOOD (Modelo de Testabilidade Baseada em Métricas para Projetos Orientado a Objetos). A pesquisa utilizou as métricas de encapsulamento, herança e acoplamento para analisar o fator de testabilidade de um software. No estudo foi proposto o coeficiente definido pela Equação 11, obtido com utilização de regressão linear múltipla (MLR), ou seja, ao medir as métricas é possível encontrar a influência relacionado a testabilidade. Neste trabalho não é possível analisar a métrica CBO de forma individual, pois a mesma foi analisada no contexto do coeficiente proposto. Nesta pesquisa seis projetos foram desenvolvidos por diferentes indivíduos e foram testados por diferentes profissionais com experiência de 8 a 12 anos em teste. De acordo com os autores, os resultados obtidos neste estudo foram relevantes relacionado a proposta do coeficiente proposto pelos autores.

$$
\text { Testabilidade }=-0.08 * \text { Encapsulamento }+1.12 * \text { Heranca }+0.97 * \text { Coupling }
$$

Em A11-(ZHOU et al., 2012), diferente dos outros trabalhos, foi realizada a comparação somente entre a classe a ser testada e a quantidade de linhas de código geradas na classe de teste (TLOC) e os resultados demonstraram que CBO é importante na testabilidade.

Na pesquisa A14-(TAHIR; MACDONELL; BUCHAN, 2014), a métrica CBO foi utilizada com objetivo de analisar a classe chave, por meio da análise das classes mais acopladas dos softwares em tempo de execução. Os resultados demonstraram que as classes chaves possuem maior influência na testabilidade. De acordo com autores, os resultados indicam que existe uma associação significante entre acoplamento dinâmico e testabilidade interna da classe.

Na pesquisa A9-(KOUT; TOURE; BADRI, 2011), a proposta foi a utilização do MTMOOD proposto por A4-(KHAN; MUSTAFA, 2009), porém, com algumas modificações. Os Autores desenvolveram o coeficiente definido pela Equação 12, onde NOO representa o número de métodos de operações em uma classe. Neste trabalho, além das características TLOC e TAssert da classe de teste, foram analisados mais três métricas: TRFC que 
representa a métrica RFC para classe de testes, TNOO que conta a quantidade de operações de uma classe de teste e por fim WMPC que representa a complexidade da classe de teste. A proposta foi analisar a correlação do modelo MTMOOP com as características da classe de teste. De acordo com os autores e os resultados, existe uma significância estatística entre o modelo e as métricas das classes de teste.

$$
\text { Testabilidade }=-0.08 * N O O+1,12 * D I T+0,97 * C B O
$$

Nas Pesquisas A2-(BRUNTINK; DEURSEN, 2004), A3-(BRUNTINK; DEURSEN, 2006) e A12-(BADRI; TOURE, 2012) foram realizadas análises do esforço da testabilidade relacionado à geração dos casos de teste utilizando $\left(C, C_{t}\right)$. Nas pesquisas A2-(BRUNTINK; DEURSEN, 2004), A3-(BRUNTINK; DEURSEN, 2006) a medida de CBO foi por meio da análise de FOUT (parte de CBO que considera apenas o que a classe analisada utilizou de outras classes). A Tabela 13 representa os resultados do cálculo da correlação desses artigos que analisaram a correlação da métrica CBO das classes $C$ em relação as classes de teste $C_{t}$. Como já definido, o termo TLOC representa a quantidade de linhas de código gerada na classe de testes e TAssert a quantidade de casos de testes gerados na classe de teste. Na maioria dos trabalhos foi aplicado um nível de significância de $\alpha=0,01$ ou $\alpha=0,05$. Os resultados que demonstraram uma significância estatística são apresentados em negrito. Esta mesma análise foi aplicada em todas as métricas CK apresentadas nas próximas seções que realizaram o mesmo tipo de análise.

Tabela 13 - Resultado da métrica CBO - software x classe de teste

\begin{tabular}{|c|c|c|c|c|c|c|}
\hline \multirow[b]{2}{*}{ Software } & \multicolumn{3}{|c|}{ TLOC } & \multicolumn{3}{|c|}{ TAssert } \\
\hline & A2 & A3 & A12 & A2 & A3 & A12 \\
\hline ANT & 0,465 & 0,465 & 0,394 & 0,307 & 0,307 & 0,135 \\
\hline DOCGEN & 0,555 & 0,555 & & 0,457 & 0,457 & \\
\hline JFC & & & 0,305 & & & $\overline{0,261}$ \\
\hline POI & & & 0,305 & & & 0,280 \\
\hline $\mathrm{ZPC}$ & & 0,481 & & & 0,240 & \\
\hline
\end{tabular}

Fonte: Robinson Crusoé da Cruz, 2017

Em geral o resultado da métrica CBO foi importante e indicou uma influência por meio dos resultados da correlação entre a métrica e as linhas de código (TLOC) e casos de testes (TAssert) gerados nas classes de teste. O Software DocGen possui o melhor resultado entre os estudos realizados. Em relação ao TAssert, a pesquisa A12-(BADRI; TOURE, 2012) possui o pior resultado. 
Os resultados de CBO indicam que esta métrica é importante ao analisar a sua influência no esforço da testabilidade, pois os dados na Tabela 13 mostram que CBO mantém uma significância estatística em relação a quantidade de linhas de código (TLOC) e casos de testes (TAssert) gerados na classe de teste.

\subsubsection{Resultados das pesquisas relacionadas a métrica DIT}

Nesta seção são analisados os resultados dos artigos em relação a métrica DIT. A Tabela 12 representa os trabalhos que analisaram esta métrica.

Em A9-(KOUT; TOURE; BADRI, 2011) a métrica DIT foi importante dentro da proposta. Entretanto, não é possível analisar o impacto individual da métrica, pois a mesma foi inserida no cálculo proposto na Equação 11.

Na pesquisa A5-(KHALID; ZEHRA; ARIF, 2010), DIT foi analisada dentro do contexto da análise da complexidade com dados extraídos do diagrama de classe (DC), porém, a análise dos resultados é com base na complexidade dos testes e não na correlação. De acordo com autores, os resultados foram importantes no contexto da pesquisa.

Nas pesquisas A2-(BRUNTINK; DEURSEN, 2004), A3-(BRUNTINK; DEURSEN, 2006) e A12-(BADRI; TOURE, 2012) foram realizadas análises do esforço da testabilidade em relação à geração dos casos de teste, utilizando análise dos pares de classe $\left(C, C_{t}\right)$. Ao analisar os resultados na Tabela 14 é notório que não existe correlação entre DIT e as métricas da classe de teste, seja em relação TLOC ou TAssert.

Tabela 14 - Resultado da métrica DIT em relação software x classe de teste

\begin{tabular}{l|ccc|ccc} 
& \multicolumn{3}{c}{ TLOC } & \multicolumn{3}{c}{ TAssert } \\
\hline Software & $\mathbf{A 2}$ & $\mathbf{A 3}$ & $\mathbf{A 1 2}$ & $\mathbf{A 2}$ & $\mathbf{A 3}$ & $\mathbf{A 1 2}$ \\
\hline ANT & $-0,047$ & $-0,047$ & 0,006 & $-0,020$ & $-0,020$ & $\mathbf{- 0 , 2 0 3}$ \\
\hline DOCGEN & $-0,037$ & $-0,037$ & & $-0,059$ & $-0,059$ & \\
\hline JFC & & & $\mathbf{0 , 1 6 6}$ & & 0,069 \\
\hline POI & & & $\mathbf{- 0 , 3 2 7}$ & & $-0,100$ \\
\hline ZPC & & 0,109 & & $\mid r$ & $-0,064$ \\
\hline
\end{tabular}

Fonte: Robinson Crusoé da Cruz, 2017

Os resultados apresentados nesta seção indicam que não existem influências da métrica DIT em relação a testabilidade quando analisado os pares de classes $\left(C, C_{t}\right)$. Entretanto, os resultados podem estar relacionados ao modelo de desenvolvimento aplicado nos softwares analisados, ou seja, talvez a herança tenha sido pouco utilizada no desen- 
volvimento. Contudo, é preciso considerar DIT em outros contextos, por exemplo, quando os métodos de uma superclasse são alterados suas classes filhas precisam ser testadas novamente.

\subsubsection{Resultados das pesquisas relacionadas a métrica LCOM}

Nesta seção são analisados os resultados dos artigos em relação a métrica LCOM (Falta de Coesão na Classe). A Tabela 12 apresenta os resultados dos trabalhos que analisaram esta métrica.

Como citado anteriormente, foram considerados para esta análise somente artigos que utilizaram cálculos matemáticos para realizar os testes, principalmente por meio de correlação.

Nas pesquisas A2-(BRUNTINK; DEURSEN, 2004), A3-(BRUNTINK; DEURSEN, 2006), A12-(BADRI; TOURE, 2012) e A8-(BADRI; TOURE, 2011) foram realizadas análises do esforço da testabilidade em relação à geração dos casos de teste utilizando análise dos pares de classe $\left(C, C_{t}\right)$. Os resultados em relação a métrica LCOM foram importantes, entretanto, existe uma discrepância entre os resultados, pois de acordo com a Tabela 15 a correlação nos softwares ANT e JFC foram importantes em todos os resultados, ao contrário do softwares DOCGEN, POI e ZPC que tiveram resultados relevantes apenas na análise do TAssert.

Tabela 15 - Resultado da métrica LCOM em relação software x classe de teste

\begin{tabular}{l|cccc|cccr} 
& \multicolumn{4}{c}{ TLOC } & \multicolumn{5}{c}{ TAssert } \\
\cline { 3 - 10 } Software & $\mathbf{A 2}$ & $\mathbf{A 3}$ & $\mathbf{A 8}$ & $\mathbf{A 1 2}$ & $\mathbf{A 2}$ & $\mathbf{A 3}$ & $\mathbf{A 8}$ & $\mathbf{A 1 2}$ \\
\hline ANT & $\mathbf{0 , 4 3 7}$ & $\mathbf{0 , 4 3 7}$ & $\mathbf{0 , 4 0 4}$ & $\mathbf{0 , 4 3 4}$ & $\mathbf{0 , 3 8 2}$ & $\mathbf{0 , 3 8 2}$ & $\mathbf{0 , 3 2 6}$ & $\mathbf{0 , 3 4 7}$ \\
\hline DOCGEN & 0,166 & 0,166 & & & $\mathbf{0 , 2 0 7}$ & $\mathbf{0 , 2 0 7}$ & & \\
\hline JFC & & & $\mathbf{0 , 3 7 9}$ & $\mathbf{0 , 3 8 8}$ & & & $\mathbf{0 , 4 2 4}$ & $\mathbf{0 , 4 3 9}$ \\
\hline POI & & & & 0,040 & & & & $\mathbf{0 , 1 5 5}$ \\
\hline ZPC & & 0,112 & & & & $\mathbf{0 , 2 1 5}$ & \\
\hline
\end{tabular}

Fonte: Robinson Crusoé da Cruz, 2017

Os resultados em relação aos testes no software ANT, foram idênticos nos estudos A2-(BRUNTINK; DEURSEN, 2004),A3-(BRUNTINK; DEURSEN, 2006), A8-(BADRI; TOURE, 2011) e A12-(BADRI; TOURE, 2012), seja em relação a TLOC ou TAssert. Isto pode indicar um padrão de desenvolvimento utilizado no software. 
Os dados indicam que a métrica LCOM tem impacto parcialmente importante em relação a testabilidade na geração de casos de teste, baseado na análise dos pares de classe. Entretanto, esta métrica está diretamente ligada ao padrão de desenvolvimento adotado, pois é possível trabalhar com uma estrutura com alto ou baixo LCOM, principalmente relacionada a padrões adotados no desenvolvimento do software.

\subsubsection{Resultados das pesquisas relacionadas a métrica NOC}

Nesta seção são analisados os resultados dos artigos em relação a métrica NOC (Número de Filhos da Classe). A Tabela 12 apresenta os resultados dos trabalhos que analisaram esta métrica.

O artigo A5-(KHALID; ZEHRA; ARIF, 2010) indica que existe uma relação entre as medidas de NOC retiradas da classe em relação a complexidade dos testes, entretanto, a análise não foi com base na análise das classes de teste. Neste artigo as métricas AHF (total de atributos escondidos) e MHF (total de métodos escondidos) de Abreu (ABREU et al., 1995) representadas na Tabela 3 foram utilizadas. Neste estudo as métricas DIT, NOC e CBO foram coletadas por meio da análise de Diagrama de Classes (DC). De acordo com os autores, predizer a complexidade com a análise do diagrama de classe, ajuda a simplificar o projeto. O estudo mostra que é possível utilizar esta premissa para analisar o nível de complexidades dos testes.

Tabela 16 - Resultado da métrica NOC em relação software x classe de teste

\begin{tabular}{l|ccc|ccc}
\cline { 2 - 7 } & \multicolumn{3}{c}{ TLOC } & \multicolumn{3}{c}{ TAssert } \\
\hline Software & A2 & $\mathbf{A 3}$ & $\mathbf{A 1 2}$ & $\mathbf{A 2}$ & $\mathbf{A 3}$ & $\mathbf{A 1 2}$ \\
\hline ANT & 0,0537 & 0,0537 & 0,0480 & 0,0262 & 0,0262 & 0,0340 \\
\hline DOCGEN & $-0,0274$ & 0,0274 & & 0,00241 & 0,00241 & \\
\hline JFC & & & 0,106 & & & $\mathbf{0 , 2 2 4}$ \\
\hline POI & & & 0,025 & & 0,011 \\
\hline ZPC & & 0,049 & & \multicolumn{3}{|c}{0,0218} \\
\hline
\end{tabular}

Fonte: Robinson Crusoé da Cruz, 2017

Nas pesquisas A2-(BRUNTINK; DEURSEN, 2004), A3-(BRUNTINK; DEURSEN, 2006) e A12-(BADRI; TOURE, 2012), foram realizadas análises do esforço da testabilidade em relação à geração dos casos de teste utilizando análise dos pares de classe $(C$, $C_{t}$ ). Entre as métricas $\mathrm{CK}$, NOC foi a que obteve o pior resultado, ou seja, não existe correlação entre NOC e o esforço de teste, seja em TLOC ou TAssert. Porém, ao analisar 
o trabalho (KHALID; ZEHRA; ARIF, 2010), a métrica pode ser considerada importante quando analisada em relação a um contexto geral. Por exemplo, NOC pode interferir na testabilidade ao analisar que em caso de alteração de uma classe pai, todos os seus filhos (NOC) precisam ser testados novamente, ou seja, com um valor alto de NOC, mais testes deverão ser produzidos (SHAHEEN; BOUSQUET, 2010).

\subsubsection{Resultados das pesquisas relacionadas a métrica RFC}

Nesta seção são analisados os resultados dos artigos em relação a métrica RFC (Resposta de uma classe). A Tabela 12 apresenta os resultados dos trabalhos que analisaram esta métrica.

Na análise proposta por A12-(ZHOU et al., 2012) não foram encontradas significâncias entre a métrica RFC e os softwares analisados, porém, o tipo de análise foi diferente dos resultados apresentados na Tabela 17.

Nas pesquisas A2-(BRUNTINK; DEURSEN, 2004), A3-(BRUNTINK; DEURSEN, 2006) e A12-(BADRI; TOURE, 2012) foram realizadas análises do esforço da testabilidade em relação à geração dos casos de teste utilizando análise dos pares de classe $\left(C, C_{t}\right)$. Os resultados apresentados na Tabela 17 demonstram que a métrica RFC está diretamente ligada ao esforço de testes da classe de teste.

Tabela 17 - Resultado da métrica RFC em relação software x classe de teste

\begin{tabular}{l|ccc|ccc} 
& \multicolumn{3}{c}{ TLOC } & \multicolumn{3}{c}{ TAssert } \\
\cline { 2 - 7 } Software & $\mathbf{A 2}$ & $\mathbf{A 3}$ & $\mathbf{A 1 2}$ & $\mathbf{A 2}$ & $\mathbf{A 3}$ & $\mathbf{A 1 2}$ \\
\hline ANT & $\mathbf{0 , 3 4 1}$ & $\mathbf{0 , 3 4 1}$ & $\mathbf{0 , 3 4 2}$ & $\mathbf{0 , 5 2 6}$ & $\mathbf{0 , 5 2 6}$ & 0,071 \\
\hline DOCGEN & $\mathbf{0 , 5 2 0}$ & $\mathbf{0 , 5 2 0}$ & & $\mathbf{0 , 5 3 7}$ & $\mathbf{0 , 5 3 7}$ & \\
\hline JFC & & & $\mathbf{0 , 2 5 7}$ & & & $\mathbf{0 , 2 5 7}$ \\
\hline POI & & $\mathbf{0 , 2 3 7}$ & & & $\mathbf{0 , 2 3 7}$ & \\
\hline ZPC & & $\mathbf{0 , 4 5 5}$ & & \multicolumn{3}{|c}{$\mathbf{0 , 5 6 9}$} \\
\hline
\end{tabular}

Fonte: Robinson Crusoé da Cruz, 2017

Os resultados das análises dos artigos indicam que existe um relacionamento importante entre a testabilidade dos casos de teste e a métrica RFC, baseado na análise dos pares de classe $\left(C, C_{t}\right)$. Fato que pode ser compreendido pois RFC está diretamente ligada com a quantidade de métodos. Porém, o padrão de desenvolvimento aplicado pode interferir nos resultados, ou seja, uma mesma classe desenvolvida em padrões diferentes de desenvolvimento pode ter quantidade de RFC diferente. 
3.4.6 Resultados das pesquisas relacionadas a métrica WMC

Nesta seção são analisados os resultados das pesquisas em relação a métrica WMC (Complexidade da Classe). A Tabela 12 apresenta os resultados dos trabalhos que analisaram esta métrica.

No trabalho de A11-(ZHOU et al., 2012) os resultados também foram positivos em todos resultados e softwares analisados. No trabalho A19-(BADRI; TOURE; LAMONTAGNE, 2015) a métrica foi importante na proposta de pesquisa.

Tabela 18 - Resultado da Métrica WMC em relação software x classe de teste

\begin{tabular}{|c|c|c|c|c|c|c|}
\hline \multirow[b]{2}{*}{ Software } & \multicolumn{3}{|c|}{ TLOC } & \multicolumn{3}{|c|}{ TAssert } \\
\hline & A2 & A3 & A12 & A2 & A3 & A12 \\
\hline $\mathrm{ANT}$ & 0,531 & 0,531 & 0,566 & 0,348 & 0,348 & 0,391 \\
\hline DOCGEN & 0,422 & 0,422 & & 0,460 & 0,460 & \\
\hline $\mathrm{JFC}$ & & & 0,450 & & & $\overline{0,453}$ \\
\hline POI & & & 0,398 & & & 0,400 \\
\hline $\mathrm{ZPC}$ & & 0,440 & & & 0,511 & \\
\hline
\end{tabular}

Fonte: Robinson Crusoé da Cruz, 2017

Ao analisar os resultados e as considerações dos artigos A2-(BRUNTINK; DEURSEN, 2004), A3-(BRUNTINK; DEURSEN, 2006) e A12-(BADRI; TOURE, 2012), os resultados indicam que quanto maior o WMC, maior esforço nos testes. De acordo com a Tabela 18 todos os resultados foram positivos e isso indica que a métrica WMC deve ser considerada na análise da testabilidade baseado na análise do teste unitário. Notoriamente, a complexidade tem uma relação com a geração de casos de teste, pois quando maior a complexidade de um método, maior a quantidade de casos de testes.

\subsection{Análise dos artigos conceituais (B)}

Nesta seção os artigos classificados como conceituais são apresentados de forma agrupada com objetivo de tentar analisar as pesquisas com propostas idênticas.

O estudo proposto por (SINGH; SAHA, 2010) analisou a testabilidade com utilização do conceito de contrato de software (E.; ALEXANDER; HUTCHINSON, 1997). Os resultados da pesquisa demonstram que a utilização desta metodologia pode reduzir os casos de teste em até $50 \%$. 
Conforme apresentado na Seção 3.4, as pesquisas que analisaram as métricas DIT e NOC demonstraram um resultado insignificante em relação à correlação da classe a ser testada $(C)$ e classe de teste correspondente $\left(C_{t}\right)$. Entretanto, essas métricas podem ser importantes no contexto geral da análise da testabilidade. Os artigos (PATWA; MALVIYA, 2012) e (GOEL, 2014) desenvolveram pesquisas relacionadas à reusabilidade de software que podem auxiliar na análise das métricas DIT e NOC dentro do contexto da testabilidade. Em (PATWA; MALVIYA, 2012) foi realizado um estudo propondo três métricas: RCS (reusabilidade da classe em um sistema), AR (grau de reusabilidade) e SBRM (análise do resultado final da reusabilidade). O resultado da pesquisa indica que quanto maior a reusabilidade, menor o esforço na testabilidade. Porém, durante a pesquisa, vários fatores como polimorfismo e métodos desenvolvidos na subclasse não foram considerados.

Na pesquisa proposta em (GOEL, 2014), foi proposto um estudo com base na herança. Um coeficiente denominado ITC (teste de herança em classe) foi proposto com objetivo de calcular os métodos puros, que representam os métodos que foram implementados na subclasse, métodos sobrescritos e métodos herdados pela subclasse que não foram testados. O estudo indica que um alto ITC representa um maior esforço na testabilidade e os autores indicam que sua proposta pode substituir as métricas DIT e NOC pela métrica ITC para predizer o esforço de testabilidade.

Em (SHAHEEN; BOUSQUET, 2010), é proposta uma análise crítica sobre as métricas e a testabilidade de software OO. O mesmo define o trabalho com uma extensão da proposta de (BINDER, 1994). Neste trabalho são analisadas mais de 40 métricas. Na pesquisa a perspectiva da testabilidade é analisada como um conceito difícil de ser capturado e formalizado, pois vários são os fatores que podem afetar a testabilidade. Este trabalho serve como análise das métricas analisadas em relação a testabilidade.

No artigo (BENIWAL, 2015), foi realizada uma análise em relação ao tempo e custo da execução dos testes unitários. Foi proposta uma análise baseada em curva progressiva para analisar o número de casos testes planejados, executados e os testes que passaram em relação ao tempo. Como segunda proposta foram analisados os números de defeitos encontrados em relação ao tempo e avaliação. O estudo foi baseado na análise de testes de dois softwares.

Nos trabalhos analisados nesta seção é notória a busca por encontrar um caminho para auxiliar na testabilidade ou pesquisadores tentam definir medidas e métricas que possam complementar ou substituir a análise da testabilidade baseado nas métricas CK. 


\subsection{Artigos de Revisão Sistemática (C)}

Nesta seção são apresentados dois artigos de revisão sistemática sobre testabilidade de software OO (ABDULLAH; KHAN, 2013; HUDA; KHAN, 2014).

Em (ABDULLAH; KHAN, 2013) foi proposta uma revisão sobre a estimativa de testabilidade de software orientado a objetos. A proposta deste trabalho foi diferente da proposta desta RS, pois em (ABDULLAH; KHAN, 2013) foi realizada de forma descritiva e sem comparações entre dados e resultados das pesquisas analisadas. Em (HUDA; KHAN, 2014) foi realizada uma revisão com a proposta de analisar as pesquisas que consideraram a análise da testabilidade de software OO baseado em estimativa de: (a) testabilidade na fase do projeto, (b) artigos que consideraram a análise de fatores específicos de testabilidade e por fim, (c) baseado na contribuição, questões e limitações de cada artigo.

De acordo com (HUDA; KHAN, 2014), pesquisadores definem que a análise dos fatores da testabilidade devem ser aplicadas na fase do projeto de software. Fatores como abstração, encapsulamento, herança, coesão e entre outros devem ser analisados no projeto em relação ao seu impacto na testabilidade. Nesta fase, o autor apresentou de forma sintética a análise de 13 artigos com este perfil.

Os artigos foram organizados propondo uma análise dos fatores como controlabilidade, construção de casos de teste, reusabilidade e entre outros fatores em relação a testabilidade. Foram selecionados 16 artigos. Em destaque está o artigo (BINDER, 1994), que analisou $50 \%$ dos fatores de testabilidade propostos na revisão.

Na Tabela 19 é apresentada a correspondência entre os artigos que foram analisados nesta Revisão Sistema (RS) com os artigos analisados nas pesquisas de (ABDULLAH; KHAN, 2013) e (HUDA; KHAN, 2014).

Tabela 19 - Análise dos trabalhos correlatos entre as Revisões Sistemáticas (RS)

\begin{tabular}{l|c|c}
\hline \multicolumn{1}{c}{ Revisão Sistemática } & (ABDULLAH; KHAN, 2013) & (HUDA; KHAN, 2014) \\
\hline (BINDER, 1994) & $\boldsymbol{V}$ & $\boldsymbol{V}$ \\
\hline (BRUNTINK; DEURSEN, 2004) & $\boldsymbol{V}$ & $\boldsymbol{V}$ \\
\hline (BRUNTINK; DEURSEN, 2006) & & $\boldsymbol{V}$ \\
\hline (KHAN; MUSTAFA, 2009) & & $\boldsymbol{V}$ \\
\hline (KOUT; TOURE; BADRI, 2011) & & $\mathbf{v}$ \\
\hline (BADRI; TOURE, 2012) & $\boldsymbol{v}$ & \\
\hline
\end{tabular}

Fonte: Robinson Crusoé da Cruz, 2017 
A similaridade dos artigos selecionados entre a revisão sistemática proposta neste trabalho e os artigos analisados (ABDULLAH; KHAN, 2013) e (HUDA; KHAN, 2014) é visivelmente pequena. Porém, este resultado pode ser justificado baseado nas questões de pesquisa que foram abordadas na fase de condução desta revisão. Pois, como informado anteriormente, o foco desta revisão sistemática foi a análise da testabilidade em relação às métricas $\mathrm{CK}$, ao contrário das outras revisões, que tiveram como proposta, uma visão mais ampla sobre a testabilidade de software OO.

\subsection{Lacunas dos trabalhos relacionados e ferramentas}

Durante o desenvolvimento da pesquisa e na revisão das ferramentas e trabalhos correlatos foram detectadas lacunas em relação aos cálculos e análises realizadas pelas ferramentas. Foram encontradas definições das métricas CK em determinadas pesquisas que podem induzir a análise incorreta dos dados da classe em relação a sua testabilidade.

Métrica DIT (profundidade na árvore de herança): as ferramentas que são citadas a seguir, consideram inicialmente que todas as classes ao serem criadas possuem nível de herança de $D I T=1$, conforme representado pela Figura 13-A. Este resultado está relacionado a arquitetura das linguagem C\# e Java, pois toda classe desenvolvida nessas linguagens herdam da classe System.Object. Porém, este resultado pode levar a uma análise incorreta em relação a testabilidade da classe, pois pode induzir o analista de teste que não possua experiência e/ou conhecimento deste fato, a realizar uma definição incorreta da classe. Por exemplo, ao analisar a Figura 13-A a medida de DIT poderia indicar que a classe B depende dos métodos de duas classes para realizar os seus testes, entretanto a testabilidade depende apenas dos métodos da classe A. 
Figura 13 - Diagrama de classe com duas análises de DIT

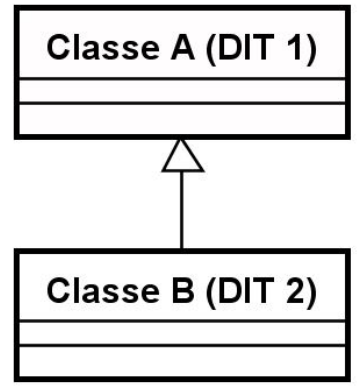

Diagrama A

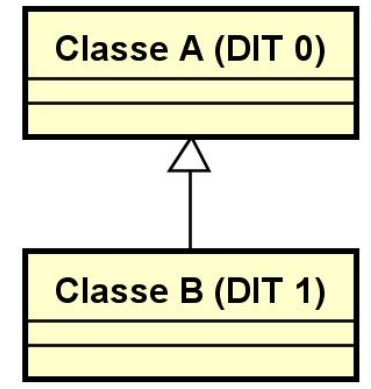

Diagrama B

Fonte: Robinson Crusoé da Cruz, 2017

As ferramentas Visual Studio da Microsoft utilizada neste projeto para o desenvolvimento da ferramenta de coleta de métrica e análise de métricas de software desenvolvimento na linguagem C\#, JHawk e Eclipse Metrics utilizadas neste projeto para coleta das métricas CK dos softwares Java, realizam a análise de DIT conforme a Figura 13-A.

Métrica RFC (resposta de uma classe): Ao analisar a Ferramenta JHawk, foi detectado que a mesma possui um erro ao contabilizar os métodos das classes externas. Para realizar a medida correta a instância da classe deve ser declarada como uma instância global da classe analisada, conforme representado pela linha 8 do Algoritmo 6. Ao analisar a Classe B com a ferramenta JHawk o valor seria calculado corretamente com $R F C=1$. Entretanto, se a instância da classe for criada dentro do método, conforme o código apresentado na linha 9 do Algoritmo 7, o valor é calculado incorretamente com $R F C=0$.

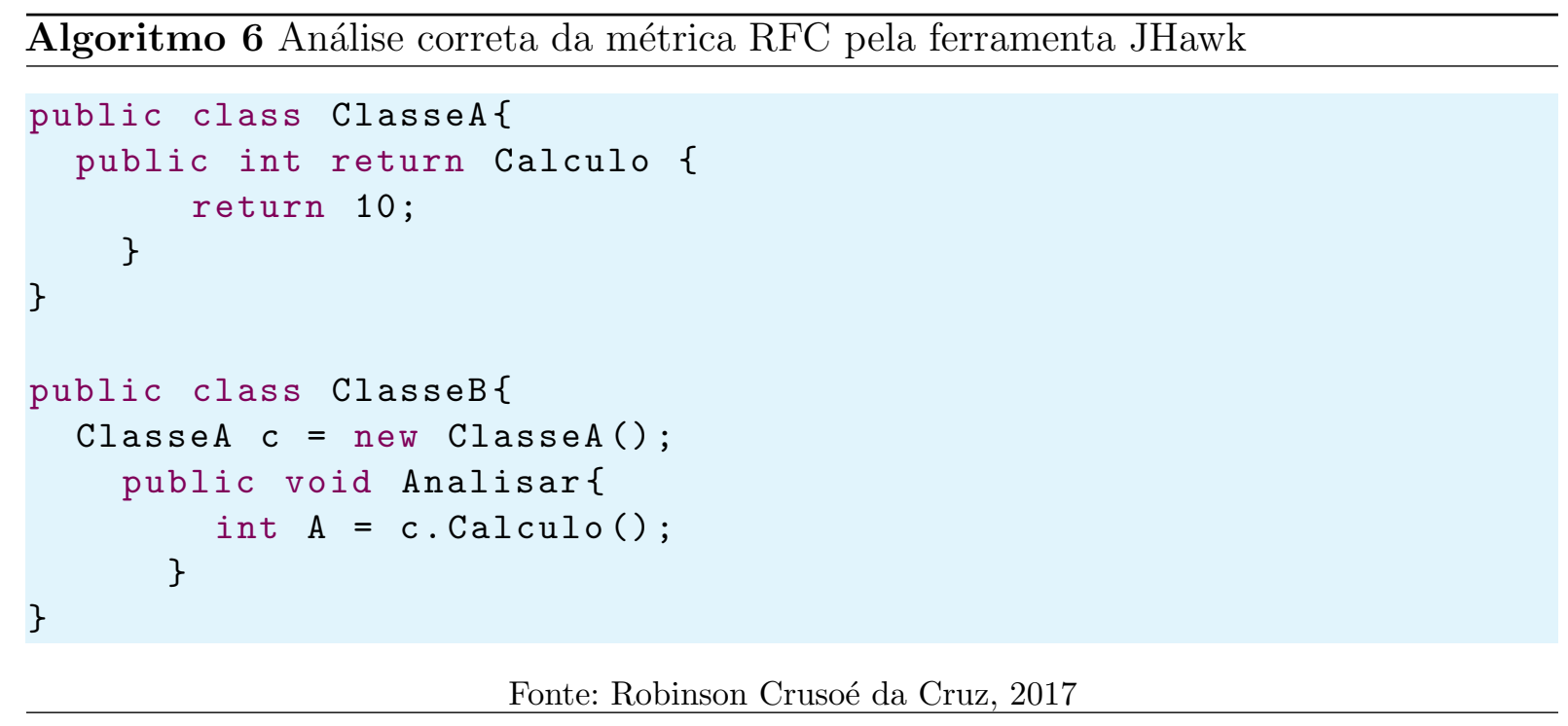




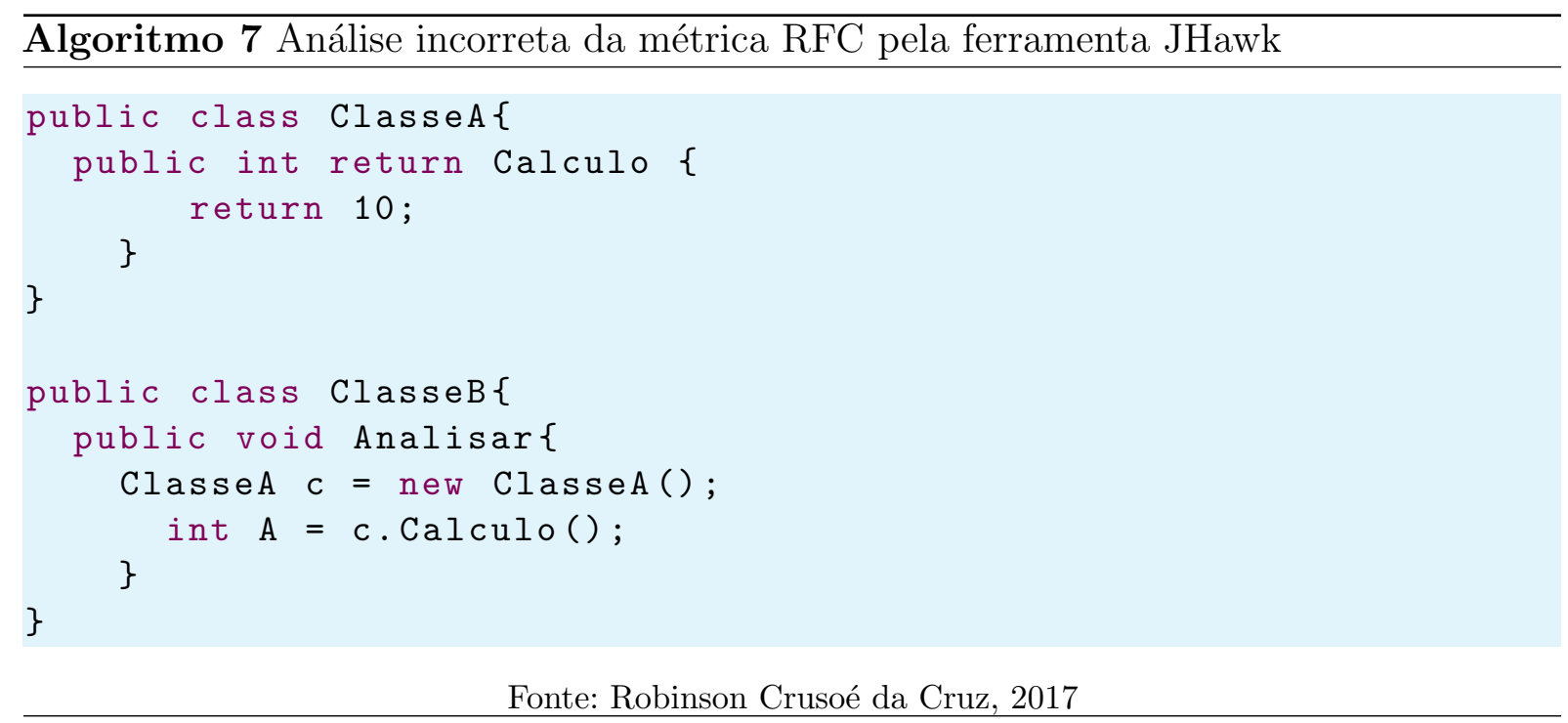

Como boa prática da Engenharia de Software seria importante que as classes externas a serem utilizadas, sejam instanciadas como instancia global dentro da classe, conforme representado pelo o Algoritmo 6, porém, isto não garante que o desenvolvedor aplique esta premissa. Este fato em relação a medida de RFC, pressupõe a necessidade de analisar se outras ferramentas possui o mesmo problema.

Métrica CBO (acomplamento entre as classes): A definição desta métrica em algumas pesquisas, como (VALE, 2016), descrevem ou definem a métrica CBO apenas como a análise das classes utilizadas pela classe analisada, seja por meio da utilização de métodos ou de variáveis de classe. Entretanto, Chidamber e Kemerer (CHIDAMBER; KEMERER, 1994) definem que uma classe está acoplada a outra quando uma realiza uma ação sobre a outra. Então, se uma determinada classe foi utilizada por outra classe, o valor de CBO das duas classes é igual a 1. Por exemplo, nos Algoritmos 6 e 7 a Classe B está utilizando um método da Classe A, então pode-se considerar o valor de CBO das duas classes igual a 1.

Os resultados apresentados e discutidos nesta seção indicam que existem lacunas para novas pesquisas. As análises indicam que é preciso analisar os resultados das ferramentas durante a coleta das métricas para que os resultados não interfiram na qualidade da pesquisa. 


\subsection{Análise crítica e considerações finais}

Notoriamente, os resultados da revisão foram importantes como estudo relacionado ao estado da arte sobre a relação das métricas CK e testabilidade. As principais considerações identificadas na revisão, são apresentadas a seguir:

- nas pesquisas apresentados na Seção 3.4 foram utilizados softwares desenvolvidos na linguagem Java. Considerando que existem outras linguagens de programação OO, como C\#, VB.net, entre outras. Então, seria interessante uma pesquisa utilizando outras linguagens ou a proposta de desenvolvimento de uma ferramenta para coletar e analisar as métricas CK e as medidas de teste;

- na Seção 3.4 foram apresentadas análises quantitativas de comparação entre os resultados das pesquisas. Porém, é preciso considerar que apesar de algumas pesquisas utilizarem o mesmo software, a versão do software pode ser diferente, e como consequência, os casos de teste também podem ser. Isto indica que as versões precisam ser consideradas na pesquisa;

- o resultado das métricas DIT e NOC relacionadas no contexto do teste unitário foram insignificantes. Porém, foram importantes em vários artigos quando analisadas em outro contexto. Este fato pode indicar que a métricas DIT e NOC quando analisadas individualmente não fornecem informações relevantes em relação a testabilidade do teste unitário;

- sobre a métrica DIT, não é possível garantir que uma classe mais profunda na árvore de herança seja mais complexa do que outra menos profunda em relação a testabilidade. Conforme os resultados, esta métrica mostrou-se com resultados inconsistentes quando analisada individualmente em relação aos testes unitários. Porém, a sua utilidade pode garantir que um software que utiliza reusabilidade, pode ser considerado importante para melhorar a testabilidade, pois um teste realizado na superclasse não precisa ser refeito na subclasse, caso o método seja utilizado sem aplicação de polimorfismo. A métrica NOC, segue o mesmo raciocínio da métrica DIT, pois analisar se uma superclasse possui muitas subclasses, pode auxiliar no impacto em relação a testabilidade;

- a métrica CBO representa uma análise importante, porém, vários autores descrevem que um alto $\mathrm{CBO}$ em uma classe indica uma maior complexidade na testabilidade 
e talvez um mau uso da métrica. Este fator pode estar relacionado ao padrão de desenvolvimento utilizado;

- uma classe com alto LCOM, indica que existem poucas variáveis em comum dentro da classe, isto indica uma falta de coesão, porém, em algumas classes específicas, a falta de coesão é necessária, como por exemplo em classes especialistas que foram criadas para agrupar cálculos ou regras de negócio.

- a métrica RFC pode ser considerada importante, porém, a sua medida pode estar relacionada a forma e padrão de desenvolvimento, como por exemplo: um método pode ser dividido em $N$ métodos;

- a métrica WMC se torna importante na análise da complexidade, porém, ela está ligada muito mais a complexidade do código, do que relacionada as medidas de software orientado a objetos. O seu resultado pode depender do grau de maturidade do desenvolvedor e da metodologia utilizada. Entretanto, esta métrica obteve o maior impacto na testabilidade baseado nos testes unitários;

- apenas (BRUNTINK; DEURSEN, 2006) consideraram uma análise sobre a qualidade dos casos de testes unitário. O fato de outras pesquisas não considerarem a qualidade dos casos é um fator negativo, pois, como é possível garantir que os casos de teste disponibilizados possuem qualidade?

- entre todos os projetos analisados o padrão de desenvolvimento aplicado nos softwares não foi considerado. Então, será que o padrão de desenvolvimento iterativo ou em cascata pode influenciar nos resultados? 


\section{Análises Empíricas}

Este Capítulo apresenta os resultados de um estudo empírico realizado com o intuito de analisar a correlação entre as métricas CK e a qualidade dos testes criados pelos desenvolvedores de um software. A Seção 4.1 apresenta os projetos de software analisados e as ferramentas de apoio utilizadas. A Seção 4.2 apresenta a análise da correlação das métricas CK, cobertura dos testes e escore de mutação, enquanto a Seção 4.3 apresenta uma análise das métricas CK e de teste utilizadas com base na clusterização das classes do software, cujo objetivo foi definir grupos de métricas que possuam um determinado padrão de testabilidade. Por fim, na Seção 4.5, têm-se as considerações finais deste Capítulo.

\subsection{Ferramentas utilizadas e softwares analisados}

Quatro projetos de software desenvolvidos na linguagem Java foram utilizados nas análises propostas nesta pesquisa. Estes softwares foram selecionados porque são aplicações amplamente utilizadas; os casos de teste criados pelos desenvolvedores estavam disponíveis; e principalmente porque foram utilizados em pesquisas anteriores, o que facilita a comparação entre os resultados obtidos aqui com os trabalhos relacionados. Os softwares escolhidos são os seguintes:

- Apache POI: uma ferramenta para criar e manter APIs Java de manipulação de arquivos baseados em Open Office, XML e Microsoft (OLE2).

- JABREF: uma ferramenta que gerencia referências bibliográficas no formato BibTeX.

- JFREECHART(JFC): uma biblioteca de gráficos para linguagem Java.

- MOEA: um Framework baseado em Java para desenvolvimento e otimização de algoritmos.

As seguintes ferramentas/plugins foram utilizadas para coletar e calcular métricas, gerar os mutantes, realizar a clusterização e realizar os cálculos estatísticos:

- Eclipse Metrics ${ }^{1}$ e $\mathbf{J H a w k}^{2}$ : foram utilizadas para coleta das métricas CK.

1 http://eclipse-metrics.sourceforge.net

2 http://www.virtualmachinery.com 
- JUnit $^{3}$ : foi utilizada para para executar os caso de testes.

- Emma ${ }^{4}$ foi utilizada para calcular a cobertura dos testes.

- PITEST ${ }^{5}$ : foi utilizada para gerar e analisar os mutantes.

- RStudio ${ }^{6}$ : foi utilizada para realizar os cálculos estatísticos e geração dos clusters com base na linguagem $\mathrm{R}$.

- $\mathbf{W E K A}^{7}$ : foi utilizada para classificar as classes de acordo com os clusters gerados pela linguagem $\mathrm{R}$.

- Visual Studio ${ }^{8}$ : utilizada para analisar softwares desenvolvidos na plataforma .NET e no desenvolvimento da ferramenta de coleta de métricas (Capítulo 5).

4.2 Análise Empírica da correlação entre as métricas CK e a Cobertura de Teste e Escore de Mutação

Quatro trabalhos relacionados a esta pesquisa fizeram uma análise da correlação da quantidade de Casos de Testes (TAsserts) e Linhas de Código (TLOC) com as métricas CK. Este tipo de análise é importante para medir o esforço do teste, entretanto considerar a adequação dos casos de teste com base no critério de cobertura (line and branches) e o escore de mutação pode prover uma análise mais detalhada sobre a qualidade dos testes produzidos para aquele software.

Com base neste contexto, a proposta apresentada nesta seção tem como objetivo principal avaliar se existe um correlação entre as métricas CK e as medidas de adequação de testes, como cobertura de código (Lines and Branches) e escore de mutação. Espera-se, com isso, entender se os valores das métricas CK tem alguma influência na qualidade dos testes produzidos e consequentemente na testabilidade do software.

Inicialmente na Seção 4.2.1 são apresentados os detalhes da fase de coleta de dados. $\mathrm{Na}$ Seção 4.2.2 são apresentados os resultados da correlação entre cada métrica CK e as medidas de testes, cobertura de código (lines e branches), escore de mutação e uma análise entre os resultados desta pesquisa e os trabalhos analisados na Revisão Sistemática. Por fim, é apresentada uma discussão sobre os resultados.

\footnotetext{
http://junit.org

http://emma.sourceforge.net

http://pitest.org

http://www.rstudio.com

http://www.cs.waikato.ac.nz/ml/index.html

https://www.visualstudio.com
} 


\subsubsection{Coleta dos dados e análise estatística}

Inicialmente foram coletados os dados das métricas CK, cobertura (line and branches) e escore de mutação dos softwares citados na Seção 4.1. Em seguida os dados foram analisados de acordo com quatro configurações mostradas na Tabela 20. A primeira configuração considera todas as classes, desde que tenham pelo menos um caso de teste. A segunda configuração considera todas as classes que tenham mais de $66 \%$ de cobertura de linha de código. A terceira configuração considera todas as classes em que a porcentagem de linhas cobertas seja maior ou igual a média encontrada durante a análise apresentada na Tabela 22. Finalmente, a quarta configuração considera apenas classes em que mais de $90 \%$ das linhas de código foram cobertas. Esta última configuração visa investigar as características das classes que foram quase ou totalmente cobertas.

Tabela 20 - Configurações de cobertura para análise de correlação

\begin{tabular}{c|c|c|c}
\hline \multirow{2}{*}{ CONFIGURAÇÃO } & $\begin{array}{c}\text { COBERTURA DE } \\
\text { LINHA (LINE) }\end{array}$ & $\begin{array}{c}\text { COBERTURA DE } \\
\text { RAMO (BRANCH) }\end{array}$ & $\begin{array}{c}\text { ESCORE DE } \\
\text { MUTAÇÃ O }\end{array}$ \\
\hline $\mathbf{1}$ & $>0.0 \%$ & $>=0.0 \%$ & $>=0.0 \%$ \\
$\mathbf{2}$ & $>=66.0 \%$ & $>=0.0 \%$ & $>=0.0 \%$ \\
$\mathbf{3}$ & $>=$ média\% & $>=0.0 \%$ & $>=0.0 \%$ \\
$\mathbf{4}$ & $>=90.0 \%$ & $>=0.0 \%$ & $>=0.0 \%$ \\
\hline
\end{tabular}

Fonte: Robinson Crusoé da Cruz, 2017

A Tabela 21 representa a soma total de classes analisadas em cada configuração. Ao analisar a porcentagem da quantidade de classe em cada cobertura, a configuração 4, que representa classes com alta cobertura, possui uma representatividade de $46,18 \%$ do total das classes coletadas, este resultado indica os softwares possuem alta cobertura de linha de código.

Tabela 21 - Classes analisadas nos testes com base na configuração (Tab. 20)

\begin{tabular}{c|c|c|c|c|cc}
\hline CONFIGURAÇÃO & JABREF & JFREECHART & \multicolumn{1}{c}{ MOEA } & POI & \multicolumn{1}{c}{ SOMA } & \% \\
\hline $\mathbf{1}$ & 318 & 411 & 359 & 694 & $\mathbf{1 7 8 2}$ & $\mathbf{1 0 0 , 0 0 \%}$ \\
$\mathbf{2}$ & 236 & 224 & 316 & 602 & $\mathbf{1 3 7 8}$ & $\mathbf{7 7 , 3 2 \%}$ \\
$\mathbf{3}$ & 210 & 242 & 250 & 444 & $\mathbf{1 1 4 6}$ & $\mathbf{6 4 , 3 0 \%}$ \\
$\mathbf{4}$ & 159 & 69 & 230 & 365 & $\mathbf{8 2 3}$ & $\mathbf{4 6 , 1 8 \%}$ \\
\hline
\end{tabular}

Fonte: Robinson Crusoé da Cruz, 2017

Com os dados agrupados e de acordo com as configurações da Tabela 20, foi aplicada uma análise da correlação entre as métricas CK e a cobertura de teste (line e branch) e escore de mutação. Na análise foi aplicada a correlação de Sperman's que é a medida de associação entre duas variáveis, onde o resultado é um valor entre -1 (correlação perfeita negativa) a 1 (correlação perfeita positiva), e valores próximo a 0 indicam que não existe 
correlação. Para analisar se o resultado não foi um acaso, foi aplicada uma significância estatística de $\alpha \leq 0,05(5 \%)$ e apenas os valores apresentados em negrito indicam que existe significância estatística.

\subsubsection{Análise dos resultados}

Nesta seção os dados são apresentados seguindo as configurações definidas na Tabela 20 e agrupados de acordo com cada métrica ou medida de teste. Como citado, apenas os valores em negrito possuem significância estatística de 5\%. Entretanto, antes de iniciar a análise da correlação das métricas foi aplicada uma análise dos softwares em relação a cobertura das classes selecionadas, conforme a Tabela 22. Em destaque temos os softwares POI e MOEA que possuem uma média alta de cobertura de linhas de código, porém, o software MOEA obteve uma baixa cobertura no escore de mutação.

Tabela 22 - Cobertura e escore de mutação dos softwares

\begin{tabular}{c|c|c|c|c}
\hline \multirow{2}{*}{ SOFTWARE } & $\begin{array}{c}\text { CLASSES } \\
\text { ANALISADAS }\end{array}$ & \multicolumn{1}{c}{$\begin{array}{c}\text { COBERTURA DE } \\
\text { LINHAS (LINES) }\end{array}$} & $\begin{array}{c}\text { COBERTURA DE } \\
\text { RAMOS (BRANCHES) }\end{array}$ & $\begin{array}{c}\text { ESCORE DE } \\
\text { MUTAÇA O O }\end{array}$ \\
\hline JABREF & 318 & $77,43 \%$ & $52,00 \%$ & $66,82 \%$ \\
JFC & 411 & $62,45 \%$ & $47,52 \%$ & $42,70 \%$ \\
MOEA & 359 & $87,22 \%$ & $61,47 \%$ & $26,63 \%$ \\
POI & 694 & $84,69 \%$ & $54,51 \%$ & $69,40 \%$ \\
\hline
\end{tabular}

Fonte: Robinson Crusoé da Cruz, 2017

CBO (acomplamento entre classes): A Tabela 23 mostra os resultados da correlação entre a métrica CBO e as medidas de teste. A correlação entre CBO e cobertura de código pode ser considerada baixa e negativa. A correlação negativa pode significar um baixo acoplamento entre os objetos, enquanto a correlação positiva pode ser o oposto. Entretanto, a correlação negativa no JABREF é moderada em relação a cobertura de linhas de código. 
Tabela 23 - Análise da correlação de CBO

\begin{tabular}{|c|c|c|c|c|}
\hline \multirow[b]{2}{*}{ SOFTWARE } & \multicolumn{4}{|c|}{ CBO x COBERTURA DE LINHA } \\
\hline & $>=0 \%$ & $>=66 \%$ & $>=$ mean $\%$ & $>=90 \%$ \\
\hline JABREF & $-0,420$ & $-0,480$ & $-0,490$ & $-0,440$ \\
\hline JFREECHART & $-0,160$ & $-0,220$ & $-0,210$ & $-0,170$ \\
\hline MOEA & $-0,170$ & $-0,200$ & $-0,170$ & $-0,190$ \\
\hline \multirow[t]{2}{*}{ POI } & $-0,110$ & $-0,200$ & $-0,190$ & $-0,190$ \\
\hline & \multicolumn{4}{|c|}{ CBO $\times$ COBERTURA DE RAMOS } \\
\hline JABREF & $-0,160$ & $-0,170$ & $-0,120$ & $-0,120$ \\
\hline JFREECHART & $-0,050$ & $-0,050$ & $-0,040$ & $-0,040$ \\
\hline MOEA & 0,100 & 0,120 & 0,160 & 0,160 \\
\hline \multirow[t]{2}{*}{ POI } & 0,150 & 0,180 & 0,160 & 0,160 \\
\hline & \multicolumn{4}{|c|}{ CBO x ESCORE DE MUTAÇÃO } \\
\hline JABREF & $-0,360$ & $-0,400$ & $-0,420$ & $-0,370$ \\
\hline JFREECHART & $-0,270$ & $-0,340$ & $-0,350$ & $-0,320$ \\
\hline MOEA & 0,170 & 0,180 & 0,220 & 0,250 \\
\hline POI & $-0,080$ & $-0,140$ & $-0,080$ & $-0,100$ \\
\hline
\end{tabular}

Fonte: Robinson Crusoé da Cruz, 2017

DIT (profundidade na árvore de herança): a Tabela 24 representa os resultados da correlação entre a métrica DIT e as medidas de teste. O resultado mostra que não existe um padrão nos resultados ao considerar cada software individualmente. Em vários projetos não existe correlação, ou uma correlação baixa positiva ou negativa. A correlação com escore de mutação indica uma correlação negativa baixa.

Tabela 24 - Análise da correlação de DIT

\begin{tabular}{l|cccc|}
\cline { 2 - 5 } & \multicolumn{4}{c}{ DIT x COBERTURA DE LINHA } \\
\hline SOFTWARE & $>=\mathbf{0 \%}$ & $>=\mathbf{6 6 \%}$ & $>=$ média\% & $>=\mathbf{9 0 \%}$ \\
\hline JABREF & $-0,080$ & $-0,030$ & $-0,050$ & $-0,140$ \\
JFREECHART & $\mathbf{- 0 , 3 0 0}$ & $\mathbf{- 0 , 1 8 0}$ & $\mathbf{- 0 , 1 9 0}$ & $\mathbf{- 0 , 2 3 0}$ \\
MOEA & 0,010 & 0,010 & 0,040 & 0,040 \\
POI & $\mathbf{0 , 2 8 0}$ & $\mathbf{0 , 2 6 0}$ & $\mathbf{0 , 2 0 0}$ & $\mathbf{0 , 2 0 0}$ \\
\hline \multicolumn{4}{c}{ DIT x COBERTURA } & DE RAMOS \\
\hline JABREF & $-0,100$ & $-0,090$ & $-0,090$ & $-0,100$ \\
JFREECHART & $\mathbf{- 0 , 2 6 0}$ & $\mathbf{- 0 , 2 8 0}$ & $\mathbf{- 0 , 2 9 0}$ & $\mathbf{- 0 , 3 2 0}$ \\
MOEA & $\mathbf{0 , 1 2 0}$ & $\mathbf{0 , 2 5 0}$ & $\mathbf{0 , 2 6 0}$ & $\mathbf{0 , 2 7 0}$ \\
POI & $\mathbf{- 0 , 3 0 0}$ & $\mathbf{- 0 , 3 4 0}$ & $\mathbf{- 0 , 3 8 0}$ & $\mathbf{- 0 , 3 7 0}$ \\
\hline & DIT & $\mathbf{2 S C O R E}$ & $\mathbf{D E}$ MUTAÇÃO \\
\hline JABREF & $-0,040$ & 0,070 & 0,070 & 0,070 \\
JFREECHART & $\mathbf{- 0 , 3 1 0}$ & $\mathbf{- 0 , 2 4 0}$ & $\mathbf{- 0 , 2 5 0}$ & 0,060 \\
MOEA & $\mathbf{- 0 , 1 8 0}$ & $\mathbf{- 0 , 1 5 0}$ & $\mathbf{- 0 , 2 0 0}$ & $\mathbf{- 0 , 2 0 0}$ \\
POI & $-0,020$ & $\mathbf{- 0 , 0 9 0}$ & $\mathbf{- 0 , 1 4 0}$ & $\mathbf{- 0 , 1 5 0}$ \\
\hline
\end{tabular}

Fonte: Robinson Crusoé da Cruz, 2017

LCOM (falta de coesão da classe): a Tabela 25 mostra o resultados da correlação entre a métrica LCOM e as medidas de teste. Os resultados indicam que existe uma correlação baixa negativa entre LCOM e cobertura de linha de código e escore de mutação. A correlação não segue um padrão específico em relação a cobertura de branches. 
Tabela 25 - Análise da correlação de LCOM

\begin{tabular}{l|cccc|}
\cline { 2 - 5 } & \multicolumn{4}{c}{ LCOM x COBERTURA DE LINHA } \\
\hline SOFTWARE & $>=\mathbf{0 \%}$ & $>=\mathbf{6 6 \%}$ & $>=$ média\% & $>=\mathbf{9 0 \%}$ \\
\hline JABREF & $\mathbf{- 0 , 3 0 0}$ & $\mathbf{- 0 , 3 3 0}$ & $\mathbf{- 0 , 3 0 0}$ & $\mathbf{- 0 , 2 1 0}$ \\
JFREECHART & $\mathbf{- 0 . 1 2 0}$ & $\mathbf{- 0 , 1 6 0}$ & $\mathbf{- 0 , 1 5 0}$ & $\mathbf{- 0 , 1 8 0}$ \\
MOEA & $\mathbf{- 0 , 2 4 0}$ & $\mathbf{- 0 , 3 1 0}$ & $\mathbf{- 0 , 2 9 0}$ & $\mathbf{- 0 , 3 4 0}$ \\
POI & 0,040 & $-0,050$ & $-0,040$ & -0.080 \\
\hline \multicolumn{4}{c}{ LCOM } & COBERTURA DE RAMOS \\
\hline JABREF & $-0,110$ & $-0,100$ & $-0,090$ & $-0,040$ \\
JFREECHART & 0,030 & 0,110 & 0,120 & $\mathbf{0 , 2 6 0}$ \\
MOEA & 0,090 & 0,070 & $\mathbf{0 , 1 0 0}$ & 0,110 \\
POI & $\mathbf{- 0 , 1 0 0}$ & $\mathbf{- 0 , 1 4 0}$ & $\mathbf{- 0 , 2 0 0}$ & $\mathbf{- 0 , 2 0 0}$ \\
\hline & $\mathbf{L C O M} \mathbf{x}$ ESCORE $\mathbf{D E ~ M U T A C ̧ A ̃ O ~}$ \\
\hline JABREF & $\mathbf{- 0 , 3 1 0}$ & $\mathbf{- 0 , 3 6 0}$ & $\mathbf{- 0 , 3 7 0}$ & $\mathbf{- 0 , 3 8 0}$ \\
JFREECHART & $\mathbf{- 0 , 1 3 0}$ & $\mathbf{- 0 , 1 7 0}$ & $\mathbf{- 0 , 1 6 0}$ & $\mathbf{- 0 , 1 8 0}$ \\
MOEA & 0,060 & $-0,070$ & $-0,030$ & $-0,020$ \\
POI & $-0,080$ & $\mathbf{- 0 , 1 3 0}$ & $\mathbf{- 0 , 1 5 0}$ & $\mathbf{- 0 , 1 5 0}$ \\
\hline
\end{tabular}

Fonte: Robinson Crusoé da Cruz, 2017

NOC (quantidade de filhos classe): a Tabela 26 mostra os resultados da correlação entre a métrica NOC e as medidas de teste. Os resultados indicam que não existe um padrão entre NOC e as medidas de teste.

Tabela 26 - Análise da correlação de NOC

\begin{tabular}{|c|c|c|c|c|}
\hline \multirow[b]{2}{*}{ SOFTWARE } & \multicolumn{4}{|c|}{ NOC $\times$ COBERTURA DE LINHA } \\
\hline & $>=0 \%$ & $>=66 \%$ & $>=$ média $\%$ & $>=90 \%$ \\
\hline JABREF & $-0,230$ & $-0,120$ & $-0,120$ & $-0,090$ \\
\hline JFREECHART & $-0,130$ & 0,000 & 0,010 & $-0,060$ \\
\hline MOEA & 0,010 & 0,000 & $-0,130$ & $-0,090$ \\
\hline \multirow[t]{2}{*}{ POI } & $-0,020$ & 0,130 & 0,020 & $-0,010$ \\
\hline & \multicolumn{4}{|c|}{ NOC $x$ COBERTURA DE RAMOS } \\
\hline JABREF & $-0,130$ & $-0,050$ & $-0,040$ & $-0,090$ \\
\hline JFREECHART & 0,100 & 0,070 & 0,070 & 0,020 \\
\hline MOEA & 0,190 & 0,190 & 0,170 & 0,200 \\
\hline \multirow[t]{2}{*}{ POI } & 0,030 & 0,030 & 0,040 & 0,030 \\
\hline & \multicolumn{4}{|c|}{ NOC x ESCORE DE MUTAÇÃO } \\
\hline JABREF & $-0,170$ & $-0,020$ & $-0,030$ & $-0,070$ \\
\hline JFREECHART & 0,010 & $-0,110$ & $-0,110$ & $-0,170$ \\
\hline MOEA & 0,070 & 0,090 & 0,070 & 0,070 \\
\hline POI & 0,020 & 0,050 & $-0,020$ & 0,020 \\
\hline
\end{tabular}

Fonte: Robinson Crusoé da Cruz, 2017

RFC (resposta de uma classe): a Tabela 27 mostra os resultados da correlação entre a métricas RFC e as medidas de teste. Os resultados mostram que existe uma correlação negativa baixa e moderada entre RFC e cobertura de linha e escore de mutação. Entretanto, entre RFC e cobertura de ramos (branches) não existe um padrão. 
Tabela 27 - Análise da correlação de RFC

\begin{tabular}{|c|c|c|c|c|}
\hline \multirow[b]{2}{*}{ SOFTWARE } & \multicolumn{4}{|c|}{ RFC x COBERTURA DE LINHA } \\
\hline & $>=0 \%$ & $>=66 \%$ & $>=$ média $\%$ & $>=90 \%$ \\
\hline JABREF & $-0,440$ & $-0,430$ & $-0,420$ & $-0,350$ \\
\hline JFREECHART & $-0,110$ & $-0,320$ & $-0,300$ & $-0,540$ \\
\hline MOEA & $-0,400$ & $-0,510$ & $-0,550$ & $-0,540$ \\
\hline \multirow[t]{2}{*}{ POI } & $-0,120$ & $-0,180$ & $-0,170$ & $-0,240$ \\
\hline & \multicolumn{4}{|c|}{ RFC X COBERTURA DE RAMOS } \\
\hline JABREF & $-0,100$ & $-0,050$ & $-0,040$ & 0,020 \\
\hline JFREECHART & 0,190 & 0,210 & 0,200 & 0,440 \\
\hline MOEA & 0,110 & 0,070 & 0,120 & 0,150 \\
\hline \multirow[t]{2}{*}{ POI } & 0,000 & $-0,030$ & $-0,070$ & 0,050 \\
\hline & \multicolumn{4}{|c|}{ RFC x ESCORE DE MUTAÇÃO } \\
\hline JABREF & $-0,450$ & $-0,480$ & $-0,500$ & $-0,500$ \\
\hline JFREECHART & $-0,080$ & $-0,200$ & $-0,210$ & $-0,260$ \\
\hline MOEA & $-0,130$ & 0,140 & 0,090 & $-0,070$ \\
\hline POI & $-0,230$ & $-0,250$ & $-0,220$ & $-0,240$ \\
\hline
\end{tabular}

Fonte: Robinson Crusoé da Cruz, 2017

WMC (complexidade dos métodos da classe): a Tabela 28 mostra os resultados da correlação entre a métricas WMC e as medidas de teste. Os resultados mostram que existe uma correlação negativa moderada entre WMC e cobertura de linha. Ou seja, quanto maior a complexidade, menor a cobertura de linha. Existe uma correlação positiva baixa em relação a WMC e a cobertura de branches. Alem disso, os resultados indicam uma correlação baixa entre WMC e o escore de mutação.

Tabela 28 - Análise da correlação de WMC

\begin{tabular}{|c|c|c|c|c|}
\hline \multirow[b]{2}{*}{ SOFTWARE } & \multicolumn{4}{|c|}{ WMC x COBERTURA DE LINHA } \\
\hline & $>=0 \%$ & $>=66 \%$ & $>=$ média $\%$ & $>=90 \%$ \\
\hline JABREF & $-0,450$ & $-0,460$ & $-0,490$ & $-0,430$ \\
\hline JFREECHART & $-0,210$ & $-0,320$ & $-0,310$ & $-0,590$ \\
\hline MOEA & $-0,370$ & $-0,500$ & $-0,610$ & $-0,600$ \\
\hline \multirow[t]{2}{*}{ POI } & $-0,210$ & $-0,330$ & $-0,270$ & $-0,360$ \\
\hline & \multicolumn{4}{|c|}{ WMC x COBERTURA DE RAMOS } \\
\hline JABREF & 0,110 & 0,150 & 0,150 & 0,250 \\
\hline JFREECHART & 0,140 & 0,240 & 0,230 & 0,590 \\
\hline MOEA & 0,270 & 0,210 & 0,270 & 0,330 \\
\hline \multirow[t]{2}{*}{ POI } & 0,550 & 0,220 & 0,220 & 0,230 \\
\hline & \multicolumn{4}{|c|}{ WMC x ESCORE DE MUTAÇÃO } \\
\hline JABREF & $-0,370$ & $-0,390$ & $-0,420$ & $-0,420$ \\
\hline JFREECHART & $-0,160$ & $-0,210$ & $-0,220$ & $-0,280$ \\
\hline MOEA & 0,020 & $-0,040$ & $-0,040$ & $-0,070$ \\
\hline POI & $-0,170$ & $-0,180$ & $-0,090$ & $-0,130$ \\
\hline
\end{tabular}

Fonte: Robinson Crusoé da Cruz, 2017

Cobertura de Código x Escore de Mutação: outras análises foram desenvolvidas para comparar as métricas com as medidas de teste. Um análise importante foi a correlação entre cobertura de linha de código e escore de mutação. Os resultados desta análise indicam 
que uma maior cobertura poderia ajudar a revelar mais falhas, ou levar a mais mutantes mortos. A Tabela 29 mostra o resultado da correlação entre a cobertura de linha e escore de mutação. Os dados indicam uma correlação positiva moderada, indicando que quanto maior a cobertura de código, maior o escore de mutação. Entretanto, a correlação do software MOEA indica uma baixa correlação, porém, este resultado pode ser explicado pela média baixa de escore de mutação de 26,63\% (Tabela 22).

Tabela 29 - Análise da correlação entre cobertura de linha e escore de mutação

\begin{tabular}{l|cccc|}
\cline { 2 - 5 } & \multicolumn{4}{c}{ COBERTURA DE LINHA x ESCORE DE MUTAÇÃO } \\
\hline SOFTWARE & $>=\mathbf{0} \%$ & $>=\mathbf{6 6 \%}$ & $>=$ média\% & $>=\mathbf{9 0 \%}$ \\
\hline JABREF & $\mathbf{0 , 7 5 0}$ & $\mathbf{0 , 5 8 0}$ & $\mathbf{0 , 5 4 0}$ & $\mathbf{0 , 3 8 0}$ \\
JFREECHART & $\mathbf{0 , 7 3 0}$ & $\mathbf{0 , 5 2 0}$ & $\mathbf{0 , 5 4 0}$ & $\mathbf{0 , 3 1 0}$ \\
MOEA & $\mathbf{0 , 3 1 0}$ & $\mathbf{0 , 2 3 0}$ & 0,070 & 0,010 \\
POI & $\mathbf{0 , 4 6 0}$ & $\mathbf{0 , 3 9 0}$ & $\mathbf{0 , 3 8 0}$ & $\mathbf{0 , 3 5 0}$ \\
\hline
\end{tabular}

Fonte: Robinson Crusoé da Cruz, 2017

Análise da correlação entre as métricas: A Tabela 30 mostra a correlação entre cada métricas CK, considerando os resultados dos trabalhos analisados na Revisão Sistemática e os resultados coletados nesta pesquisa. O objetivo principal desta comparação foi verificar se existe um padrão das métricas coletadas nesta pesquisa relacionado aos trabalhos analisados na Revisão Sistemática. Os resultados indicam uma similaridade entre as pesquisa. Existe uma correlação forte entre (RFC x WMC), (CBO x RFC), correlação moderada entre (CBO x LCOM), (CBO x WMC) e (LCOM x WMC). O resultado indica que as métricas DIT e NOC possuem a menor correlação entre as métricas CK.

Tabela 30 - Correlação entre as métricas CK - comparativo entre os trabalhos relacionados e esta pesquisa

\begin{tabular}{|c|c|c|c|c|c|c|c|c|c|c|c|c|c|c|c|}
\hline & \multicolumn{15}{|c|}{ MÉTRICAS CORRELACIONADAS } \\
\hline & $\begin{array}{l}\text { CBO } \\
\text { DIT }\end{array}$ & $\begin{array}{l}\mathrm{CBO} \\
\mathrm{LCOM}\end{array}$ & $\begin{array}{l}\mathrm{CBO} \\
\text { NOC }\end{array}$ & $\begin{array}{l}\mathrm{CBO} \\
\mathrm{RFC}\end{array}$ & $\begin{array}{c}\text { CBO } \\
\text { WMC }\end{array}$ & $\begin{array}{c}\text { DIT } \\
\text { LCOM }\end{array}$ & $\begin{array}{l}\text { DIT } \\
\text { NOC }\end{array}$ & $\begin{array}{l}\text { DIT } \\
\text { RFC }\end{array}$ & $\begin{array}{c}\text { DIT } \\
\text { WMC }\end{array}$ & $\begin{array}{c}\text { LCOM } \\
\text { NOC }\end{array}$ & $\begin{array}{c}\text { LCOM } \\
\text { RFC }\end{array}$ & $\begin{array}{l}\text { LCOM } \\
\text { WMC }\end{array}$ & $\begin{array}{l}\text { NOC } \\
\text { RFC }\end{array}$ & $\begin{array}{c}\text { NOC } \\
\text { WMC }\end{array}$ & $\begin{array}{c}\text { RFC } \\
\text { WMC }\end{array}$ \\
\hline $\begin{array}{l}\text { Média dos Trab. } \\
\text { Relacionados }\end{array}$ & 0,117 & 0,366 & 0,040 & 0,812 & 0,658 & 0,145 & 0,023 & 0,260 & 0,030 & 0,105 & 0,210 & 0,432 & 0,089 & 0,144 & 0,802 \\
\hline Média da Pesquisa & 0,140 & 0,330 & 0,250 & 0,470 & 0,480 & 0,120 & $-0,040$ & 0,220 & 0,080 & 0,120 & 0,540 & 0,460 & 0,150 & 0,120 & 0,850 \\
\hline
\end{tabular}

Fonte: Robinson Crusoé da Cruz, 2017

Análise entre esta pesquisa e os trabalhos da Revisão Sistemática: A Tabela 31 representa uma análise da importância de cada métrica dentro das pesquisas que analisaram o esforço do teste por meio da análise dos casos de testes (TAssert) e Linhas de Código da Classe de teste (TLOC), conforme apresentado na Seção 3.4 e com resultados encontrados nesta seção. Os resultados encontrados foram classificados como: 
quando a métrica foi importante nos resultados;

$\diamond$ quando a métrica não foi importante e;

$X$ quando a métrica não foi analisada.

O resultado mostra similaridade na importância das métricas $\mathrm{CBO}, \mathrm{LCOM}, \mathrm{RFC}$ e WMC dentro do contexto de todas as pesquisas.

Tabela 31 - Análise da importância das métricas nos resultados de correlação

\begin{tabular}{l|cccccc} 
& CBO & DIT & LCOM & NOC & RFC & WMC \\
\hline (CRUZ; ELER, 2017a) & $\diamond$ & $\diamond$ & $\diamond$ & $\diamond$ & $\diamond$ & $\diamond$ \\
(BRUNTINK; DEURSEN, 2004) & $\diamond$ & $\diamond$ & $\diamond$ & $\diamond$ & $\diamond$ & $\diamond$ \\
(BRUNTINK; DEURSEN, 2006) & $\diamond$ & $\diamond$ & $\diamond$ & $\diamond$ & $\diamond$ & $\diamond$ \\
(BADRI; TOURE, 2011) & $\times$ & $\times$ & $\diamond$ & $\times$ & $\times$ & $\times$ \\
(BADRI; TOURE, 2012) & $\diamond$ & $\diamond$ & $\diamond$ & $\diamond$ & $\diamond$ & $\diamond$ \\
\hline
\end{tabular}

Fonte: Robinson Crusoé da Cruz, 2017

\subsubsection{Discussão dos resultados}

Esta fase de desenvolvimento auxiliou na comparação dos trabalhos relacionados que utilizaram correlação entre as métricas CK e o esforço de teste relacionado a quantidade de casos de testes (TAssert) e a quantidade de linhas de código da classe de teste (TLOC) com a qualidade por meio da análise das medidas de teste. Então, é possível inferir algumas análises específicas com base no resultados e nos fatos presentes na literatura:

- Ao analisar o resultado de CBO, nota-se que quanto maior o acoplamento entre as classes, maior a utilização de métodos e variáveis de outras classes, isto pode levar o teste a executar chamadas externas, aumentando o esforço dos testes.

- Em relação ao LCOM, apesar da baixa correlação, uma baixa coesão pode dificultar a interpretação da classe, aumentando a complexidade do testes.

- O RFC está relacionado com a quantidade de métodos internos e externos, este fator pode aumentar a complexidade da geração dos casos de teste e como consequência o aumento no esforço da testabilidade. Este fato depende da arquitetura utilizada e da experiência do desenvolvedor. Entretanto, se a classe for organizada de forma que contenha apenas métodos ligados no seu contexto, a complexidade dos testes pode diminuir. 
- Em relação ao WMC o resultado era esperado, pois complexidade de um método pode aumentar a quantidade de casos de testes e como consequência o esforço do teste. E se existe uma complexidade alta, maiores as chances de diminuir as medidas de teste (cobertura, escore de mutação).

- Ao comparar os resultados da relevância das métricas CK com a testabilidade das métricas e apesar dos valores baixos de correlação, nota-se que as métricas CBO, LCOM, RFC e WMC são importantes medidas para analisar a testabilidade. Os resultados apresentados na Tabela 31 indicam uma similaridade entre esta pesquisa e as pesquisas publicadas por outros autores.

- Ao analisar os resultado das métricas DIT e NOC, tanto nesta fase da pesquisa como nos trabalhos da Revisão Sistemática, nota-se que essas métricas precisam ser consideradas em outros contextos relacionados à testabilidade, por exemplo, na organização do teste de regressão, pois os resultados da correlação não indicam resultados importantes para prever o esforço da testabilidade.

- Nos trabalhos da Revisão Sistemática que analisaram a correlação do esforço dos testes relacionado a quantidade de casos de testes (TAsserts) e Linhas de Código (TLOC), a correlação foi positiva, ou seja, se a métrica aumenta é necessário uma quantidade maior de casos de testes e como consequência as linhas de código aumentam. Nos resultados apresentados nesta seção, a correlação na maioria dos resultados foi negativa, indicando que, quando a métrica aumenta, a cobertura de teste e escore de mutação diminuem proporcionalmente, exceto nas métricas DIT e NOC.

\subsection{Análise de agrupamento de classes de acordo com a inferência das métricas}

Esta seção apresenta uma proposta de clusterização das métricas CK para tentar identificar características que levam a uma maior ou menor testabilidade da classe. Inicialmente, espera-se que esta fase possa contribuir com um modelo para avaliação de todos os softwares sem a necessidade da análise individual de cada software. Espera-se encontrar características de testabilidade dentro de cada clusters e que o modelo possa servir como base de desenvolvimento de uma ferramenta para coleta, clusterização e correlação das métricas. 
Inicialmente na Seção 4.3.1 é apresentada a definição dos clusters. Na Seção 4.3.2 são apresentados os resultados da clusterização conforme os clusters definidos na Tabela 32. Em seguida é realizada uma análise dos clusters. Por fim, é apresentada a discussão sobre os resultados.

\subsubsection{Definição dos clusters das classes}

A Tabela 32 mostra o número de clusters encontrados ao utilizar o algoritmo EM (Maximização de Expectativa) considerando uma análise individual de cada métrica, ou uma combinação de todas ou algumas métricas. As métricas NOC e DIT não foram analisadas individualmente, pois nas análises iniciais a quantidade foi definida como 1 cluster. Este resultado está ligado às características dessas métricas que possuem valores geralmente próximos de zero. A métrica LCOM foi analisada individualmente em dois contextos diferentes: primeiro considerando todas as classes, onde foram encontrados apenas dois clusters; na segunda análise foram analisadas somente as classes com valores abaixo do outlier $($ Valor < 37), com 6 clusters. Na segunda análise de LCOM, 1.446 classes foram analisadas de um total de 1.782 .

Tabela 32 - Número de clusters para cada configuração

\begin{tabular}{ll}
\hline \multicolumn{1}{c}{ MÉTRICA(S) } & NÚMERO DE CLUSTERS \\
\hline CBO & 5 \\
\hline LCOM & 2 \\
\hline LCOM (Valor $<\mathbf{3 7})$ & 6 \\
\hline RFC & 5 \\
\hline WMC & 7 \\
\hline TODAS AS MÉTRICAS CK & 2 \\
\hline CBO, LCOM, RFC E WMC & 9 \\
\hline CBO E WMC & 8 \\
\hline LCOM E WMC & 9 \\
\hline RFC E WMC & 7 \\
\hline
\end{tabular}

Fonte: Robinson Crusoé da Cruz, 2017

\subsubsection{Resultados}

Clusterizando e combinando todas as Métricas: inicialmente, considerando todas as métricas CK dos 4 softwares, foram encontrados 2 clusters. Como as métricas DIT e 
NOC possuem valores próximos a zero, no segundo teste foi realizada uma clusterização desconsiderando DIT e NOC. O resultado foi a clusterização dos dados em 9 clusters. A Tabela 33 mostra os detalhes de cada cluster. Em cada cluster é possível analisar a média de cobertura de linha e escore de mutação, bem como o valor mínimo, máximo, quantidade de classes, porcentagem do cluster em relação ao total de classes, média, mediana, Desvio Padrão $(\alpha)$ e Coeficiente de Variação (CV). Foi calculada a correlação entre a cobertura de linha de código e escore de mutação, onde o resultado encontrado indica que existe uma correlação positiva moderada e alta entre as duas medidas.

Ao utilizar o Algoritmo $k \mathrm{NN}$ com auxílio da ferramenta WEKA para classificar e validar os clusters gerados pelo algoritmo EM, foi possível obter uma acurácia de 81,53\%, mostrando que é possível utilizar este algoritmo para classificar uma classe desconhecida em um conjunto de dados conhecidos e clusterizados por CBO, LCOM, RFC e WMC. Este resultado indica que ao tentar classificar uma classe e analisar suas características de acordo com uma base conhecida, é possível obter uma margem de acerto de 81,53\%. Neste resultado e nas outras análises apresentas neste trabalho que utilizaram o algoritmo $k \mathrm{NN}$, foi considerado $k$ vizinhos igual a 3 . 
88

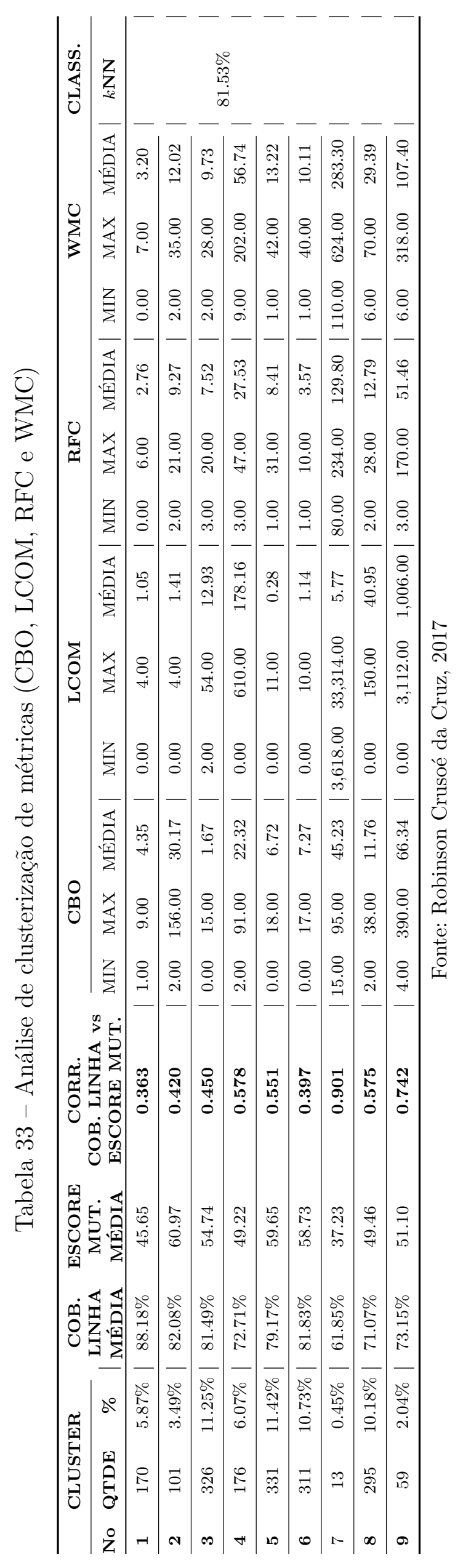


Clusterizando CBO: a respeito da métrica CBO, a Tabela 34 mostra que existe um padrão, porque quanto maior a média de CBO menor a cobertura de linha de código, com exceção do cluster 5 , que tem alta média de CBO e uma cobertura de linha menor do que o cluster 3. Uma classe com alto CBO pode ser importante dentro do contexto e talvez prioritária na geração dos testes em tempo de desenvolvimento. Porém, o cluster 5 possui apenas 2,30\% das classes analizadas, indicando que este tipo de classe não é muito comum dentro do contexto dos softwares analisados. Ao validar o resultado da clusterização de CBO com $k \mathrm{NN}$, o nível de acurácia foi de 100,00\%. A Figura 14 mostra a distribuição dos valores da métrica CBO nos cinco clusters e a Figura 15 mostra a distribuição da cobertura de linha em cada cluster.

Figura 14 - Distribuição dos valores da métrica CBO nos clusters

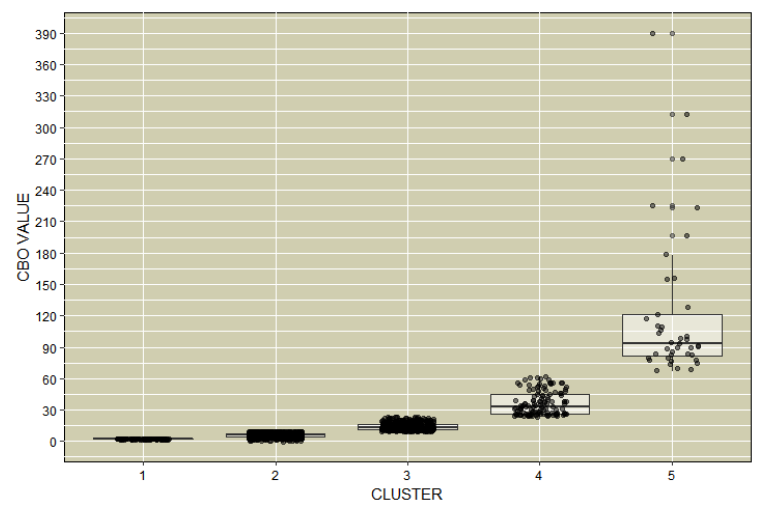

Fonte: Robinson Crusoé da Cruz, 2017

Figura 15 - Distribuição da cobertura de linha em cada cluster CBO

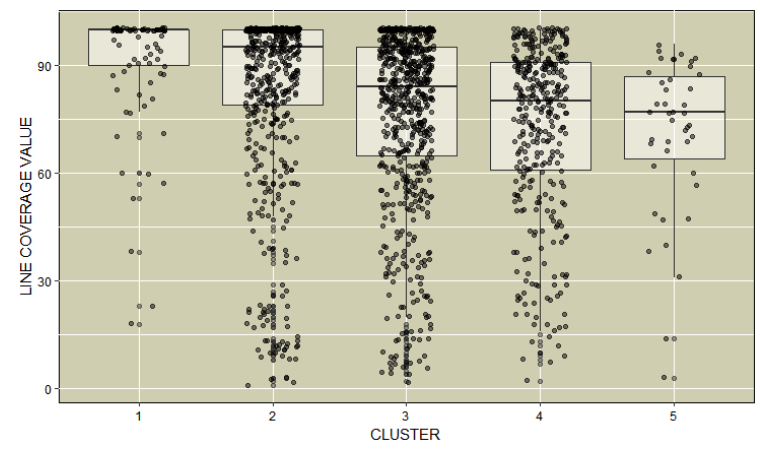

Fonte: Robinson Crusoé da Cruz, 2017 


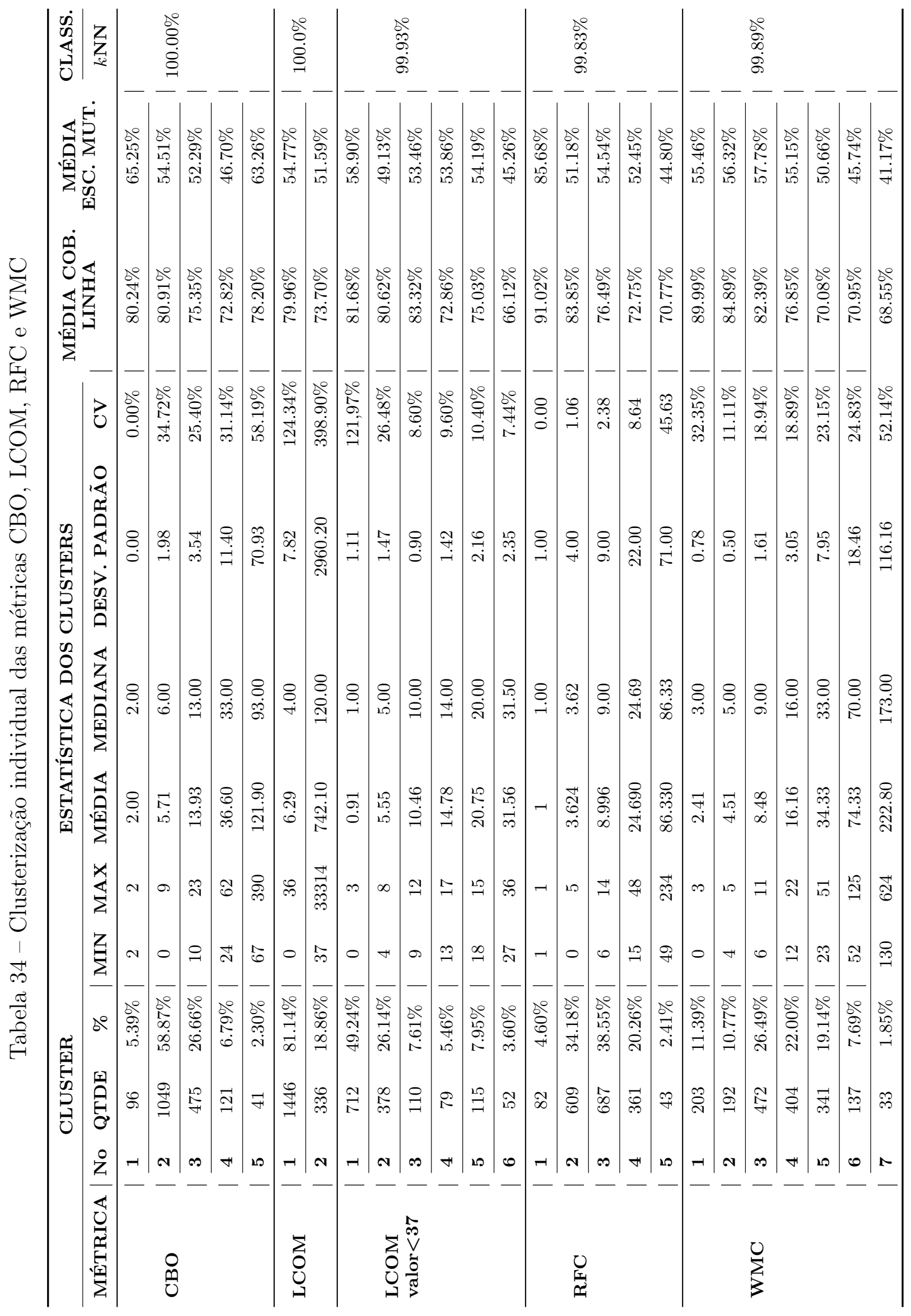


Clusterizando LCOM: a respeito da métrica LCOM (com 6 clusters), somente as classes sem outliers $(L C O M<37)$ foram analisadas. A Tabela 34 mostra que dentre as métricas analisadas individualmente, foi a que obteve o pior padrão entre a média e a cobertura de linha. A importância da métricas foi identificada com este mesmo padrão conforme apresentado na Seção 4.2.3. Contudo, é possível notar o intervalo de valores e sua associação com as medidas de qualidade de teste. Na validação dos resultados dos clusters com algoritmo $k \mathrm{NN}$, o nível de acurácia foi de 99,93\%. A Figura 16 mostra a distribuição dos valores da métrica LCOM nos seis clusters e a Figura 17 mostra a distribuição da cobertura de linha em cada cluster.

Figura 16 - Distribuição dos valores da métrica LCOM nos clusters

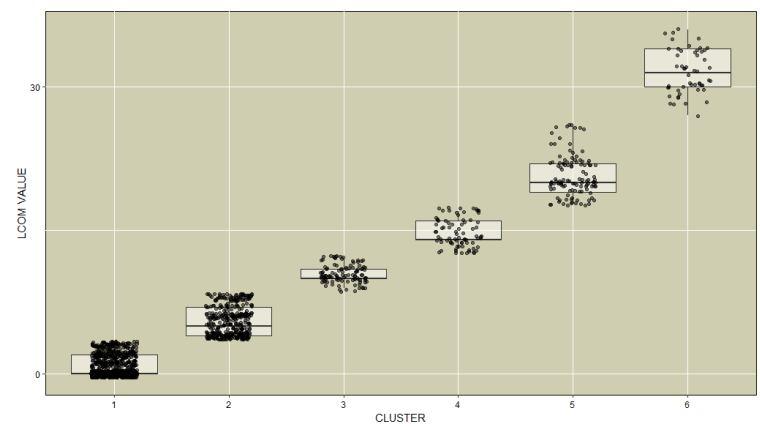

Fonte: Robinson Crusoé da Cruz, 2017

Figura 17 - Distribuição da cobertura de linha em cada cluster LCOM

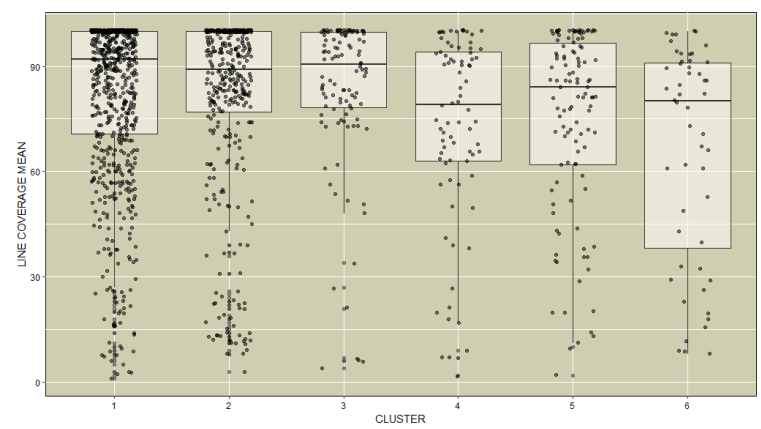

Fonte: Robinson Crusoé da Cruz, 2017

Clusterizando RFC: nos resultados da métrica RFC, a Tabela 34 mostra que existe um padrão, porque quando maior a média de RFC menor a cobertura de linha. Isto pode ser explicado, pois, um alto valor de RFC indica que existe uma maior quantidade de chamadas de métodos internos e externos na classe, então o esforço de teste pode aumentar consideravelmente e levar a uma baixa cobertura das medidas de teste. Ao validar os valores de RFC com algoritmo $k \mathrm{NN}$, o nível de acurácia foi de 99,93\%. A Figura 18 mostra a distribuição dos valores da métrica RFC em cada cluster e a Figura 19 mostra a 
distribuição dos valores da cobertura de linha em cada cluster. Note que a quantidade de cluster nas métricas RFC e CBO é a mesma (cinco clusters). Este resultado pode estar relacionado ao fato que as duas métricas são fortemente relacionadas.

Figura 18 - Distribuição dos valores da métrica RFC nos clusters

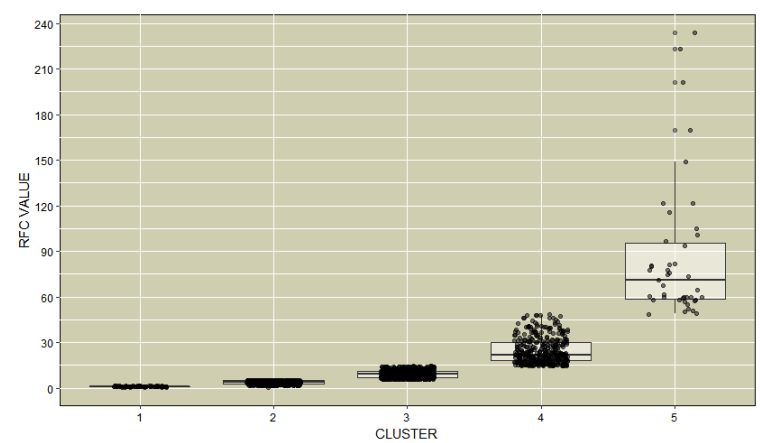

Fonte: Robinson Crusoé da Cruz, 2017

Figura 19 - Distribuição da cobertura de linha em cada cluster RFC

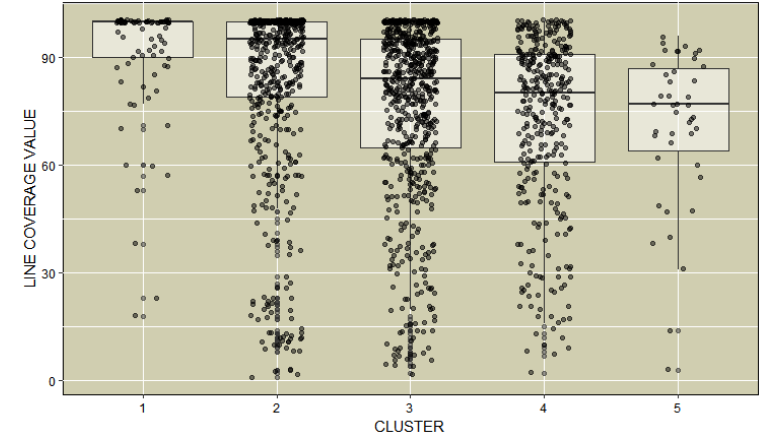

Fonte: Robinson Crusoé da Cruz, 2017

Clusterizando WMC: a respeito da métrica WMC, a Tabela 34 mostra que quando maior a média de WMC, menor a cobertura de linha. Este resultado era esperado, pois quanto maior a complexidade maior o esforço necessário nos testes. Ao validar os clusters com algoritmo $k \mathrm{NN}$, foi obtido um nível de acurácia de 99,89 \%. A Figura 20 mostra a distribuição dos valores de WMC nos cinco clusters e a Figura 21 mostra a distribuição da cobertura de linha em cada cluster. 
Figura 20 - Distribuição dos valores da métrica WMC nos clusters

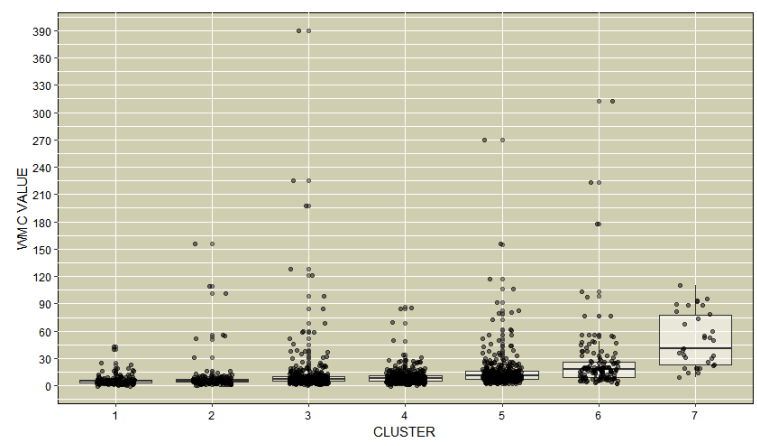

Fonte: Robinson Crusoé da Cruz, 2017

Figura 21 - Distribuição da cobertura de linha em cada cluster WMC

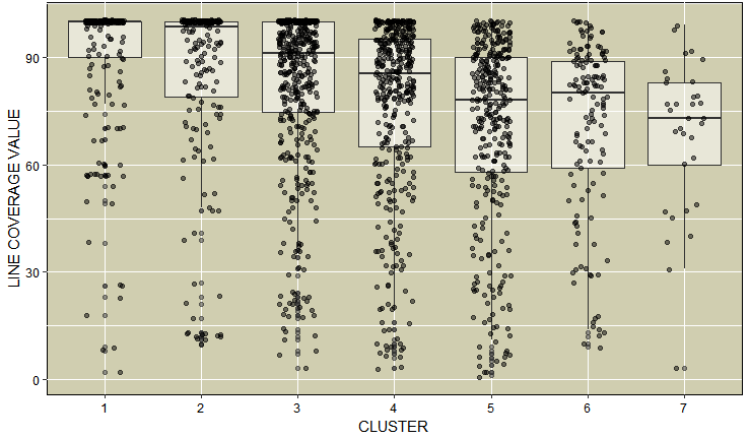

Fonte: Robinson Crusoé da Cruz, 2017

Análise dos Clusters: a Figura 22 mostra a análise da média da cobertura de linha de acordo com cada cluster criado pra cada métrica. O primeiro cluster contém uma média menor, enquanto os clusters seguintes contém uma média mais alta. Nota-se que, em geral, uma maior média da métrica implica em uma menor cobertura de linha. Porém, existem algumas exceções. No cluster 5 da métrica CBO, por exemplo, a cobertura cresce. Isto pode ser explicado pelo fato que CBO é calculado usando duas medidas: o número de classes externas que a classe utilizou (FOUT) e o número de classes que utilizaram a classe (FIN). Então, uma classe com alto CBO pode indicar que a mesma esteja sendo utilizada por muitas classes, indicando que a mesma é importante no contexto do software, sugerindo uma concentração maior de testes nesta classe. O mesmo padrão pode ser observado quando é analisado o escore de mutação, como mostra a Figura 23. 
Figura 22 - Média de cobertura de linha x cluster

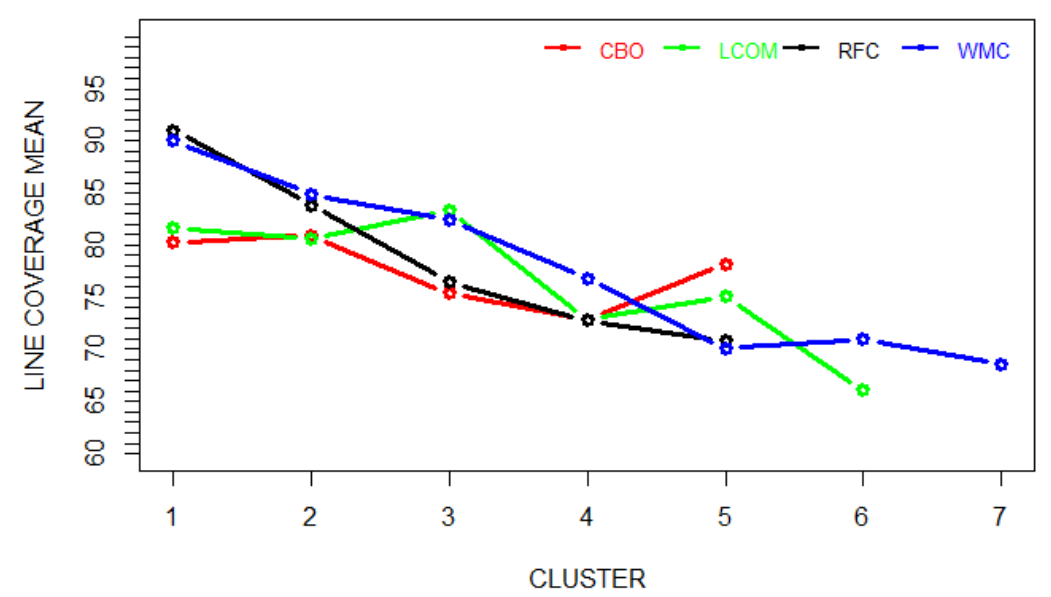

Fonte: Robinson Crusoé da Cruz, 2017

Figura 23 - Média de escore de mutação x cluster

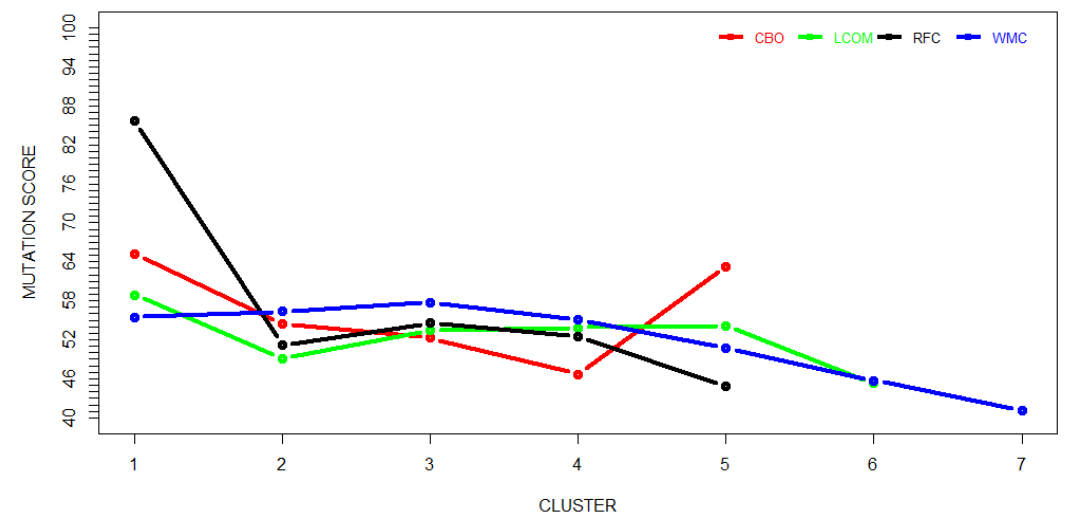

Fonte: Robinson Crusoé da Cruz, 2017

\subsubsection{Discussão dos resultados}

Os resultados dos experimentos apresentados neste seção, mostraram que é possível classificar as métricas em clusters utilizado o Algoritmo EM. Os resultados apresentados aqui podem auxiliar a identificar qual a classe de métricas que resulta em melhores conjuntos de testes. Ao analisar as métricas individualmente, foi possível notar um padrão que indica que quanto maior a média do cluster, menor a cobertura do código e o resultado da escore da mutação. Baseado nesta análise e nos fatos presentes na literatura, foi possível elaborar algumas análises e recomendações: 
- não é possível clusterizar as métricas DIT e NOC. Este resultado está relacionado aos seus valores, pois classe possuem valores similares, sendo impossível tentar clusterizar em mais de um cluster;

- nos resultados da métrica WMC, foi possível obter um grande número de clusters e os resultados indicam que quanto maior a média de WMC, menor a testabilidade;

- os resultados da utilização do algoritmo de classificação $k \mathrm{NN}$ indica que é possível utilizá-lo em futuros trabalhos para classificar uma classe desconhecida e determinar com que precisão ela pode ser classificada como pertencente a um dos clusters, de acordo com suas características;

- na literatura, autores e pesquisadores citam que a métrica CBO pode influenciar na qualidade do código e na testabilidade, entretanto, os resultados indicam que esta métrica deve ser analisada em duas partes (FOUT e FIN), pois representam os dois caminhos de medida de CBO. Ao analisar o grau de testabilidade de uma classe, não seria necessário considerar se esta classe foi utilizada por outras classes e sim o que ela utiliza de outras classes;

- os resultados da métrica RFC mostraram que existe um padrão interessante, pois quanto maior a média, menor a cobertura dos testes. Este resultado pode estar relacionado com a complexidade, pois RFC tem um alto relacionamento com WMC. Então, na fase de desenvolvimento seria importante considerar se o método faz parte do contexto da classe e se existe a possibilidade de unificar métodos.

\subsection{Recomendações práticas}

Com base nos resultados deste capítulo, nos trabalhos relacionados e nos fatos presentes na literatura, foram elaboradas recomendações para os desenvolvedores de software e arquitetos para auxiliar a projetar softwares com uma maior testabilidade:

- CBO: Com citado por outros autores na literatura, é importante organizar o código para manter o projeto menos acoplado. O alto acoplamento pode levar a unidades mais complexas e a necessidade de uma quantidade maior de teste de integração. Isto pode resultar em casos de teste pobres, principalmente dependendo do tempo disponível para as atividades de teste. Então, quanto maior o acoplamento, menor a cobertura da linha e eficácia do teste. 
- LCOM: separação adequada das classes de acordo com sua finalidade e responsabilidade ajuda a criar classes com alta coesão, e classe com alta coesão resulta em melhores projetos e uma maior testabilidade das classes.

- RFC: os desenvolvedores devem organizar o código dos métodos e considerar se existe a necessidade de chamadas externas, uma vez que isto leva a mais acoplamento no projeto. Os resultados demonstraram que uma quantidade maior de RFC aumenta o esforço e a qualidade dos testes. Então, seria importante o desenvolvedor analisar a possibilidade de mesclar os métodos das classes de acordo com padrões de refatoração para que possa diminuir a quantidade de chamadas entre métodos.

- WMC: escrever códigos mais simples e investir em refatoração para obter métodos mais simples. Desenvolvedores e testadores experientes sabem que classes com lógica complexa são mais difíceis de testar. Estudos recentes foram conduzidos para quantificar a influência das características dos programas na atividade de testes e os resultados indicam quem quanto mais complexo o método, menor a cobertura de branches (CASTRO; JR; ELER, 2016).

\subsection{Considerações finais}

As fases apresentadas neste capítulo foram importantes para identificar o impacto das medidas das métricas na testabilidade. Em relação a fase da pesquisa apresentada na Seção 4.2, foi realizada uma análise da correlação entre as métricas CK e as medidas de teste. Os resultados foram importantes para comparar os resultados com algumas pesquisas analisadas na Revisão Sistemática. Com relação às métricas DIT e NOC, os resultados indicam que as mesmas podem ser descartas na análise de correlação, entretanto relacionado ao planejamento é necessário considerá-las. Por exemplo, se uma classe possui

filhos $N O C \geq 1$, seria importante iniciar os testes por ela, por outro lado, se uma classe possui $D I T \geq 1$ é aconselhável que seus ancestrais sejam testados antes de iniciar os testes na classe analisada. Em relação às métrica CBO, LCOM, RFC e WMC os resultados indicam que suas medidas influenciam no esforço e na qualidade da testabilidade.

Os resultados encontrados na segunda fase da pesquisa apresentada na Seção 4.3 foram importantes para definir um padrão das métricas relacionado a qualidade dos testes. Inicialmente os resultados indicam que é possível clusterizar as métricas CBO, LCOM, 
RFC e WMC individualmente e classificar conforme o seu nível de testabilidade relacionado a cobertura de linha de código. Os resultados indicaram que CBO precisa ser dividida em FIN e FOUT durante a análise de testabilidade. Contudo, por mais que possa existir uma diferença entre outros softwares a serem analisados, a clusterização pode ser um caminho importante para analisar as características de grupos de classes.

Os resultados apresentados neste Capítulo motivaram o desenvolvimento de uma ferramenta para coleta, análise e clusterização de métricas CK. Esta ferramenta é apresentada no próximo capítulo. 


\section{MineMetrics - Ferramenta de coleta de métricas, análise estatística e clus- terização}

Neste Capítulo é apresentada a ferramenta de coleta de métricas, análise estatística e clusterização de métricas desenvolvida para apoiar desenvolvedores e projetistas no desenvolvimento de software, com foco em identificar classes pouco testáveis no contexto do software em desenvolvimento. Inicialmente, é realizada uma breve apresentação das ferramentas correlatas que foram utilizadas ou testadas durante o ciclo de vida deste projeto de pesquisa. Em seguida, é apresentada uma visão geral do ambiente e arquitetura de desenvolvimento da ferramenta proposta, as principais funcionalidades e as informações sobre os testes da ferramenta. Por fim, são apresentadas as considerações finais deste capítulo.

\subsection{Ferramentas correlatas}

Nesta seção são apresentadas as ferramentas correlatas que realizam a coleta e análise das métricas CK e cobertura de teste. O objetivo principal aqui é disponibilizar informações sobre as ferramentas que foram testadas ou analisadas na execução deste projeto de pesquisa (Capítulo 4), que serviram como base o desenvolvimento da ferramenta de apoio proposta.

\subsubsection{JHawk}

A ferramenta $\mathrm{JHawk}^{1}$ realiza a coleta de métricas CK de software desenvolvidos na linguagem Java por meio da análise dos arquivos de extensão (.java). Esta ferramenta é paga, entretanto existe a possibilidade de utilizar uma versão de demonstração por 30 dias. A Figura 24 representa a tela de coleta de métricas da ferramenta.

1 http://www.virtualmachinery.com 
Figura 24 - JHawk - Ferramenta de coleta de métricas CK

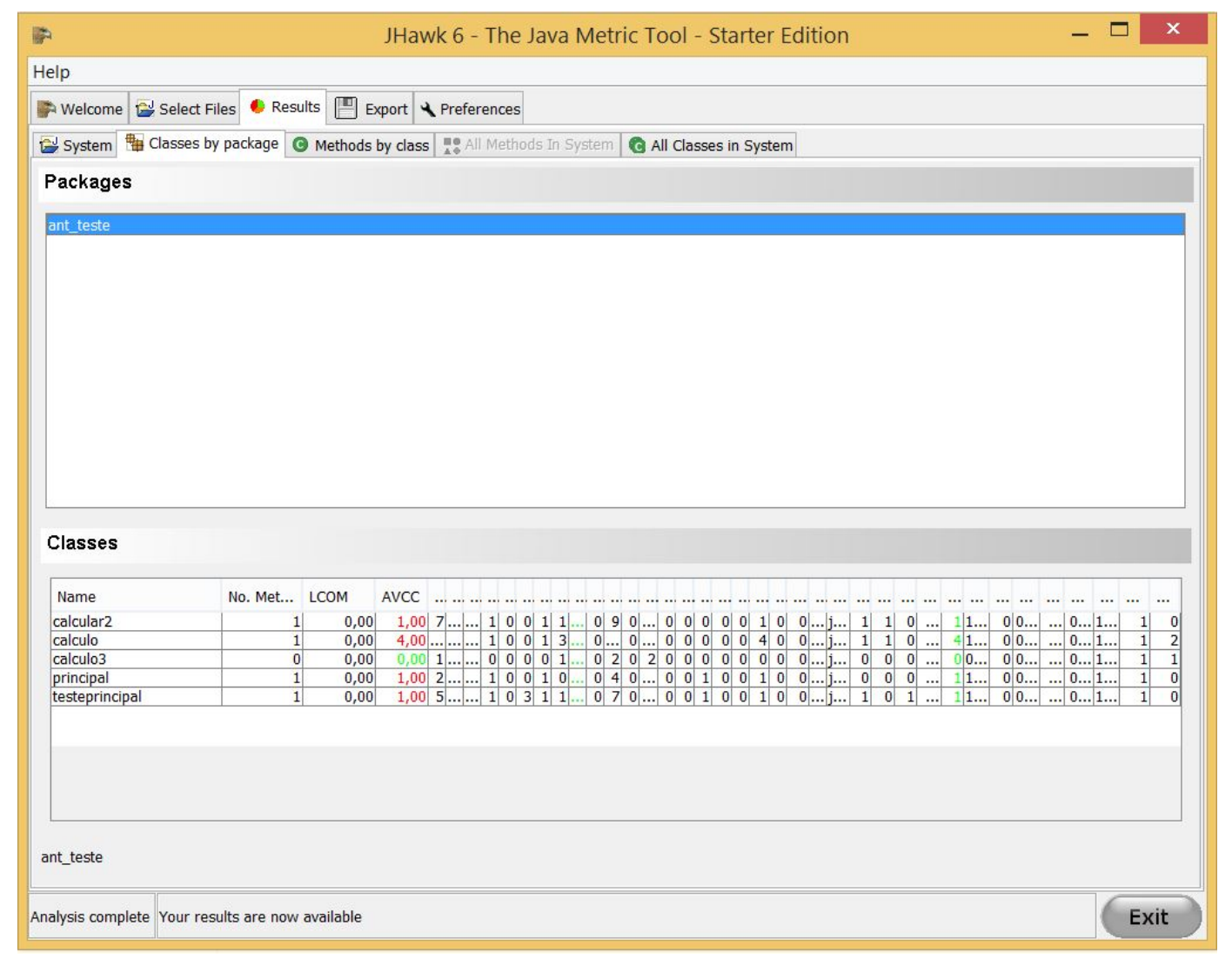

Fonte: JHawk, 2017

As vantagens que foram identificadas na ferramenta são: i) existe a possibilidade de coleta de várias métricas além das métricas CK; ii) existe a possibilidade de coleta das métricas no nível de método, classe, software e pacote; iv) coleta das métricas por meio dos arquivos de extensão (.java), sem a necessidade de utilizar uma IDE e puglins na coleta de métricas. As desvantagens da ferramenta estão relacionadas a sua interface pouco intuitiva e pelo erro citado na Seção 3.7.

\subsubsection{Eclipse Metrics Plugin}

Esta ferramenta disponibiliza a coleta de métricas CK por meio da utilização da IDE Eclipse. Este plugin foi utilizado durante a pesquisa para comparar as métricas coletadas pelas ferramenta JHawk. As desvantagens desta ferramenta estão relacionadas à necessidade de utilizar uma IDE para coletar as métricas e por não realizar a análise da métrica RFC. A Figura 25 representa a tela de coleta de métricas da ferramenta. 
Figura 25 - Eclipse Metrics - Plugin de coleta de métricas CK

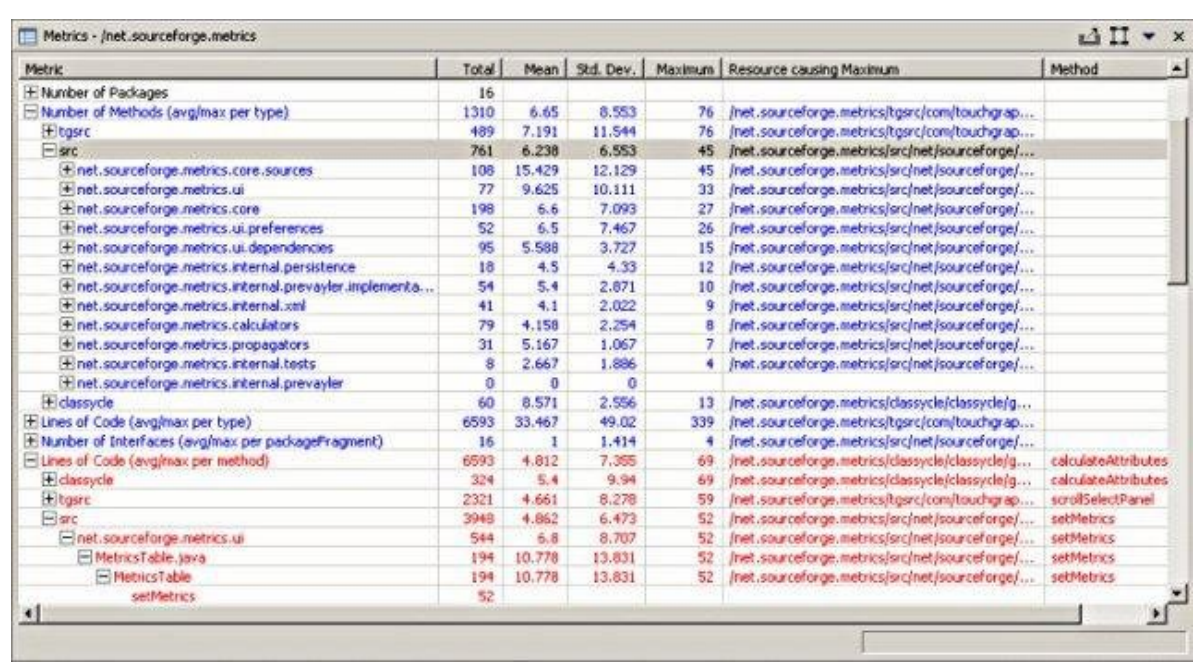

Fonte: Eclipse Metrics, 2017

\subsubsection{SUVSoft}

Esta ferramenta foi o resultado do trabalho de mestrado de Juliano (2014), da Universidade Federal de Uberlândia (UFU). O objetivo principal foi a visualização das métricas CK dos softwares desenvolvidos na plataforma .NET da Microsoft. Uma das vantagens da ferramenta é a possibilidade da coleta das métricas por meio do Assembly gerado pela aplicação, ou seja, sem a necessidade de utilizar uma IDE. A ferramenta possui uma interface intuitiva, principalmente na visualização das métricas.

Figura 26 - SUVSOFT - Uma metáfora do universo para compreensão de programas

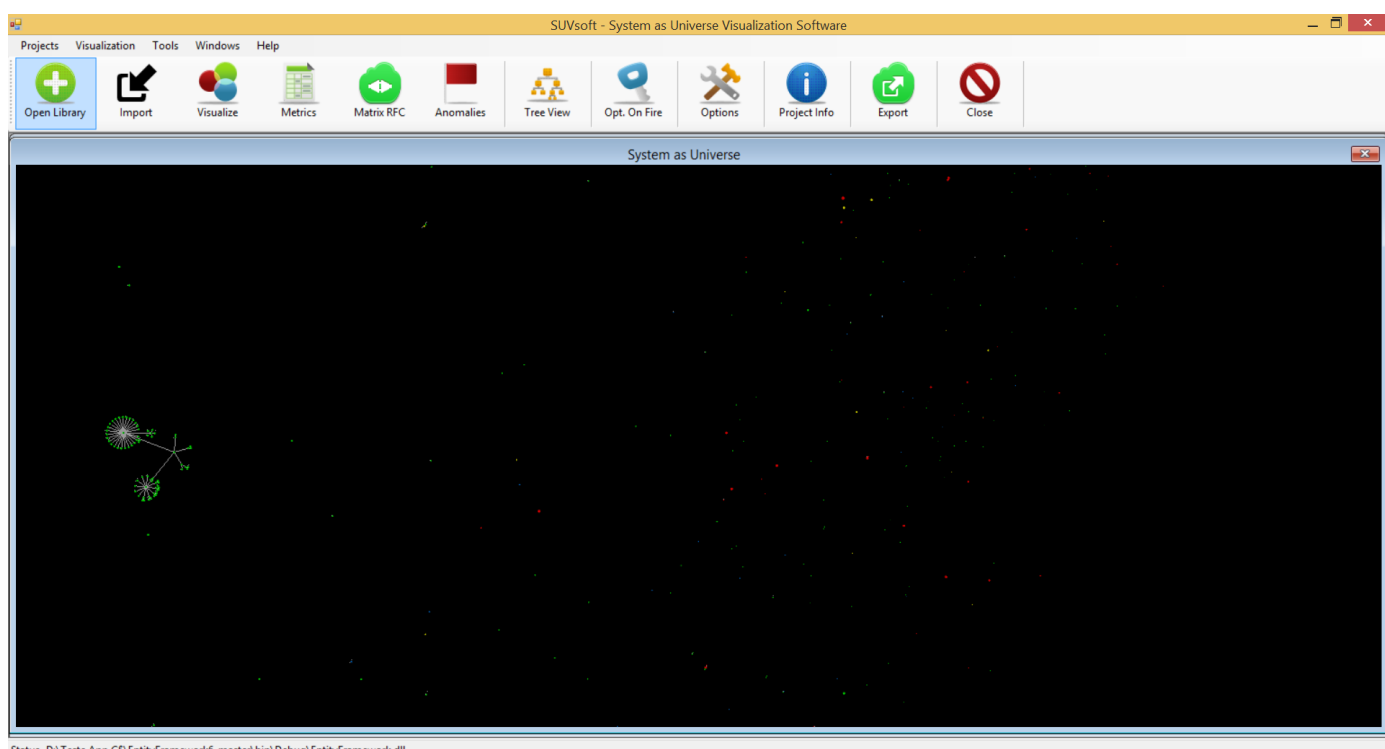

Fonte: (JULIANO, 2014) 


\subsubsection{Artigos de Revisão Sistemática sobre ferramentas}

Além de analisar individualmente algumas ferramentas, foram analisados artigos que tinham como objetivo realizar uma revisão sistemática sobre as ferramentas de coletas de métricas de software orientado a objetos. Entre estes artigos é possível citar (RIBEIRO; REIS; ABELéM, 2015), pois os autores realizaram uma Revisão Sistemática sobre ferramentas de coleta de métricas de software orientado a objetos. Neste trabalho foram identificadas 18 ferramentas de coleta de métricas em que apenas 3\% (Figura 27) realizam coleta de métricas em software desenvolvidos na plataforma .NET da Microsoft. Esta porcentagem representa uma única ferramenta (NDepend), que realiza coleta das métricas CK em software desenvolvidos na plataforma .NET, porém, esta ferramenta não coleta todas as métricas CK. Motiva-se, portanto, a criação de ferramentas para esta plataforma específica.

Figura 27 - Ferramentas de coletas de métricas de software OO

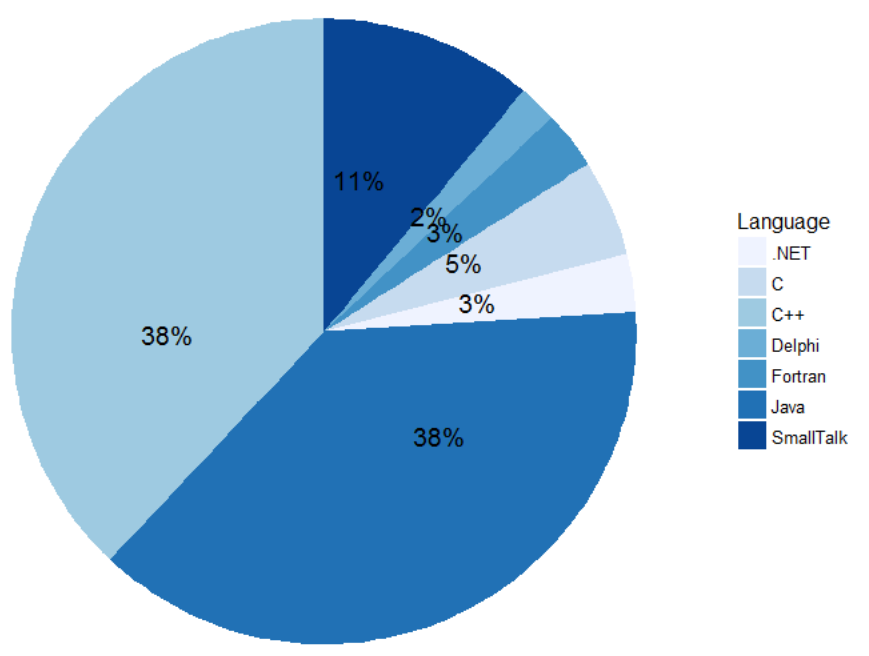

Fonte: (RIBEIRO; REIS; ABELéM, 2015)

5.1.5 Considerações sobre as ferramentas correlatas

Conforme apresentado nesta seção, é notório que existem poucas ferramentas na academia e na indústria de coleta e análise de métricas CK de software desenvolvidos 
na plataforma .NET. Com base neste contexto, foi identificado que é possível contribuir com futuras pesquisas ao desenvolver e disponibilizar gratuitamente uma ferramenta para coleta, análise de métricas e cobertura de teste de software em projetos desenvolvidos na plataforma .NET. Nas seções seguintes, portanto, são apresentadas as informações sobre a estrutura da ferramenta desenvolvida.

\subsection{Ambiente de desenvolvimento}

No desenvolvimento da ferramenta foi utilizado a IDE Visual Studio da Microsoft e o projeto foi desenvolvido com base na arquitetura de aplicativo desktop. A seguir são descritas algumas características do ambiente e da arquitetura de desenvolvimento:

- na coleta das métricas foi utilizado o módulo de coleta de métricas da ferramenta SUVSoft (JULIANO, 2014), com ajustes nos cálculos;

- na coleta de métricas também foram utilizas algumas bibliotecas disponibilizadas pelo projeto MONO, que é um projeto de desenvolvimento de um Framework .NET de código aberto;

- foi utilizada a versão 7.0 da linguagem C\#, porém algumas bibliotecas desenvolvidas em versões anteriores foram utilizadas;

- Nos cálculos propostos pela ferramenta, foi utilizado o Framework Accord (SOUZA, 2012).

\subsection{Funcionalidades}

Nesta seção, são apresentados as principais funcionalidades desenvolvidas na ferramenta. O objetivo é realizar uma breve explicação das 3 principais funcionalidades e suas principais características

\subsubsection{Coleta e importação de métricas}

A importação das métricas pela ferramenta MineMetrics pode ser realizada pela extração das Métricas dos Assemblys (DLLs) ou com a importação de dados de arquivos 
CSV. Nesta segunda opção é possível analisar dados coletados de outras linguagens de programação. A Figura 28 representa a funcionalidade de coleta de métricas.

Figura 28 - MineMetrics - Tela de coleta de métricas

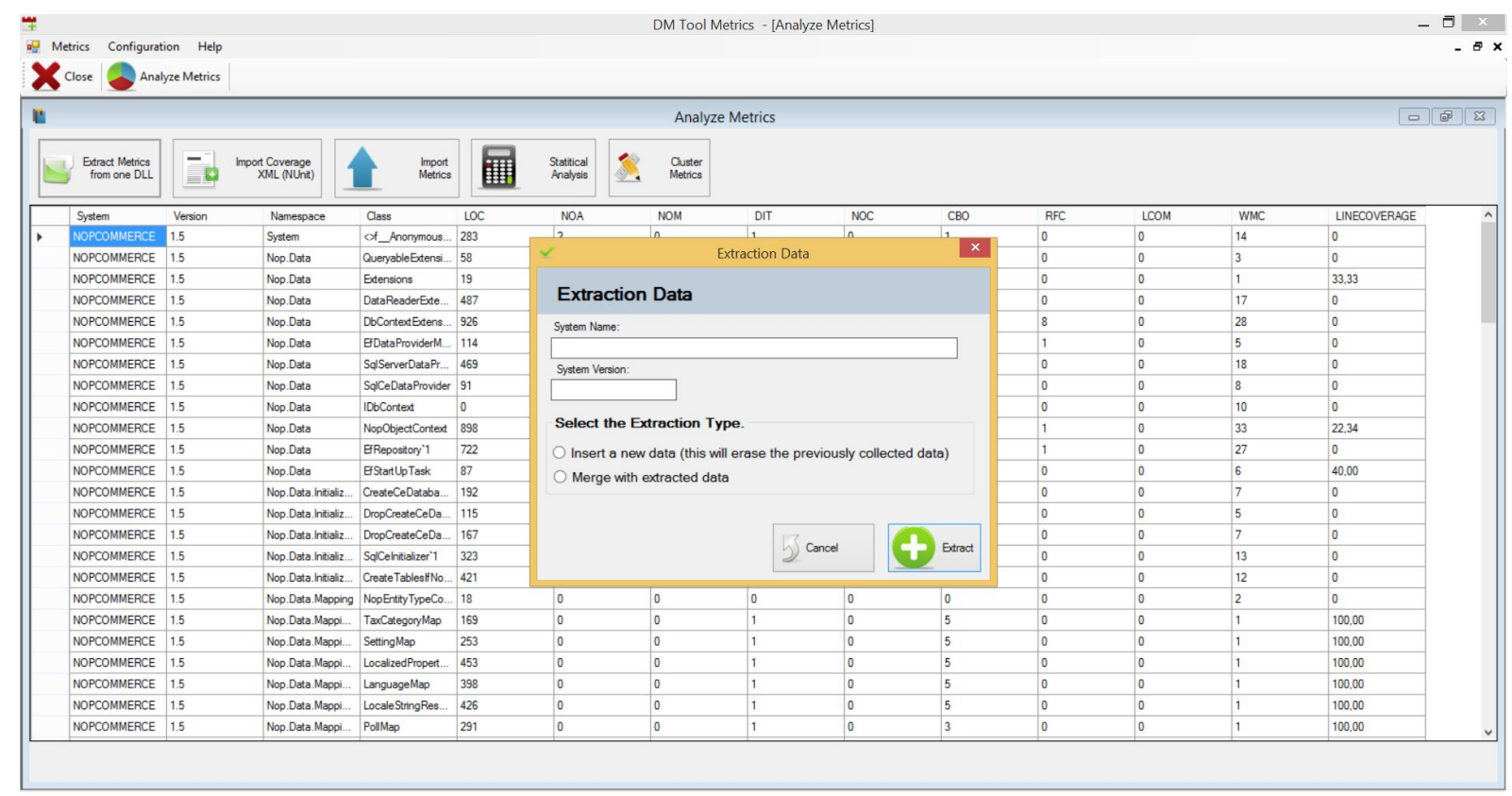

Fonte: Robinson Crusoé da Cruz, 2017

As principais funcionalidades da tela de coleta de métricas são as seguintes:

- Importação da cobertura de linha de código gerada pela ferramenta nUnit $^{2}$ : Nesta opção é possível importar o arquivo XML com informações da cobertura de teste gerados pela ferramenta nUnit. Ao importar os dados é realizada uma junção entre cada classe coletada e a cobertura de linha de código.

- Exportar as métricas coletadas para arquivos CSV: Nesta opção é possível exportar as métricas coletadas para arquivo CSV. O objetivo desta funcionalidade é fornecer uma opção para que os dados sejam utilizados em outras ferramentas.

- Importar as Métricas de arquivo CSV: Nesta opção é possível importar as métricas que estejam em arquivos CSV. A vantagem desta opção é a disponibilidade de analisar outras métricas além da métricas CK.

- Merge na importação da métricas dos Assemblys: Um mesmo projeto pode ser dividido em vários Assemblys, então, é possível realizar uma união das métricas coletadas de vários Assemblys para que seja realizada uma única análise. Outra característica é a possibilidade de coleta de softwares diferentes.

$\overline{2}$ Ferramenta de execução de teste unitário para plataforma .NET 


\subsubsection{Análise estatística}

A Figura 29 representa a funcionalidade de análise estatística. O objetivo foi disponibilizar informações estatísticas que possam auxiliar na análise das métricas coletadas. Os resultados apresentados pela Figura 29 mostram a análise da correlação entre a métricas WMC e LINE COVERAGE do software NOPCOMMERCE ${ }^{3}$.

Figura 29 - MineMetrics - Tela de análise estatística

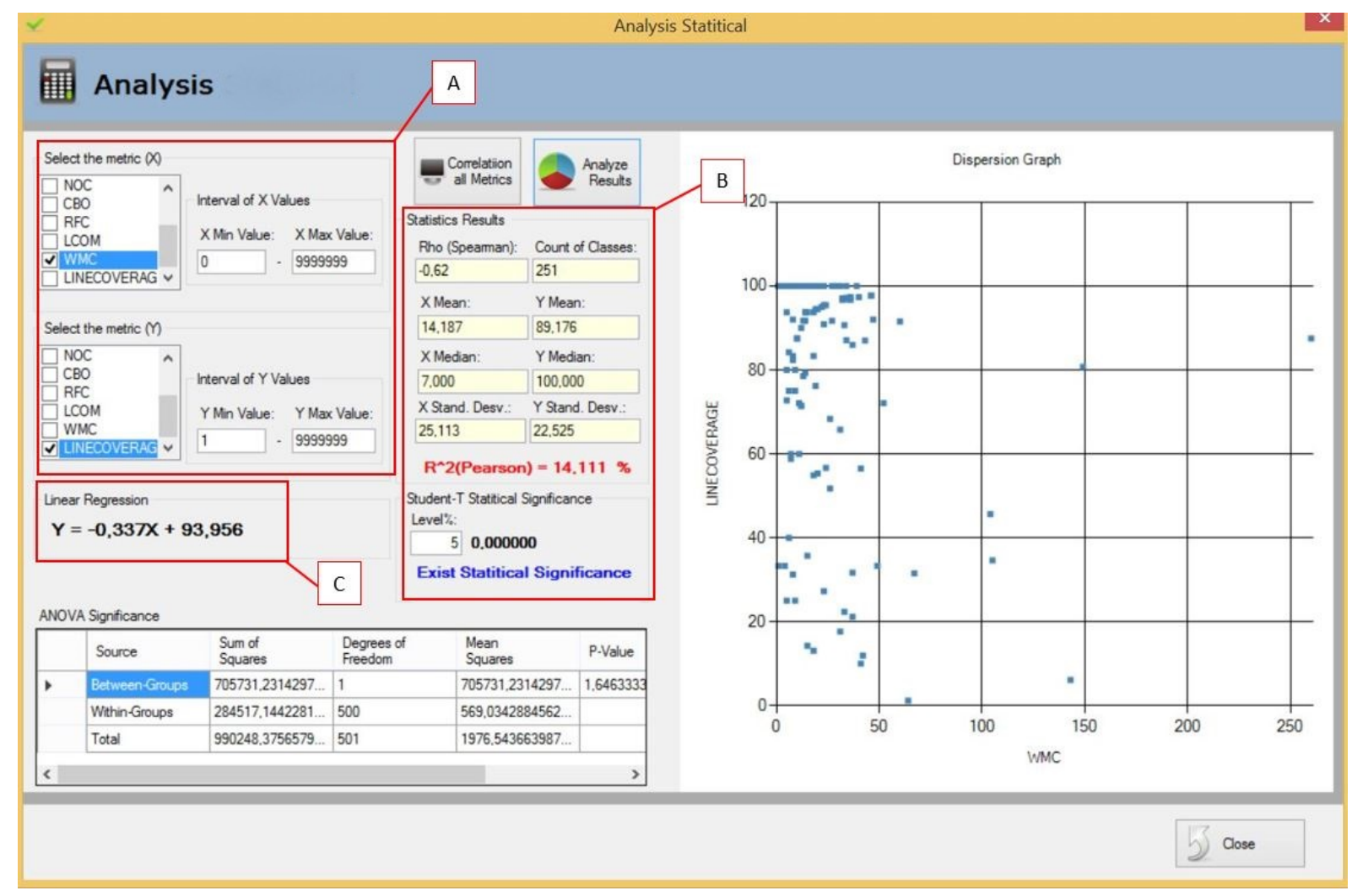

Fonte: Robinson Crusoé da Cruz, 2017

As principais caracterísitcas da análise estatísticas são as seguintes:

- Análise da correlação: Por meio do item A da Figura 29 é possível definir as variáveis $X$ e $Y$ para análise da correlação, além disso, é possível definir o intervalo de valores que deseja analisar.

- Resultados Estatísticos: Por meio do item B representado da Figura 29 é possível analisar os seguintes resultados estatísticos: Valor de $\rho$ da correlação de Spearman, Quantidade de Classes analisadas, Médias, Mediana Desvio padrão, valor $r^{2}$ da

3 Software Open Source desenvolvido na plataforma .NET utilizando a linguagem C\# e disponível em: www.nopcommerce.com 
correlação de pearson que define o quanto a variável $X$ pode explicar os dados da variável $Y$ e por último é possível de definir e analisar a significância estatística $(\alpha)$.

- Regressão Linear: Por meio do item C representado pela Figura 29, é possível analisar o cálculo da Regressão Linear.

- Análise de Correlação: É possível analisar a correlação e se existe significância entre todas as métricas coletadas. A Figura 30 representa a análise das métricas coletadas do Software NOPCOMMERCE.

Figura 30 - MineMetrics - Análise de correlação

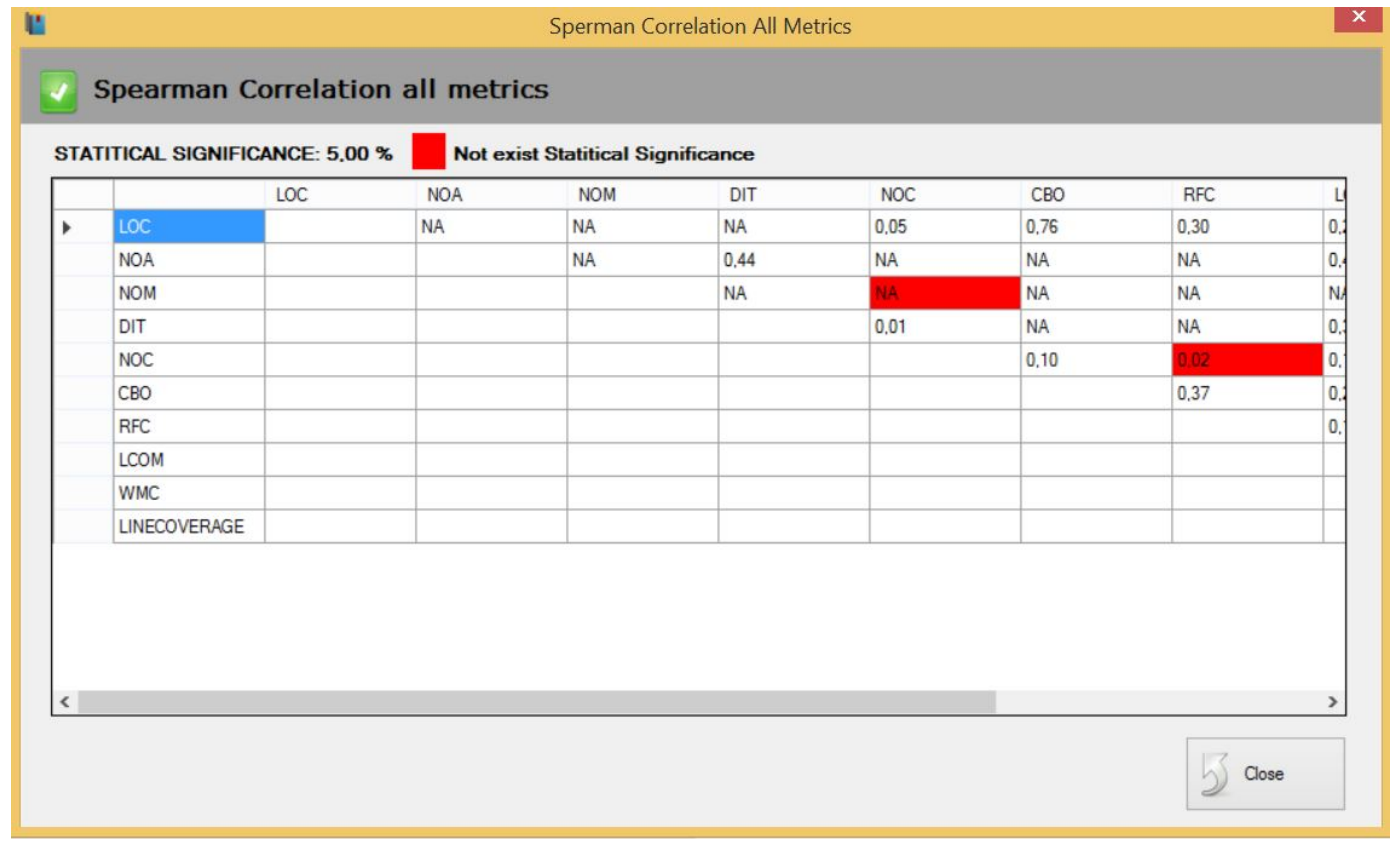

Fonte: Robinson Crusoé da Cruz, 2017

\subsubsection{Clusterização}

A Figura 31 representa a funcionalidade de clusterização das métricas coletadas pela ferramenta. O objetivo foi disponibilizar opções de clusterização das métricas para auxiliar na análise de classes que possuem características idênticas, conforme proposta apresentada na Seção 4.2.

As principais características desta funcionalidade são as seguintes:

- Definindo os atributos dos clusters: por meio desta característica é possível utilizar de 1 a $N$ métricas para realizar a clusterização e análise dos resultados. 
Figura 31 - MineMetrics - Clusterização das métricas

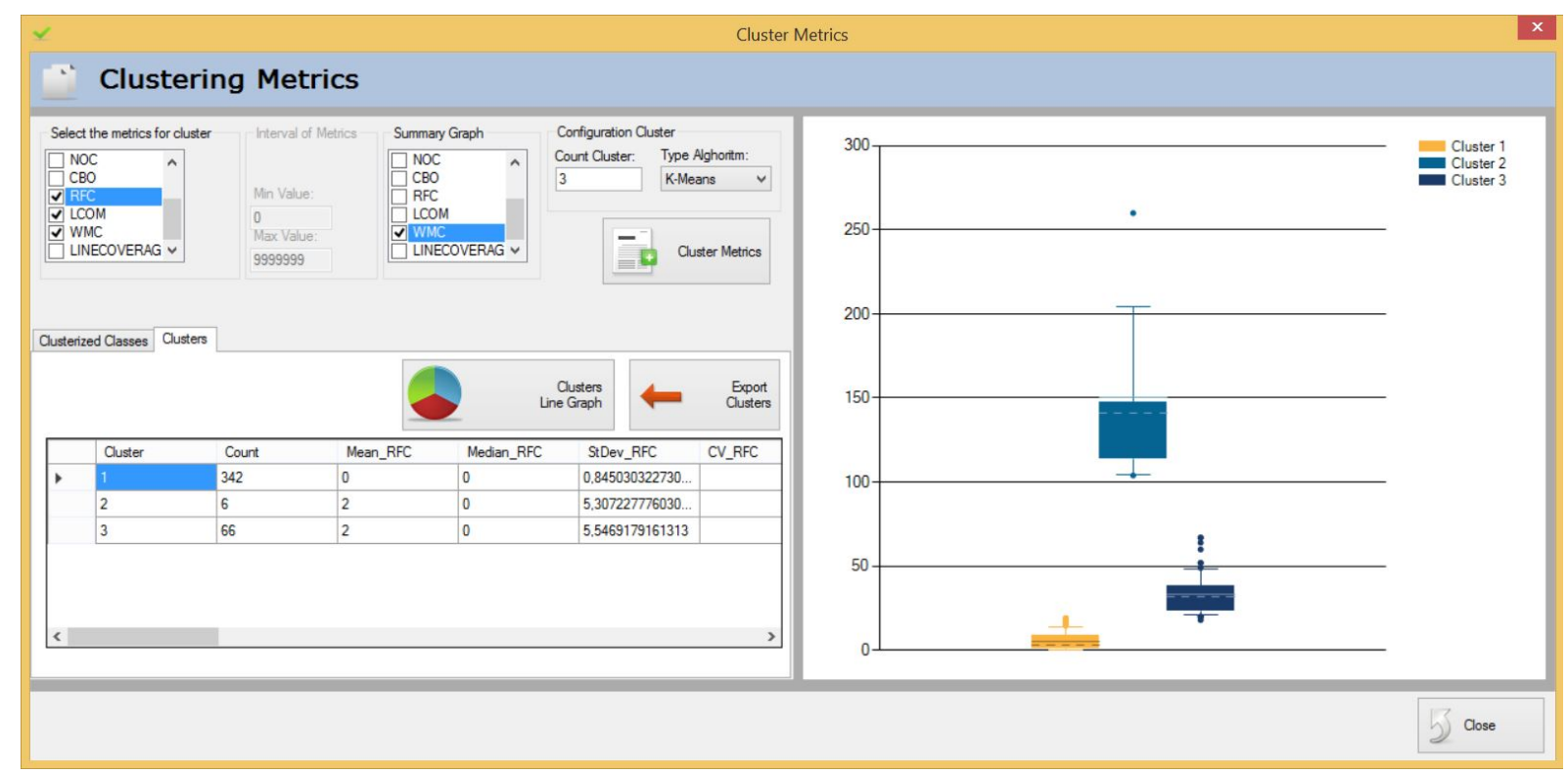

Fonte: Robinson Crusoé da Cruz, 2017

- Exportação dos resultados: por maio desta característica é possível exportar os resultados da clusterização das métricas para arquivos CSV.

- Gráfico de sumarização: por meio desta característica é possível definir qual métrica será sumarizada na plotagem do gráfico e na tabela de resultados. O objetivo é proporcionar uma opção para analisar as características de uma determinada métrica em cada grupo de cluster definido pela ferramenta.

\subsection{Validação da ferramenta MineMetrics}

Durante o desenvolvimento da ferramenta, os resultados foram comparados com resultados de outras ferramentas utilizadas no meio acadêmico. Nos testes foram utilizadas as métricas disponibilizadas pelo software NOPCOMMERCE e os resultados foram validados em cada fase do desenvolvimento. Por exemplo, a análise estatística relacionado a média, mediana, desvio padrão, correlação de spearman, correlação de pearson e significância estatística. Todos os resultados foram idênticos aos gerados pela ferramenta RStudio. Em relação a clusterização das métricas, os dados foram exportados e analisados pela ferramenta WEKA, e ao aplicar a classificação com algoritmo de classificação $k \mathrm{NN}$, obteve-se uma acurácia de $100 \%$. 


\subsection{Considerações finais e futuras características na ferramenta MineMetrics}

A ferramenta apresentada neste capítulo foi desenvolvida com objetivo de auxiliar futuras pesquisa que tenham com objetivo analisar métricas CK ou qualquer outro tipo de métrica por meio da funcionalidade de importação de métricas. É notório que a ferramenta necessita de modificações e melhorias, principalmente relacionado a validações e exceções das funcionalidades. Entretanto, no estado atual, a ferramenta pode ser utilizada para coleta, análise e clusterização de métricas, pois os seus resultados foram validados com outras ferramentas utilizadas no meio acadêmico. As funcionalidades disponibilizadas pela ferramenta podem ser utilizadas em outras pesquisas para repetir os estudos empíricos apresentados no Capítulo 4 ou para auxiliar na análise de métricas extraídas por outras ferramentas, por exemplo, extrair dados utilizando o Eclipse Metrics e analisar os resultados.

No futuro, pretende-se desenvolver as seguintes características na ferramenta: i) implementar coleta de outras métricas além das métricas CK; ii) implementar a funcionalidade e enviar as métricas coletadas para um dataset on-line; iii) com base em estudos presentes da literatura, pretende-se desenvolver uma análise das características de testabilidade baseadas na definição de theresholds; iv) implementar a classificação de classes desconhecidas com base nas métricas armazenas para tentar predizer o esforço de teste da classe;

Sobre o dataset, o objetivo principal será organizar uma base de dados estruturados de métricas de software de acordo com tipo de linguagem, tipo de metodologia de desenvolvimento do projeto, cobertura dos testes, domínio da aplicação e outras características que possam auxiliar na análise das características dos softwares desenvolvido no paradigma OO. Então, ao analisar um conjunto de classes desconhecidas com auxilio do algoritmo $k \mathrm{NN}$ será possível classificar e analisar os dados desconhecidos de acordo com os dados armazenados no dataset. Espera-se que este tipo de análise possa fornecer informações que possam auxiliar o desenvolvedor na refatoração e na análise da testabilidade. 


\section{Conclusões}

Neste trabalho foi apresentado um estudo empírico sobre a importância da análise das métricas CK na testabilidade, bem como o desenvolvimento de uma ferramenta para coleta, clusterização e análise estatísticas das métricas CK.

No desenvolvimento foram abordados os conceitos que auxiliaram no entendimento do projeto e uma Revisão Sistemática para analisar como estava o estado da arte da proposta deste trabalho. Após o desenvolvimento da Revisão Sistemática foi possível identificar que existiam possibilidades de novas pesquisas, principalmente relacionada a análise da qualidade dos testes. Neste mesmo capítulo, foi apresentada uma análise das lacunas encontradas nas ferramentas e trabalhos analisados, com objetivo de contribuir com novas pesquisas e com desenvolvimento deste trabalho.

No Capítulo 4 foram apresentadas duas fases da pesquisa que foram importantes para analisar a relação das métricas CK com a qualidade dos testes e a possibilidade de clusterização das métricas para identificar características semelhantes relacionadas ao esforço dos testes. Após os resultados das análises empíricas no Capítulo 4, foi apresentada no Capítulo 5 a ferramenta de coleta e análise de métricas. Esta ferramenta foi desenvolvida com objetivo de auxiliar no desenvolvimento de novas pesquisas, principalmente pesquisas que tenham um caminho idêntico apresentado neste trabalho.

Acredita-se que os resultados deste Projeto de Mestrado possam contribuir com a pesquisa relacionada à testabilidade de software orientado a objetos, principalmente relacionado a análise das métricas CK. Espera-se que a disponibilização da ferramenta possa ser útil para auxiliar desenvolvedores na compreensão da estrutura de produtos de software relacionado à testabilidade, servindo como base para avaliação e consequentemente refatoração das classes desenvolvidas, levando o software a ter uma arquitetura e estrutura mais testável, o que pode reduzir significativamente o esforço de teste.

\subsection{Limitações}

Durante o desenvolvimento do projeto foram identificadas algumas limitações da pesquisa, entretanto, o que se esperava do trabalho foi atingido no que se refere a contribuir 
com a pesquisa relacionada à testabilidade com base na correlação entre métricas CK e medidas de qualidade dos testes do software analisado. Entre as limitações é possível citar:

- o número de aplicações analisadas não é estatisticamente significativo e os aplicativos podem não ser representativos. Contudo, selecionamos quatro softwares porque foram analisados em trabalhos relacionados, portanto, com a análise desses softwares foi possível comparar os resultados deste trabalho com trabalhos relacionados;

- Não é possível saber como os casos de teste foram gerados, o que significa que não temos certeza se os desenvolvedores não quiseram alcançar uma alta cobertura de código. No entanto, os softwares analisados possuem uma alta cobertura de código;

- na análise de clusterização das métricas apresentadas na Seção 4.3, o intervalo de valores de cada métrica em cada cluster pode ser diferente de outros softwares. No entanto, o objetivo foi mostrar que a análise de cluster pode ajudar a entender qual classe de métricas possui uma melhor testabilidade.

\subsection{Trabalhos futuros}

Com base nos resultados e na perspectiva de melhorarias no projeto é possível destacar os seguintes trabalhos futuros:

- analisar se as métricas CK ou outras métricas podem auxiliar na otimização da geração de mutantes. Durante a pesquisa foi identificado que existe um grande esforço computacional para geração de mutantes, pois vários são os operadores utilizados, resultando e um grande número de mutantes. Entretanto, foi identificado que vários mutantes convergem para o mesmo resultado. Então, baseado nesta percepção, espera-se em um trabalho futuro analisar se é possível inferir as medidas das métricas no nível de métodos para tentar definir quais operadores podem ser desabilitados ou habilitados sem prejudicar a efetividade da técnica;

- com auxílio da ferramenta, espera-se ser possível conduzir um estudo para realizar a análise das características de testabilidade entre diferentes tipos de software, aplicando análises no tipo de domínio, linguagem de programação e método de desenvolvimento do software;

- conduzir estudo com desenvolvedores para avaliar a ferramenta no que se refere ao seu apoio à avaliação das classes desenvolvidas no contexto do projeto desenvolvido, 
de tal forma que as classes com características diferentes das classes mais testáveis sejam refatoradas se for possível;

- após a conclusão do desenvolvimento da ferramenta, pretende-se realizar um estudo empírico idêntico ao apresentado nas Seções 4.2 e 4.3 em softwares desenvolvidos na plataforma .NET;

- com base nos resultados relacionados a métrica CBO, pretende-se no futuro desenvolver um estudo relacionado a utilização das métricas FIN e FOUT com a combinação da métrica RFC para tentar definir uma medida que possa auxiliar na análise da testabilidade. A ideia principal é tentar definir um grafo direcionado e um peso para as arestas que serão responsáveis por identificar o grau de ligação entre as classes e como consequência uma análise da influência desta ligação no projeto de software e na testabilidade.

\subsection{Contribuições}

Nesta Seção são descritas pontualmente as principais contribuições deste trabalho de mestrado:

- uma Revisão Sistemática sobre trabalhos que relacionam métricas CK com a testabilidade de um software, conforme apresentada no Capítulo 3. Espera-se, com os resultados apresentados, contribuir com outras pesquisas relacionadas;

- resultados das análises empíricas sobre a correlação de métricas CK e medidas de qualidade dos testes do software. Espera-se que os resultados sirvam como base para novas pesquisas relacionadas ao tema, e também para desenvolvedores e arquitetos entenderem características das classes que levam o software a ser mais ou menos testável;

- resultados do estudo sobre clusterização das métricas CK. Espera-se que os resultados também sejam úteis para novas pesquisas na área, bem como para desenvolvedores e arquitetos na construção de software mais testáveis. O método utilizado para a agrupamento de classes com características semelhantes e que podem levar ao mesmo nível de testabilidade foi utilizado como base na produção da ferramenta de apoio MineMetrics. 
- a ferramenta desenvolvida neste projeto será disponibilizada no padrão free para que seja utilizada em outras pesquisas e como apoio ao desenvolvimento de software .NET. O download da ferramenta poderá ser realizado no website ${ }^{1}$. Atualmente, neste site é possível acessar dados sobre o desenvolvimento deste projeto como, por exemplo, as métricas utilizadas na pesquisa, os artigos publicados e um vídeo com teste da ferramenta desenvolvida.

\subsection{Produção bibliográfica}

Durante o desenvolvimento deste projeto foram publicados dois artigos relacionados aos resultados do Capítulo 4:

- Artigo:An empirical analysis of the correlation between CK metrics, test coverage and mutation score (CRUZ; ELER, 2017a).

Evento: 19th International Conference on Enterprise Information Systems (ICEIS), 2017, Porto - Portugal.

- Artigo:Using a cluster analysis method for grouping classes according to their inferred testability: an investigation of CK metrics, code coverage and mutation score (CRUZ; ELER, 2017b).

Evento: 36th International Conference of the Chilean Computer Science Society (SCCC), 2017, Arica - Chile.

$1 \quad$ http://www.minemetrics.info 


\section{Referências $^{2}$}

ABDULLAH, R. S.; KHAN, M. H. Testability estimation of object oriented design:a revisit. International Jounal of Advanced Research in Computer and Communication Engineering, p. 3086-3090, ago. 2013. ISSN 2319-5940. Citado 5 vezes nas páginas 18, 55, 56,70 e 71 .

ABREU, F. B. e et al. Toward the design quality evaluation of object-oriented software. International Conference on Software Quality, Austin, Texas, EUA,American Society for Quality, p. 44-57, 1995. Citado 4 vezes nas páginas 12, 36, 43 e 66.

AHA, D. W.; KIBLER, D.; ALBERT, M. K. Instance-based learning algorithms. Machine Learning, v. 6, n. 1, p. 37-66, 1991. ISSN 1573-0565. Disponível em: 〈http://dx.doi.org/10.1007/BF00153759〉. Citado na página 49.

BADRI, L.; TOURE, F. An empirical analysis of lack of cohesion metrics for predictiong testability of classes. International Journal of Software Engineering and its Application, Jan 2011. Citado 8 vezes nas páginas 19, 55, 56, 59, 60, 61, 65 e 84 .

BADRI, M.; TOURE, F. Empirical analysis of object-oriented design metrics for predicting unit testing. Journal of Software Engineering and Applications, p. 513-526, 2012. Disponível em: 〈http://www.scoRP.org/jounal/jsea〉. Citado 14 vezes nas páginas $33,55,56,59,60,61,63,64,65,66,67,68,70$ e 84 .

BADRI, M.; TOURE, F.; LAMONTAGNE, L. Predicting unit testing effort levels of classes: An exploratory study based on multinomial logistic regression modeling. Procedia Computer Science, v. 62, p. 529 - 538, 2015. ISSN 1877-0509. Proceedings of the 2015 International Conference on Soft Computing and Software Engineering (SCSE'15). Disponível em: 〈http://www.sciencedirect.com/science/article/pii/S1877050915026630〉. Citado 6 vezes nas páginas 55, 56, 59, 60, 61 e 68 .

BENIWAL, R. Analysis of testing metrics for object oriented applications. Computational Intelligence Communication Technology (CICT), 2015 IEEE International Conference on, p. 41-46, Feb 2015. Citado 2 vezes nas páginas 55 e 69.

BINDER, R. V. Design for testability in object-oriented systems. Commun. ACM, ACM, New York, NY, USA, v. 37, n. 9, p. 87-101, set. 1994. ISSN 0001-0782. Disponível em: $\langle$ http://doi.acm.org/10.1145/182987.184077〉. Citado 8 vezes nas páginas 9, 28, 33, 34, $55,56,69$ e 70 .

BOAS, A. L. de C. V. Gestão de configuracao para teste de software. 30-30 p. Dissertação (Mestrado) - UNICAMP, Campinas, SP, BRA, jul. 2003. Citado na página 28.

BRUNTINK, M.; DEURSEN, A. V. An empirical study into class testability. J. Syst. Softw., Elsevier Science Inc., New York, NY, USA, v. 79, n. 9, p. 1219-1232, set. 2006. ISSN 0164-1212. Disponível em: 〈http://dx.doi.org/10.1016/j.jss.2006.02.036〉. Citado 14 vezes nas páginas $55,56,59,60,61,63,64,65,66,67,68,70,75$ e 84 .

BRUNTINK, M.; DEURSEN, A. van. Predicting class testability using object-oriented metrics. Source Code Analysis and Manipulation, 2004. Fourth IEEE International

2 De acordo com a Associação Brasileira de Normas Técnicas. NBR 6023. 
Workshop on, p. 136-145, Sept 2004. Citado 14 vezes nas páginas 33, 55, 56, 59, 60, 61, $63,64,65,66,67,68,70$ e 84 .

CARVAlHO, C. R. de. Detecção de réplicas de sítios web usando aprendizado semissuperviosionado baseado em maximização de expectativa. Dissertação (Mestrado) Faculdade de Computação da Universidade Federal de Uberlândia, Uberlandia, MG, BR, 2014. Citado na página 48.

CASTRO, C. F. de; JR, D. de S. O.; ELER, M. M. Identifying characteristics of java methods that may influence branch coverage: An exploratory study on open source projects. In: Proceedings of the 35th International Conference of the Chilean Computer Science Society (SCCC 2016). [S.1.]: IEEE, 2016. Citado na página 96.

CHIDAMBER, S. R.; KEMERER, C. F. A metrics suite for object oriented design. IEEE Transactions on Software Engineering, v. 20, n. 6, p. 476-493, Jun 1994. ISSN 0098-5589. Citado 11 vezes nas páginas 19, 37, 38, 39, 40, 41, 42, 52, 54, 56 e 73.

CRUZ, R. C. da; ELER, M. M. An empirical analysis of the correlation between CK metrics, test coverage and mutation score. In: ICEIS 2017 - Proceedings of the 19th International Conference on Enterprise Information Systems, Volume 2, Porto, Portugal, April 26-29, 2017. [s.n.], 2017. p. 341-350. Disponível em: 〈https://doi.org/10.5220/0006312703410350〉. Citado 2 vezes nas páginas 84 e 111.

CRUZ, R. C. da; ELER, M. M. Using a cluster analysis method for grouping classes according to their inferred testability: an investigation of ck metrics, code coverage and mutation score. In: SCCC 2017 - 36th International Conference of the Chilean Computer Science Society, Arica, Chile, Oct 16-18, 2017. [S.l.: s.n.], 2017. Citado na página 111.

DELAMARO, M. E.; MALDONADO, J. C.; JINO, M. Introdução ao teste de software. 2. ed. [S.l.]: CAMPUS - RJ, 2016. v. 1. ISBN 9878535283525. Citado 7 vezes nas páginas 23, $24,25,26,27,28$ e 29.

DEMPSTER, A. P.; LAIRD, N. M.; RUBIN, D. B. Maximum likelihood from incomplete data via the em algorithm. Journal of the royal statistical society, Series B, v. 39, n. 1, p. 1-38, 1977. Citado na página 48.

E., J.; AlEXAnDER, R. T.; HUTCHInSOn, C. D. Design-for-testability for object-oriented software. SIGS Publications, Inc., 1997. Citado na página 68.

ELER, M. M.; ENDO, A. T.; DURELLI, V. H. An empirical study to quantify the characteristics of java programs that may influence symbolic execution from a unit testing perspective. Journal of Systems and Software, v. 121, n. Supplement C, p. 281 - 297, 2016. ISSN 0164-1212. Disponível em: 〈http: //www.sciencedirect.com/science/article/pii/S0164121216000868〉. Citado na página 34.

ELER, M. M.; ENDO, A. T.; DURELLI, V. H. S. Quantifying the characteristics of java programs that may influence symbolic execution from a test data generation perspective. In: 2014 IEEE 38th Annual Computer Software and Applications Conference. [S.l.: s.n.], 2014. p. 181-190. Citado na página 34.

FERREO, C. A. Algoritmo KNN para previsão de dados temporais: funções de previsão e critérios de seleção de vizinhos próximo aplicados a variáveis ambientais em limnologia. 
Tese (Doutorado) - Instituto de Ciência Matemáticia e de Computação ICMC-USP, São Carlos, SP, BR, 2009. Citado 3 vezes nas páginas 9, 49 e 50.

FILHO, W. de P. P. Engenharia de Software: fundamentos, métodos e padrões. 3. ed. Rio de Janeiro, RJ, BR: LTC, 2009. ISBN 9788521616504. Citado na página 25.

GOEL, B. M. A study on object-oriented testing technique and object-oriented metrics useful in reducing class testing complexity. Advanced Computing Communication Technologies (ACCT), 2014 Fourth International Conference on, p. 185-188, Feb 2014. Citado 2 vezes nas páginas 55 e 69.

GRAHAM, D. Testing object-oriented systems. In: OVUM EVALUATES: SOFTWARE TESTING TOOLS. Londres, UK: ADDISON WESLEY BRA, 1996. Citado 2 vezes nas páginas 29 e 30.

HARRISON, R.; COUNSELL, S.; NITHI, R. An overview of object-oriented design metrics. Software Technology and Engineering Practice, 1997. Proceedings., Eighth IEEE International Workshop on [incorporating Computer Aided Software Engineering], p. 230-235, Jul 1997. Citado 5 vezes nas páginas 36, 37, 39, 41 e 42.

HARTIGAN, J. A.; WONG, M. A. Algorithm as 136: A k-means clustering algorithm. Journal of the Royal Statistical Society. Series C (Applied Statistics), [Wiley, Royal Statistical Society], v. 28, n. 1, p. 100-108, 1979. ISSN 00359254, 14679876. Disponível em: 〈http://www.jstor.org/stable/2346830〉. Citado na página 46.

HUDA, Y. A. M.; KHAN, M. H. Measuring testability of object oriented design: A system review. International Jounal of Scientific Engineering and Technology, p. 1313-1319, out. 2014. ISSN 2277-1584. Citado 4 vezes nas páginas 55, 56, 70 e 71.

IEEE. Ieee standard glossary of software engineering terminology. IEEE Std 610.12-1990, p. 1-84, Dec 1990. Citado 3 vezes nas páginas 18, 30 e 33.

ISO. International standard ISO/IEC 9126. information technology:Software product evaluation: Quality characteristics and quidelines for their use. [S.l.]: ISO, 1991. Citado na página 33.

JAIN, A. K.; MURTY, M. N.; FLYNN, P. J. Data clustering: A review. ACM Comput. Surv., ACM, New York, NY, USA, v. 31, n. 3, p. 264-323, set. 1999. ISSN 0360-0300. Disponível em: 〈http://doi.acm.org/10.1145/331499.331504〉. Citado na página 46.

JULIANO, R. C. Visualização de software baseada em uma metáfora do universo utilizando o conjunto de métricas CK. Dissertação (Mestrado) - Faculdade de Computação da Universidade Federal de Uberlândia, Uberlândia, MG, BR, 2014. Citado 3 vezes nas páginas 40, 100 e 102.

KHALID, S.; ZEHRA, S.; ARIF, F. Analysis of object oriented complexity and testability using object oriented design metrics. ACM, New York, NY, USA, p. 4:1-4:8, 2010. Disponível em: 〈http://doi.acm.org/10.1145/1890810.1890814〉. Citado 5 vezes nas páginas 55, 61, 64, 66 e 67.

KHAN, R. A.; MUSTAFA, K. Metric based testability model for object oriented design (mtmood). SIGSOFT Softw. Eng. Notes, ACM, New York, NY, USA, v. 34, n. 2, p. 1-6, fev. 2009. ISSN 0163-5948. Disponível em: 〈http://doi.acm.org/10.1145/1507195.1507204〉. Citado 7 vezes nas páginas 19, 36, 55, 59, 61, 62 e 70. 
KHANNA, P. Testability of object-oriented systems: An ahp-based approach for prioritization of metrics. Contemporary Computing and Informatics (IC3I), 2014 International Conference on, p. 273-281, Nov 2014. Citado 2 vezes nas páginas 39 e 55.

KOSCIANSKI, A.; SOARES, M. dos S. Qualidade de Software: Aprenda as metodologias e técnicas mais modernas para o desenvolvimento de software. 2. ed. São Paulo: Novatec, 2007. ISBN 9788575221129. Citado 6 vezes nas páginas 18, 23, 24, 25, 29 e 36.

KOUT, A.; TOURE, F.; BADRI, M. An empirical analysis of a testability model for object-oriented programs. SIGSOFT Softw. Eng. Notes, ACM, New York, NY, USA, v. 36, n. 4, p. 1-5, ago. 2011. ISSN 0163-5948. Disponível em: 〈http://doi.acm.org/10.1145/1988997.1989020〉. Citado 8 vezes nas páginas 55, 56, 59, 60, $61,62,64$ e 70 .

KULKARNI, U. L.; KALSHETTY, Y. R.; ARDE, V. G. Validation of ck metrics for object oriented design measurement. In: Emerging Trends in Engineering and Technology (ICETET), 2010 3rd International Conference on. [S.l.: s.n.], 2010. p. 646-651. ISSN 2157-0477. Citado 2 vezes nas páginas 43 e 44.

LI, W. Software product metrics. Potentials, IEEE, v. 18, n. 5, p. 24-27, Dec 1999. ISSN 0278-6648. Citado 2 vezes nas páginas 18 e 35.

LORENZEN, M.; KIDD, J. Object-oriented software metrics : a practical guide. Englewood Cliffs, NJ: PTR Prentice Hall, 1994. ISBN 0-13-179292-X. Disponível em: 〈http://opac.inria.fr/record=b1085242〉. Citado 3 vezes nas páginas 12, 36 e 43.

MALDOnADO, J. C. Critérios Potenciais Usos: Uma contribuição ao Teste Estrutura de Software. Dissertação (Mestrado) - Faculdade de Engenharia Elétrica da UNICAMP, CAMPINAS, SP, BR, 1991. Citado na página 27.

MATHUR, N. et al. Visualization of dengue incidences using expectation maximization (em) algorithm. In: 2016 6th International Conference on Intelligent and Advanced Systems (ICIAS). [S.1.: s.n.], 2016. p. 1-5. Citado na página 48.

MCCABE, T. J. A complexity measure. Proceedings of the $2 N d$ International Conference on Software Engineering, IEEE Computer Society Press, Los Alamitos, CA, USA, p. 407-, 1976. Disponível em: 〈http://dl.acm.org/citation.cfm?id=800253.807712〉. Citado 2 vezes nas páginas 26 e 42 .

MYERS, G. J.; SANDLER, C. The Art of Software Testing. [S.l.]: John Wiley \& Sons, 2004. ISBN 0471469122. Citado 3 vezes nas páginas 18, 23 e 25.

OFFUTT, A. J. A practical system for mutation testing: help for the common programmer. Test Conference, 1994. Proceedings., International, p. 824-830, Oct 1994. ISSN 1089-3539. Citado na página 32.

OLIVEIRA, F. E. M. de. Estatística e Probabilidade. São Paulo, SP, BR: Atlas SA, 2012. Citado na página 45.

PATTON, R. Software Testing (1Nd Edition). Indianapolis, IN, USA: Sams, 2001. Citado na página 31. 
PATWA, S.; MALVIYA, A. K. Reusability metrics and effect of reusability on testing of object oriented systems. SIGSOFT Softw. Eng. Notes, ACM, New York, NY, USA, v. 37, n. 5, p. 1-4, set. 2012. ISSN 0163-5948. Disponível em: 〈http://doi.acm.org/10.1145/2347696.2347708〉. Citado 2 vezes nas páginas 55 e 69.

PFLEEGER, S. Engenharia de software: teoria e prática. Prentice Hall, 2004. ISBN 9788587918314. Disponível em: 〈https://books.google.com.br/books?id= MKhmPgAACAAJ $\rangle$. Citado na página 29.

PRESSMAN, R. Engenharia de software. [S.l.]: McGraw-Hill, 2006. ISBN 9788586804571. Citado 3 vezes nas páginas 26, 29 e 30.

RAPPS, S.; WEYUKER, E. J. Selecting software test data using data flow information. IEEE Transactions on Software Engineering, SE-11, n. 4, p. 367-375, April 1985. ISSN 0098-5589. Citado na página 27.

REZENDE, S. O. Sistemas Inteligentes: Fundamentos e Aplicações. Barueri, SP: Editora Manole Ltda, 2003. ISBN 8520416837. Citado na página 49.

RIBEIRO, M.; REIS, R. Q.; ABELéM, A. J. G. How to automatically collect oriented object metrics: A study based on systematic review. In: 2015 Latin American Computing Conference (CLEI). [S.l.: s.n.], 2015. p. 1-12. Citado na página 101.

SANCHES, M. K. Aprendizado de máquina semi-supervisionado: proposta de um algoritmo para rotular exemplos a partir de poucos exemplos rotulados. Dissertação (Mestrado) Dissertação (Mestrado em Ciências de Computação e Matemática Computacional) Instituto de Ciências Matemáticas e de Computação, University of São Paulo, São Carlos, São Paulo, 2003. Citado na página 47.

SHAHEEN, M. R.; BOUSQUET, L. D. Survey of source code metrics for evaluating testability of object oriented systems. n. RR-LIG-005, 2010. Disponível em: 〈https://hal.inria.fr/hal-00953403〉. Citado 3 vezes nas páginas 55, 67 e 69.

SILVA, L. A. da; PERES, S. M.; BOSCARIOLI, C. Introdução a mineração de dados: com aplicações em R. 1. ed. Rio de Janeiro, RJ, USA: Elsevier, 2016. ISBN 9788535284461. Citado 3 vezes nas páginas 45, 46 e 47 .

SINGH, Y.; SAHA, A. Improving the testability of object oriented software through software contracts. SIGSOFT Softw. Eng. Notes, ACM, New York, NY, USA, v. 35, n. 1, p. 1-4, jan. 2010. ISSN 0163-5948. Disponível em: 〈http://doi.acm.org/10.1145/1668862.1668869〉. Citado 2 vezes nas páginas 55 e 68.

SOMMERVILLE, I. et al. Engenharia de software. ADDISON WESLEY BRA, 2008. ISBN 9788588639287. Disponível em: 〈https://books.google.com.br/books?id=ifIYOgAACAAJ〉. Citado 4 vezes nas páginas 23, 28, 29 e 35.

SOUZA, C. R. de. A tutorial on principal component analysis with the accord.net framework. CoRR, abs/1210.7463, 2012. Disponível em: 〈http://arxiv.org/abs/1210.7463〉. Citado na página 102.

TAHIR, A.; MACDONELL, S. G.; BUCHAN, J. Understanding class-level testability through dynamic analysis. Evaluation of Novel Approaches to Software Engineering (ENASE), 2014 International Conference on, p. 1-10, April 2014. Citado 7 vezes nas páginas $18,55,58,59,60,61$ e 62 . 
VALE, G. A. do. A Benchmark-based Method to Derive Metric Thresholds. Dissertação (Mestrado) - Universidade Federal de Minas Gerais, 2016. Citado na página 73.

VOAS, J. M.; MILLER, K. W. Semantic metrics for software testability. J. Syst. Softw., Elsevier Science Inc., New York, NY, USA, v. 20, n. 3, p. 207-216, mar. 1993. ISSN 0164-1212. Disponível em: 〈http://dx.doi.org/10.1016/0164-1212(93)90064-5〉. Citado na página 33.

ZHOU, Y. et al. An in-depth investigation into the relationships between structural metrics and unit testability in object-oriented systems. Science China Information Sciences, v. 55, n. 12, p. 2800-2815, 2012. ISSN 1869-1919. Disponível em: 〈http://dx.doi.org/10.1007/s11432-012-4745-x〉. Citado 7 vezes nas páginas 55, 59, 60, $61,62,67$ e 68 .

ZHU, H.; HALL, P. A. V.; MAY, J. H. R. Software unit test coverage and adequacy. ACM Comput. Surv., ACM, New York, NY, USA, v. 29, n. 4, p. 366-427, dez. 1997. ISSN 0360-0300. Disponível em:〈http://doi.acm.org/10.1145/267580.267590〉. Citado 2 vezes nas páginas 31 e 32 . 


\section{Apêndice A - Protocolo da Revisão Sistemática}

Objetivo: Analisar os trabalhos sobre a influência das métricas CK na testabilidade.

\section{Questões de pesquisa:}

Q1: Qual a influência das métricas CK na testabilidade?

Q2: Existe uma correlação entre métricas CK e a testabilidade?

Q3: Existem lacunas a serem exploradas em relação as métricas CK e a testabilidade?

População: Projetos desenvolvidos com objetivo de analisar a testabilidade em relação as Métricas CK.

Intervenção: Avaliação das pesquisas sobre testabilidade de software baseados no paradigma orientado a objetos.

Controle: Artigos de pesquisa obtidos com orientador, Artigos publicados em veículos reconhecidos pela área e Teses.

Resultados: Espera-se que o resultado desta pesquisa possa contribuir com estado da arte relacionado a testabilidade com análise de métricas de software OO. Em especial, relacionado as métricas CK, propostas por Chidamber e Kemerer.

Palavras Chave: Testability and CK metric, Test and CK Metrics e CK metrics.

Critério de seleção de fontes: Pesquisadores da área de teste de software, Pesquisas sobre testabilidade. Pesquisa sobre métricas e testabilidade. Trabalhos publicados em períodos e jornal reconhecido pela área de Engenharia de Software.

Métodos de Pesquisa das Fontes: As fontes deverão estar disponíveis via web, preferencialmente em bases de dados científicas da área. Poderão ser selecionados também, trabalhos disponíveis em outros meios, desde que atendam aos requisitos da Revisão 
Sistemática.

\section{Repositório de busca}

Biblioteca Digital ACM (http://portal.acm.org/);

Biblioteca Digital IEEE (http://ieeexplore.ieee.org/Xplore)

Ferramenta de Busca Capes http://www.periodicos.capes.gov.br.

\section{Critérios de Inclusão:}

(I) - Aborda o estudo de testabilidade no paradigma orientado a objetos;

(I) - Aplicou estudo de testabilidade relacionada a análise das métricas CK;

(I) - Aplicou estudo de revisão sistemática sobre testabilidade

\section{Critérios de Exclusão:}

(E) - Não analisa a testabilidade relacionada com métricas baseadas em medidas de software orientado a objetos;

(E) - Não descreve sobre o relacionamento de métricas e testabilidade;

Definição de tipos de estudos: estudos que definam com detalhes a metologia utilizada. Serão separados os artigos que analisam a influência das métricas de software Orientado a Objetos relacionado a testabilidade. Em especial serão considerados os trabalhos que analisaram as métricas CK.

Seleção Inicial: Os artigos analisados deverão ter sido publicados em conferências ou periódicos de eventos importantes na área de Engenharia de Software. Trabalhos de conclusão de Mestrados e teses de Doutorado, também serão considerados como base para pesquisa. Pesquisas não científicas serão analisas para garantir a pesquisa aplicada na indústria. Uma pesquisa exploratória foi realizada para auxiliar no direcionamento da pesquisa e na definição das palavras chaves para montar as strings de busca.

Artigos encontrados na pesquisa exploratória:

- An Empirical Analysis of Lack of Cohesion

- An empirical study into class testability

- Understanding Class-level Testability through Dynamic Analysis 
Avaliação da Qualidade dos Estudos: Os critérios de inclusão são considerados importantes dentro do contexto da revisão, porém, durante a pesquisa artigo que tenham estrutura importantes relacionadas a testabilidade, serão adicionados na revisão sistemática.

Extração dos dados: Nesta fase, os artigos foram extraídos conforme os objetivos de pesquisa:

1 - Qual linguagem de programação foram desenvolvidos os software da pesquisa?

2 - Qual ferramenta de Teste foi Utilizada?

3 - Qual o tipo de pesquisa: (a) Utilizou cálculos para analisar as métricas,(b) Artigos de Revisão Sistemática, (c) Artigo conceitual, não classificados no item (a) ou (b)?

4 - Quais as métricas que foram analisadas?

5 - Qual autor e universidade do artigo? 